\title{
DIODE LASER AS AN ADDITIONAL THERAPEUTIC MEASURE IN REDUCING RED COMPLEX BACTERIA IN CHRONIC PERIODONTITIS.
}

\author{
Suné Mulder-van Staden
}

A mini-thesis submitted in partial fulfilment of the requirements for the degree of MChD in Oral Medicine and Periodontology,

University of the Western Cape

Supervisor: Dr

H. Holmes

Co-supervisor:

Prof J. Hille 


\section{DIODE LASER AS AN ADDITIONAL THERAPEUTIC MEASURE IN REDUCING RED COMPLEX BACTERIA IN CHRONIC PERIODONTITIS.}

\section{Suné Mulder-van Staden}

\section{KEYWORDS}

Chronic periodontitis

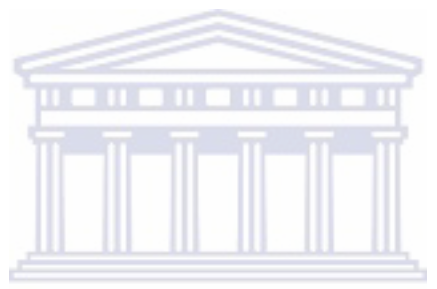

Periodontal clinical parameters

Red complex bacteria

Conventional management of periodontal diseases (i.e. scaling, root planing and polishing)

Bacterial collection

Polymerase chain reaction (PCR)

Diode laser $(810 \pm 10 \mathrm{~nm})$ 


\begin{abstract}
DIODE LASER AS AN ADDITIONAL THERAPEUTIC MEASURE IN REDUCING RED COMPLEX BACTERIA IN CHRONIC PERIODONTITIS.
\end{abstract}

\author{
Suné Mulder-van Staden \\ MChD (Oral Medicine \& Periodontics), Department of Oral Medicine and \\ Periodontology, University of the Western Cape.
}

This mini-thesis assessed whether a diode laser with a wavelength of $810 \pm$ $10 \mathrm{~nm}$ can be utilized as an adjunct to conventional management (i.e. scaling, root planing and polishing) of chronic periodontitis during initial phase therapy.

Ethical approval and study registration (Reg no: 14/9/6) was finalized prior to commencement of the study. A split mouth randomised control trial was performed on 25 participants (who presented at the Oral Medicine and Periodontology Department of the University of the Western Cape) diagnosed with active, chronic periodontitis. In order to standardise the split mouth design the quadrants $1 \& 4$ were assessed together as a set and quadrants $2 \& 3$ were assessed as a set. A set of these quadrants were randomly assigned to either the test or control quadrants after conventional management was performed in all four quadrants. The base line bacterial colony collection (Micro-IDent ${ }^{\circledR}-11$, Hain Lifescience GmbH, Nehren, Germany) and the clinical parameters were assessed prior to the commencement of conventional management and were reassessed at the 6 week re-evaluation visit.

The set of test quadrants were treated with the diode laser as an adjunct to the preceding conventional management. The control quadrant only received the conventional management. 
Evaluation of the results demonstrated that the diode laser produced no statistical decrease in the bacterial parameters in the periodontal pockets and resulted in a statistical increase of $C$. showae $(C s)$ and $T$. denticola $(T d)$. The clinical parameters resulted in no statistical difference for any clinical parameter, with the exception of the reduction in BOP that was statistically significant $(\mathrm{p}<0,05)$ with the laser as an adjunct.

It is the recommendation that within the limitations of this study, that the utilization of the diode laser $(810 \pm 10 \mathrm{~nm})$ as an adjunct at the initial visit had no statistical effect in the reduction of the bacterial parameters nor resulted in an overall improvement of the clinical parameters.

August 2016

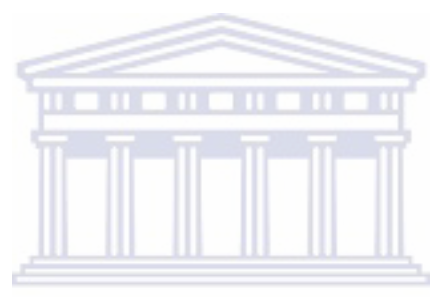




\section{DECLARATION}

I declare that "Diode laser as an additional therapeutic measure in reducing red complex bacteria in chronic periodontitis" is my own work, that it has not been submitted before for any degree or examination at any other university and that all the sources I have used or quoted have been indicated and acknowledged as complete references. I declare that I have no competitive interest in any of the companies that manufacture any of the tests used in this study. No shares and or stocks are held nor will I have any financial gain or loss with the publication of any manuscript and articles pertaining to this research.

The research in this thesis was partially funded by a NHLS grant (GRANT004_94485).

Sune Mulder- van Staden

Student number: 2382168

Date: August 2016

Signed

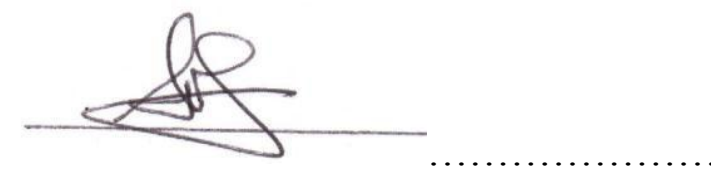




\section{ACKNOWLEDGEMENTS}

I would like to thank my supervisors Dr. H. Holmes and Prof. J. Hille for their continued support and guidance for the completion of this thesis.

I would like to acknowledge the NHLS for the research grant (GRANT004_94485) provided for the conduction of this project.

To my husband, Dr. Riaan Mulder - your unwavering support has been a pillar of strength in completion of this degree.

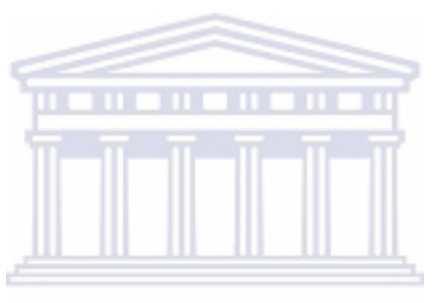

UNIVERSITY of the 


\begin{tabular}{|c|c|c|}
\hline \multicolumn{2}{|c|}{ CONTENTS PAGE: } & \multirow{2}{*}{$\begin{array}{c}\begin{array}{c}\text { Page } \\
\text { number: }\end{array} \\
\mathrm{i}\end{array}$} \\
\hline Title page & & \\
\hline Abstract & & ii-iii \\
\hline Declaration & & iv \\
\hline Acknowledgments & & $\mathrm{v}$ \\
\hline Figure list & & $x-x i$ \\
\hline Table list & & xii-xiii \\
\hline \multirow[t]{6}{*}{ CHAPTER 1: } & Introduction & \\
\hline & 1.1 Periodontitis and the bacterial flora & $1-3$ \\
\hline & $\begin{array}{l}\text { 1.2 Role of periodontal pathogens in the } \\
\text { development of systemic diseases }\end{array}$ & $3-6$ \\
\hline & $\begin{array}{l}1.3 \text { Genetic susceptibility to periodontal } \\
\text { disease }\end{array}$ & $6-7$ \\
\hline & 1.4 Periodontitis management & $8-9$ \\
\hline & 1.5 Lasers in periodontics $\mathrm{E}$ & 9 \\
\hline \multirow[t]{5}{*}{ CHAPTER 2: } & Literature review & \\
\hline & 2.1 Diode laser & $10-12$ \\
\hline & $\begin{array}{l}\text { 2.2 Application of the diode laser in } \\
\text { patients with chronic periodontitis }\end{array}$ & $12-14$ \\
\hline & $\begin{array}{l}2.3 \text { Bacterial collection and assessment of } \\
\text { bacterial parameters }\end{array}$ & $14-16$ \\
\hline & 2.4 Conclusion & 16 \\
\hline \multirow[t]{2}{*}{ CHAPTER 3: } & Research design and methodology & \\
\hline & 3.1 Introduction & $17-18$ \\
\hline
\end{tabular}




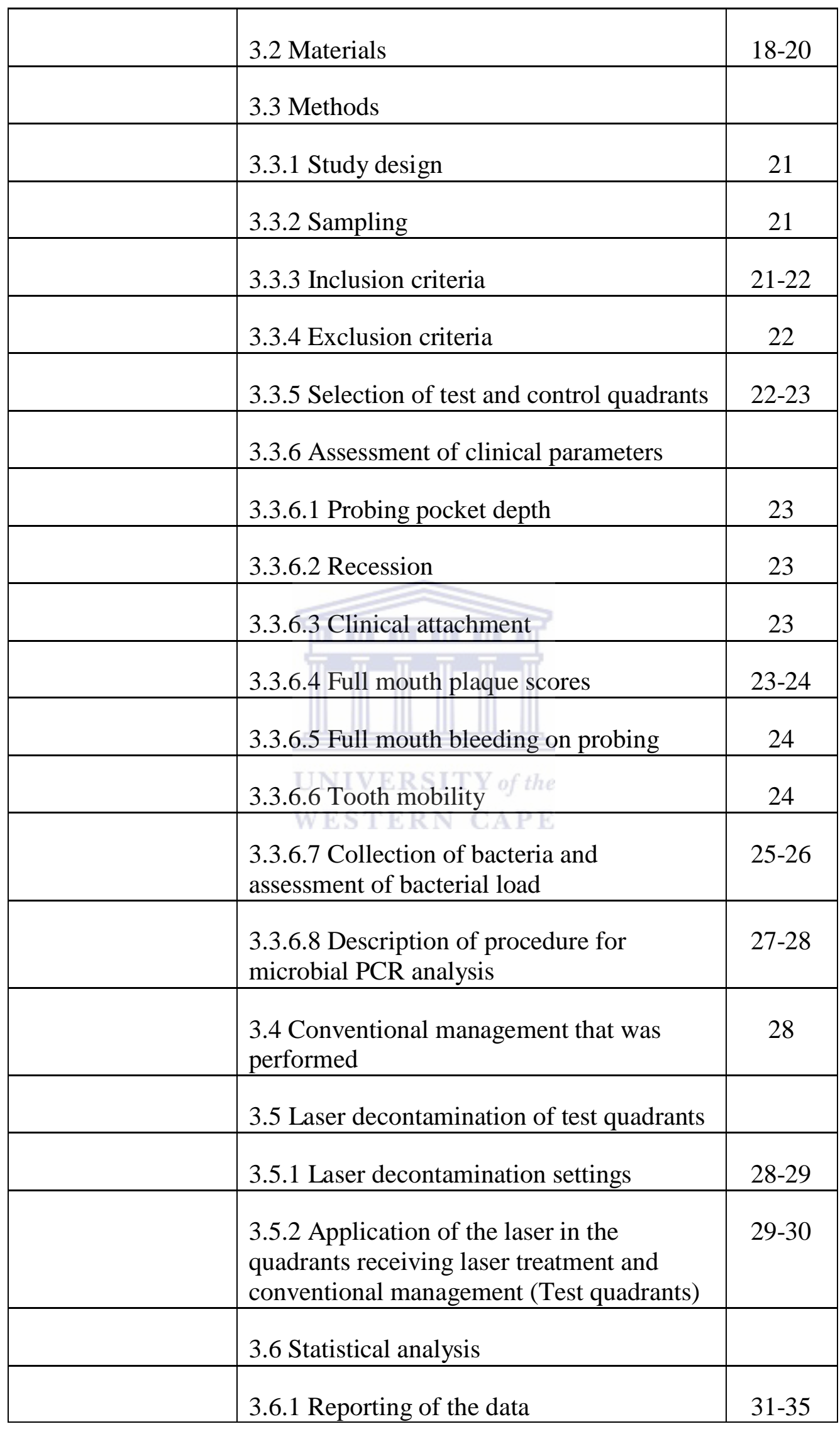




\begin{tabular}{|c|c|c|}
\hline & 3.6.2 Statistical analysis & $35-37$ \\
\hline & 3.7 Ethical considerations & $37-38$ \\
\hline & 3.8 Potential limitations & 38 \\
\hline \multirow{13}{*}{ CHAPTER 4: } & Results and discussion & \\
\hline & 4.1 Randomized control trial design & 39 \\
\hline & 4.2 Statistical analysis of split mouth model & \\
\hline & $\begin{array}{l}\text { 4.2.1. Assessment of bacterial parameters } \\
\text { for the split mouth model (before } \\
\text { conventional management was performed). }\end{array}$ & $40-41$ \\
\hline & $\begin{array}{l}\text { 4.2.2 Assessment of clinical parameters for } \\
\text { the split mouth model - before conventional } \\
\text { management performed }\end{array}$ & $42-43$ \\
\hline & 4.3 Assessment of bacterial parameters & \\
\hline & $\begin{array}{l}\text { 4.3.1. Statistical analysis for the bacterial } \\
\text { load of the before and after treatment }\end{array}$ & 44 \\
\hline & $\begin{array}{l}\text { 4.3.2. Bacterial parameters after } \\
\text { conventional periodontal therapy (Control } \\
\text { side) }\end{array}$ & $44-46$ \\
\hline & $\begin{array}{l}\text { 4.3.3. Bacterial parameters after } \\
\text { conventional management plus laser } \\
\text { treatment (Test side) }\end{array}$ & $46-48$ \\
\hline & $\begin{array}{l}\text { 4.3.4. Determining the effectiveness of the } \\
\text { conventional plus laser (Test side) to the } \\
\text { conventional management alone (Control } \\
\text { side) for the bacterial parameters }\end{array}$ & $48-50$ \\
\hline & 4.4 Assessment of clinical parameters & \\
\hline & $\begin{array}{l}\text { 4.4.1. Statistical analysis for the clinical } \\
\text { parameters before and after treatment }\end{array}$ & 50 \\
\hline & $\begin{array}{l}\text { 4.4.2. Clinical parameters after } \\
\text { conventional management alone (Control } \\
\text { side) }\end{array}$ & $51-53$ \\
\hline
\end{tabular}




\begin{tabular}{|c|c|c|}
\hline & $\begin{array}{l}\text { 4.4.3. Determining the effectiveness of the } \\
\text { conventional management plus laser as } \\
\text { adjunct (Test side) for the clinical } \\
\text { parameters }\end{array}$ & $53-55$ \\
\hline & $\begin{array}{l}\text { 4.4.4 Determining the effectiveness of the } \\
\text { conventional management with laser as } \\
\text { adjunct (Test side) compared to the } \\
\text { conventional management alone (Test side) } \\
\text { for the clinical parameters }\end{array}$ & $55-56$ \\
\hline & $\begin{array}{l}\text { 4.5 Patient distribution of Interleukin }-1 \\
\text { Genotype }\end{array}$ & \\
\hline & $\begin{array}{l}\text { 4.5.1 Bacterial parameters for the High vs } \\
\text { Low risk Genotype }\end{array}$ & $57-59$ \\
\hline & $\begin{array}{l}\text { 4.5.2 Bacterial parameters of Control and } \\
\text { Test sides after treatment }\end{array}$ & $59-61$ \\
\hline & $\begin{array}{l}\text { 4.5.3. Clinical parameters for the High vs } \\
\text { Low risk Genotype }\end{array}$ & $61-64$ \\
\hline & 4.6 Discussion & \\
\hline & 4.6.1. Split mouth study design & 65 \\
\hline & 4.6.2. Bacterial and clinical parameters & \\
\hline & 4.6.2.1. Bacterial parameters & $65-67$ \\
\hline & 4.6.2.2 Clinical parameters & $67-68$ \\
\hline & $\begin{array}{l}\text { 4.6.3. Interleukin-1 genotype and its } \\
\text { association with bacterial and clinical } \\
\text { parameters }\end{array}$ & $68-69$ \\
\hline CHAPTER 5: & Conclusions and recommendations & $70-71$ \\
\hline REFERENCES & & $72-76$ \\
\hline APPENDICES & & $77-78$ \\
\hline
\end{tabular}




\section{FIGURE LIST}

\begin{tabular}{|l|l|l|}
\hline Figure 1: & $\begin{array}{l}\text { Diagram of the relationships of species within microbial } \\
\text { complexes and between the microbial complexes } \\
(\text { Socransky }, 1998) .\end{array}$ & 2 \\
\hline Figure 2: & \begin{tabular}{l} 
Co-efficient of absorption of laser energy from various \\
\hline
\end{tabular}
\end{tabular}

\begin{tabular}{l|l|l} 
Figure 2: & Co-efficient of absorption of laser energy from various & 11
\end{tabular}

\begin{tabular}{|l|l|l|} 
& lasers (Blaiden, 2013:6). & \\
\hline & &
\end{tabular}

\begin{tabular}{|l|l|l|} 
Figure 3 & Picasso laser and essential accessories. & 19 \\
\hline & &
\end{tabular}

\begin{tabular}{|l|l|l|}
\hline Figure 4: & $\begin{array}{l}\text { Illustration of the beam profile depending on cleaving } \\
\text { status. }\end{array}$ & 20 \\
\hline & & 20
\end{tabular}

\begin{tabular}{|l|l|l|} 
Figure 5: & Correctly cleaved fiber assessed under 2X magnification. & 20 \\
\hline Figure 6: & Micro-IDent@-11, Hain Lifescience GmbH, Nehren & 26
\end{tabular}

\begin{tabular}{|l|l|l|} 
Figure 6: & $\begin{array}{l}\text { Micro-IDent } \\
\text { Germany. 11, Hain Lifescience GmbH, Nehren, }\end{array}$ & 26 \\
\hline & Gefl & 27
\end{tabular}

\begin{tabular}{|l|l|l|} 
Figure 7: & $\begin{array}{l}\text { Genotype Interleukin-1@, Hain Lifescience GmbH, } \\
\text { Nehren, Germany. }\end{array}$ & 27 \\
\hline & &
\end{tabular}

\begin{tabular}{|l|l|l|}
\hline Figure 8: & Illustration of how canula was calibrated for the laser fiber. & 29 \\
\hline Figure 9: & Calibrated Ultradent Navi 29G, 17mm tip for saline rinse. & 30 \\
\hline Figure 10: & Bacterial report from the Micro-IDent@-11 kit. & 31 \\
\hline Figure 11: & $\begin{array}{l}\text { Flow diagram of the statistical analysis of all the bacterial } \\
\text { parameters and clinical parameters. }\end{array}$ & 37 \\
\hline Figure 12: & Bacterial load of left and right side before treatment. & 41 \\
\hline Figure 13: & $\begin{array}{l}\text { Graph depicting the PPD, REC, CAL parameters for the } \\
\text { split mouth design. }\end{array}$ & 43 \\
\hline
\end{tabular}




\begin{tabular}{|c|c|c|}
\hline Figure14: & $\begin{array}{l}\text { Graph depicting the PI\%, BOP\% parameters for the split } \\
\text { mouth design. }\end{array}$ & 43 \\
\hline Figure 15: & $\begin{array}{l}\text { Bacterial load after conventional management (Control } \\
\text { side). }\end{array}$ & 46 \\
\hline Figure 16: & $\begin{array}{l}\text { Bacterial parameters after conventional management plus } \\
\text { laser (Test side). }\end{array}$ & 48 \\
\hline Figure 17: & $\begin{array}{l}\text { Graph depicting the PPD, REC, CAL parameters before } \\
\text { and after conventional management (Control side). }\end{array}$ & 52 \\
\hline Figure 18: & $\begin{array}{l}\text { Graph depicting the PI\%, BOP } \% \text { parameters before and } \\
\text { after conventional management (Control side). }\end{array}$ & 52 \\
\hline Figure 19: & $\begin{array}{l}\text { Graph depicting the PPD, REC, CAL parameters before } \\
\text { and after conventional management plus laser (Test side). }\end{array}$ & 54 \\
\hline Figure 20: & $\begin{array}{l}\text { Graph depicting the PI\%, BOP\% parameters before and } \\
\text { after conventional management plus laser (Test side). }\end{array}$ & 55 \\
\hline Figure 21: & $\begin{array}{l}\text { Flowchart of Bacterial comparison for High vs Low risk } \\
\text { Genotype. }\end{array}$ & 57 \\
\hline Figure 22 & $\begin{array}{l}\text { Bacterial parameters of High risk vs Low risk genotype at } \\
\text { baseline. }\end{array}$ & 58 \\
\hline Figure 23: & $\begin{array}{l}\text { Flowchart of Clinical parameters comparison for High vs } \\
\text { Low risk Genotype. }\end{array}$ & 61 \\
\hline Figure 24: & $\begin{array}{l}\text { Graph depicting the PPD, REC, CAL parameters for the } \\
\text { High and Low risk genotype. }\end{array}$ & 63 \\
\hline Figure 25: & $\begin{array}{l}\text { Graph depicting the PI\%, BOP } \% \text { parameters for the High } \\
\text { and Low risk genotype. }\end{array}$ & 63 \\
\hline
\end{tabular}




\section{TABLE LIST}

\begin{tabular}{|c|c|c|}
\hline Table 1: & $\begin{array}{l}\text { Comparison of studies utilizing a diode laser with a } \\
\text { wavelength of } 810 \pm 10 \mathrm{~nm} \text { as an adjunct in the } \\
\text { management of chronic periodontitis. }\end{array}$ & $\begin{array}{l}12- \\
13\end{array}$ \\
\hline Table 2: & $\begin{array}{l}\text { Detection frequency in \% of PCR vs CFU (Boutaga, } \\
\text { 2005). }\end{array}$ & 15 \\
\hline Table 3: & $\begin{array}{l}\text { Interpretation of Micro-IDent } \AA-11 \text { pathogen concentration } \\
\text { for data capturing purposes for all the pathogens } \\
\text { (excluding A.a.). }\end{array}$ & 32 \\
\hline Table 4: & $\begin{array}{l}\text { Interpretation of Micro-IDent } ®-11 \text { pathogen concentration } \\
\text { for data capturing purposes. }\end{array}$ & 32 \\
\hline Table 5: & $\begin{array}{l}\text { Micro IDent bacterial range applied to the test and control } \\
\text { sides to illustrate the precise bacterial parameter range } \\
\text { after } 6 \text { weeks. }\end{array}$ & $\begin{array}{l}33- \\
35\end{array}$ \\
\hline Table 6: & Randomisation of split mouth and side allocation. & 39 \\
\hline Table 7: & Bacterial comparison for the left and right. & $\begin{array}{l}40- \\
41\end{array}$ \\
\hline Table 8: & Clinical parameter from the split mouth model. & 42 \\
\hline Table 9: & $\begin{array}{l}\text { Bacterial load for conventional periodontal treatment } \\
\text { (Control side). }\end{array}$ & $\begin{array}{l}44- \\
45\end{array}$ \\
\hline Table 10: & $\begin{array}{l}\text { Bacterial load for conventional management plus the laser } \\
\text { (Test side). }\end{array}$ & 47 \\
\hline Table 11: & $\begin{array}{l}\text { The calculated DIDs for the conventional management } \\
\text { plus laser (Test side) compared to conventional } \\
\text { management alone (Control side). }\end{array}$ & $\begin{array}{l}49- \\
50\end{array}$ \\
\hline
\end{tabular}




\begin{tabular}{|l|l|l|}
\hline Table 12: & $\begin{array}{l}\text { Clinical parameters for conventional management alone } \\
\text { (Control side). }\end{array}$ & 51 \\
\hline Table 13: & $\begin{array}{l}\text { Clinical parameters for conventional management plus the } \\
\text { laser (Test side). }\end{array}$ & $\begin{array}{l}53- \\
54\end{array}$ \\
\hline Table 14: & $\begin{array}{l}\text { The calculated DIDs for the conventional management } \\
\text { plus laser (Test side) compared to conventional } \\
\text { management alone (Control side). }\end{array}$ & 56 \\
\hline Table 15: & $\begin{array}{l}\text { The patient distribution that presented with high and low } \\
\text { risk IL-1 genotype. }\end{array}$ & 56 \\
\hline Table 16: & $\begin{array}{l}\text { Bacterial parameters at base line between High and Low } \\
\text { genotype risk. }\end{array}$ & $\begin{array}{l}58- \\
59\end{array}$ \\
\hline Table 17: & Bacterial comparison for High vs Low risk Genotype. & 60 \\
\hline Table 18: & $\begin{array}{l}\text { Clinical parameters for High vs Low risk genotype at base } \\
\text { line. }\end{array}$ & 62 \\
\hline Clinical parameters for High vs Low risk Genotype. & 64 \\
\hline
\end{tabular}




\section{CHAPTER 1: INTRODUCTION}

\subsection{Periodontitis and the bacterial flora}

The healthy oral cavity harbours a vast number of micro-organisms which exist in a homeostatic equilibrium. However, under certain conditions (such as excessive plaque accumulation; immunosuppression, hormonal imbalances to name a few) a pathogenic subset of these micro-organisms may overgrow, resulting in the development of periodontal tissue destruction and disease (Lindhe, 2015:385).

Periodontitis is a multifactorial disease affecting most populations worldwide with tissue destruction and disease progression occurring as a result of complex interactions between micro-organisms, environmental factors and the host tissues (Holt, 2006; Cheng, 2016).

Chronic periodontitis is defined as inflammation of the gingiva extending into the adjacent attachment apparatus. The disease is characterized by a loss of clinical attachment due to the destruction of the periodontal ligament and supporting alveolar bone (Parameters of Care American Academy of Periodontology, 2000).

Periodontitis arises from a consortium of micro-organisms, with some micro-organisms demonstrating a more significant role than others as aetiologic agents (Nishihara, 2004; Lindhe, 2016:385).

The micro-organisms responsible for the destruction of periodontal tissues reside in biofilms, which colonizes the tooth surface and the periodontal pocket (Socransky, 2002). Periodontal tissue destruction is triggered by the formation of these complex biofilms (Holt, 2005), whose function is to provide protection for resident micro-organisms. This biofilm offers effective protection from competing micro-organisms, host defence mechanisms and potentially toxic substances (such as antimicrobials) in the oral cavity (Socransky, 2002; Marsh, 2011).

Socransky (1998) performed studies to define the bacterial communities that resided in the subgingival plaque. These communities were classified into five complexes and were assigned colours - namely red, orange, green, yellow and purple, which defined the different stages of bacterial colonization on the tooth surface, degree of disease severity and progression (Socransky, 1998). 


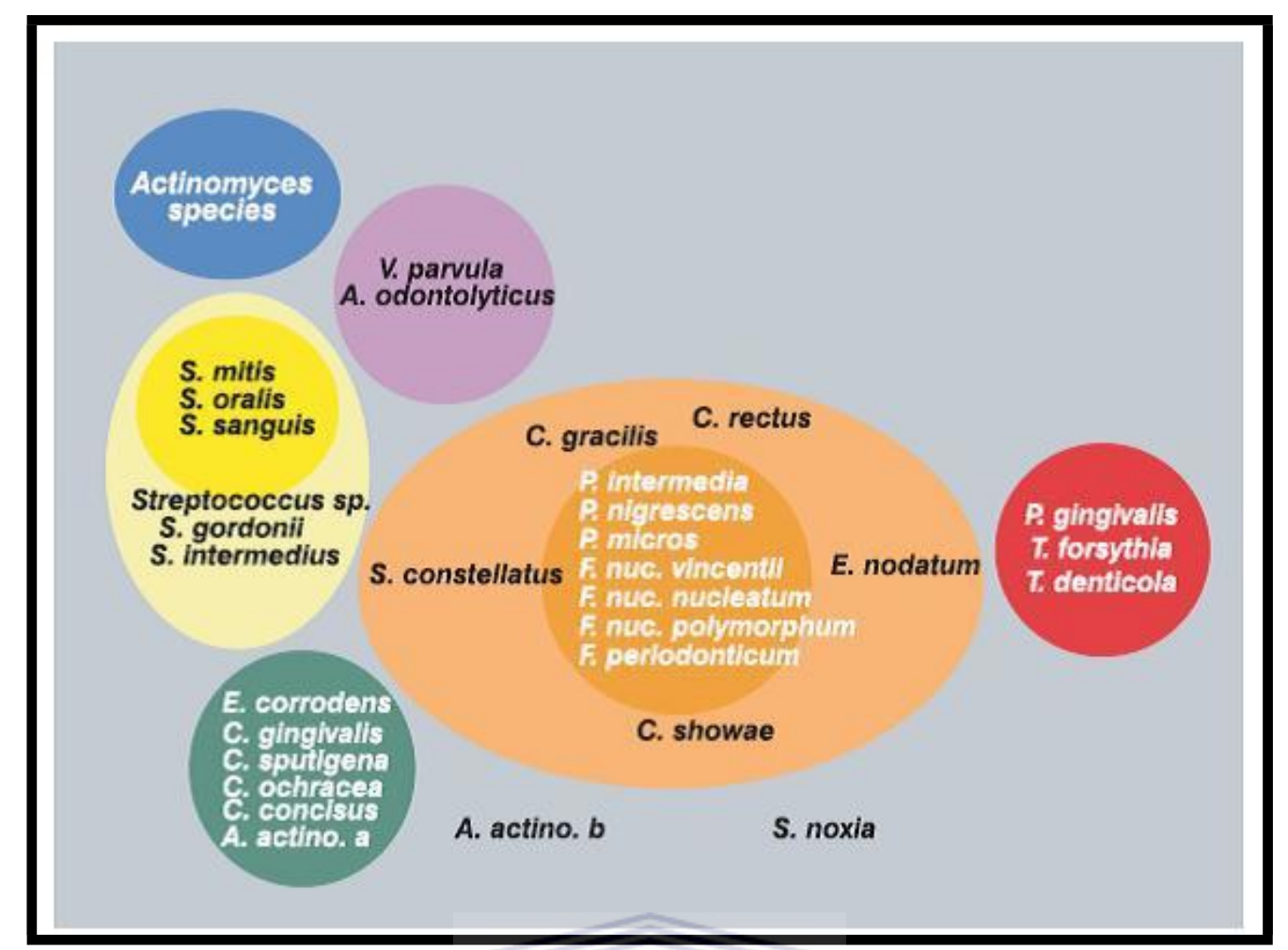

Figure 1. Diagram of the relationships of species within microbial complexes and between the microbial complexes (Socransky, 1998).

During the transition from health to periodontal disease, a shift occurs in the type of resident micro-organisms present in the periodontal pocket (Marsh, 2011). Initial colonization of the tooth surface involves the yellow, green and purple complexes, which includes the blue Actinomyces species (Socransky, 1998). As the development of periodontal disease progresses, the orange and red complexes gradually increase in number and become the predominant species (Socransky, 2005).

Cultivation of plaque micro-organisms from chronic and aggressive periodontitis sites reveals high percentages of anaerobic and gram negative bacterial species (Lindhe, 2015:410). The bacteria most predominantly found include Porphyromonas gingivalis (P.g), Tanerella forsythia (T.f), Prevotella intermedia (P.i), Camphylobacter rectus (C.r), Eikenella corrodens (E.c), Fusobacterium nucleatum (F.n), Aggregatibacter actinomycetemcomitans (A.a), Treponema species and Eubacterium species. High levels of P.g, P.i, T.f, C.r and A. $a$ are associated with disease progression. Both P.g and 
A. $a$ are known to invade host tissue cells, which is a significant factor in aggressive forms of periodontitis (Darveau, 1997. Lindhe, 2015:209).

The red complex bacteria (described by Socransky, 1998) (Figure 1) have been demonstrated to be the predominant microbial species involved in periodontal disease progression and significant periodontal tissue destruction. These red complex bacteria include P.g, T.d and T.f (Socransky, 1998).

The red complex bacteria which appear in the later stages of biofilm development are associated with periodontal disease deeper periodontal probing depths and bleeding on probing (Socransky, 1998. Socransky, 2005). These bacteria possess numerous virulence factors, such as the ability to invade the host epithelial and vascular endothelial cells (Socransky, 1998).

\subsection{Role of periodontal pathogens in the development of systemic diseases}

The potential role of periodontal pathogens in the development of systemic disease has been debated in numerous articles (Forner, 2006).

The National Institute of Dental and Craniofacial Research: National Institutes of Health have stated that: "Oral health is not an independent entity which is cut off from the rest of the body. Rather it is woven deeply into the fabric of the overall health" (Mani, 2013).

Periodontal pathogens have been implicated in the development of conditions such as cardiovascular disorders, diabetes, infective endocarditis, respiratory diseases and a low birth weight (Barnett, 2009. Mani, 2013).

Periodontal pathogens are proposed to modify the host's susceptibility to systemic disease via three mechanisms (Li, 2000):

- Shared risk factors

There are shared risk factors (such as smoking, stress, aging, race, male gender) between periodontitis and systemic diseases (especially cardiovascular disease). 
- Subgingival biofilms

The subgingival biofilms constitute renewing stores of lipopolysaccharides (LPS) and gramnegative bacteria. These substances are known to induce major vascular responses (such as inflammatory cell infiltrate in vessel walls, vascular smooth muscle proliferation, vascular fatty degeneration, intra-vascular coagulation). LPS are also known to up-regulate the expression of endothelial cell adhesion molecules (e-CAM), secretion of interleukin-1 (IL1), tumour necrosis factor alpha (TNF- $\alpha)$ and thromboxane. These substances result in platelet aggregation, formation of lipid-laden foam cells and deposition of cholesterol in the tissues - thus creating an environment for the formation of atherosclerotic plaques $(\mathrm{Li}$, 2000. Barnett, 2009).

- Periodontium as a cytokine reservoir

The pro-inflammatory cytokines TNF- $\alpha$, IL-1 $\beta$, gamma interferon $(\gamma-$ IFN) and prostaglandin E2 (PGE2) reach very high tissue concentrations in periodontal infections (Li, 2000). Thus a diseased periodontium can serve as a reservoir of inflammatory mediators, which re-enter the circulation and produce systemic effects. IL-1 and TNF- $\alpha$ are known to cause platelet aggregation and adhesion, formation of lipid-laden foam cells and deposition of cholesterol in the tissues (Li, 2000).

Numerous periodontal pathogens have been implicated in the pathways which trigger the development of cardiovascular diseases ( $\mathrm{Li}, 2000)$. Antibodies to periodontal organisms have also been identified to localize in the heart and trigger complement activation, sensitization of T- cells and subsequent heart diseases such as infective endocarditis ( $\mathrm{Li}, 2000$. Barnett, 2009).

The role of periodontal disease in the development of diabetes has also been widely debated. A possible mechanism which could increase insulin resistance and potentially contribute to the development of diabetes, is the production of oxidative stress-enhancing reactive oxygen species (ROS) by the affected periodontal tissues. TNF- $\alpha$ (which reaches high tissue concentrations in periodontal diseases) has been identified as an inflammatory mediator involved in the pathogenesis of insulin resistance (Bullon, 2009).

The role of periodontal pathogens in the development of respiratory diseases may be related to the following mechanisms (Mani, 2013): 
- Aspiration of oral pathogens (P.g. or A.a.).

- Alteration of the mucosal surfaces by salivary enzymes in periodontal disease leading to an increase in the adhesion and colonization of respiratory pathogens.

- The periodontal disease-associated enzymes may destroy the salivary pellicles on the pathogenic bacteria.

- Alteration of the respiratory epithelium by cytokines of periodontal disease, which facilitate the infection of the epithelium with respiratory pathogens.

It has become increasingly evident that the oral cavity can potentially act as a point of origin for the spread of pathogenic organisms to distant sites in the body (Li, 2000).

Transient bacteraemias and dissemination of oral micro-organisms into the bloodstream (with spread to the heart, lungs and peripheral blood capillaries) are reported to occur as rapidly as 1 minute after an oral procedure (Li, 2000. Forner, 2006).

A study by Forner (2006) investigated the development of bacteraemias after procedures such as scaling, chewing and tooth brushing in healthy patients with gingivitis or periodontitis. Blood was drawn at 5,10 and 30 minute intervals to assess the presence of a bacteraemia. Results of the study showed that a bacteraemia peaked at 5 minutes and tapered after 30 minutes. No statistically significant difference between the healthy and gingivitis groups were seen when comparing tooth brushing, chewing and scaling, at all three time intervals. The incidence and magnitude of the bacteraemia after scaling was greater in the periodontitis group. This study suggested that every day events such as mastication and tooth brushing, may contribute more significantly than dental procedures, to the cumulative exposure of the vascular system to bacteraemias from residing oral micro-organisms (Forner, 2006). These bacteraemias have been implicated in the development of distant site infections, especially in the cardiovascular system (Forner, 2006).

A systematic review by Horliana (2014) conducted a systematic review to assess the magnitude, duration, prevalence and nature of the bacteraemias caused by periodontal pathogens, found the available literature too heterogenous to conduct a meta-analysis. The review confirmed that more than half of patients will present with a positive bacteraemia after periodontal procedures. No definitive data could be determined regarding the magnitude, duration and nature of these bacteraemias (Horliana, 2014). 
Thus the effective treatment of active periodontal diseases and elimination of periodontal pathogens can reduce additional burdening of the body with inflammatory mediators and pathogens. This will minimise periodontal disease as a risk factor for in the development of numerous systemic diseases (Mani, 2013). This illustrates the need for identification of adjunctive measures, such as diode lasers, to successfully manage periodontal disease and the associated pathogens.

Studies have demonstrated that the diode laser can also be used to "seal" the periodontal pockets prior to conventional periodontal treatment in order to reduce the risk of a transient bacteraemia (Convissar, 2011:31). This was achieved by application of a 0,4W continuous wave for 7-8 seconds on both the buccal and lingual/palatal aspects of the teeth (Convissar, 2011: 31).

\subsection{Genetic susceptibility to periodontal disease}

Bacterial plaque does play an integral role in the initiation of periodontal disease however in certain patients the amount of plaque present does not correlate with the severity of periodontal destruction seen (Kornman, 1994. Yoshie, 2007). It was thought that periodontitis would always develop in those individuals with a history of poor oral hygiene and long- standing gingivitis (Laine, 2012).

However, numerous authors have alluded to the fact that certain individuals exposed to certain environmental factors, were at a greater risk of developing periodontitis than others. Each patient appears to present with an individual "dose-response curve" that determines the host's susceptibility to periodontitis. Thus host response, rather than the presence of bacteria is required as the principle determinant of disease expression and progression (Yoshie, 2007).

There is a genetic basis to many aspects of the periodontal host response. Data from human and animal studies indicate that genetic variance can influence the innate, inflammatory and host response to microbial infections (Laine, 2012). It must be emphasized that the number and types of disease modifying genes may differ for different types of periodontitis, as well as for different population groups (Laine, 2012). 
IL-1 is a potent pro-inflammatory mediator that is released by macrophages, platelets and endothelial cells (Laine, 2012). IL-1 plays an important role in the pathogenesis of periodontitis, through its involvement in the regulation of the hosts inflammatory response and bone resorption (Kornman, 1997). The IL-1 genotype has been extensively studied as a risk factor for susceptibility to periodontal disease (Kornman, 1997).

Kornman (1997) reported that the IL-1 genotype results in an increased secretion of interleukin-1, which could serve as a predisposing factor in periodontal disease development and progression. Kornman (1997) also found an association between polymorphisms in the genes encoding for IL- $1 \alpha$ and IL- $1 \beta$ and an association with an increased severity of periodontitis. Studies have confirmed that IL-1 $\beta$ levels in both the gingival crevicular fluid (GCF) and periodontal tissue biopsies are increased in patients with periodontitis, compared to healthy patients or those presenting with gingivitis (Kornman, 1997).

A study by Socransky (2000) compared the microbiological parameters in the IL-1 genotype negative and positive adults in a convenient sample of subjects with periodontal disease. The results from this study revealed that the IL-1 genotype positive patients (with pockets greater than $6 \mathrm{~mm}$ had significantly higher levels of "red" and "orange" complex bacteria), compared to shallow $(<4 \mathrm{~mm})$ and intermediate pockets (4-6mm) (Socransky, 2000).

A currently available genetic susceptibility test for periodontitis is the Genotype Interleukin$1{ }^{\circledR}$ (Hain Lifescience GmbH, Nehren, Germany). This particular test is based on the patients IL-1 genotype (Grigoriadou, 2010). This clinically available test for IL-1 has been proposed as a component of the risk assessment profile for periodontitis of a patient. A positive test result (identifying the patient as high risk) could reveal the need for more effective periodontal therapy, intensive oral hygiene interventions and more frequent recalls (Grigoriadou, 2010). 


\subsection{Periodontitis management}

Numerous studies assessing the management of periodontitis have correlated successful periodontal management with elimination or suppression of virulent red complex bacteria (Lindhe, 2015:412). However, accomplishing a reduction in the numbers of these destructive red complex bacteria, often remains a stumbling block in the management of periodontal disease. The red complex bacteria have been demonstrated to infiltrate along the tissue capillaries and penetrate the periodontal pocket connective tissue to a depth of 500 microns, making their elimination with conventional management potentially difficult (Convissar, 2011:27).

The goal of periodontal management is the disruption of the complex biofilm by debridement of the contaminated root surface, thereby achieving a reduction in the total bacterial load and suppression of target micro-organisms in subgingival areas (Van Winkelhoff, 2005, Cheng, 2016). Successful periodontal management is measured both clinically and microbiologically and is dependent on the effective removal and elimination of supragingival and subgingival bacterial biofilms. Eliminating these biofilms enhances biological compatibility between the periodontal root surface and the new connective tissue attachment (Cobb, 1996a. Greenstein, 2000. Dukic, 2013).

Several management modalities are routinely used for the removal of calcified deposits and bacterial biofilms. These include air abrasives, scaling and root planing (using hand instruments, ultrasonic and sonic devices) (Scharwz, 2003). These modalities in conjunction with patient home care plaque control regimens, are necessary in periodontal disease management (Alves, 2012). Conventional management however (i.e. scaling, root planing, polishing) has its limitations and is prone to both clinical and microbiological relapse (Cheng, 2016). These limitations may be attributed to several factors - such as complex tooth anatomy, presence of intrabony defects, limited access associated with size of instrumentation and invasion of periodontal pathogens into the surrounding soft tissues (Sculen, 2015. Cheng, 2016). Thus identifying treatment modalities that could address these limitations, would significantly improve the management of periodontal diseases (Qadri, 2015). 
An armamentarium of adjunctive interventions is available, dependent upon the diagnosis and management needs of the patient. These adjunctive procedures include antibiotic prescriptions and surgical flap procedures. Lasers have recently been proposed as an adjunctive intervention (Cobb, 1996a. Socransky, 2002).

\subsection{Lasers in Periodontitis}

There are various commercially available lasers, each with a unique range of wavelengths and frequencies that can be adjusted according to the procedure requirements (Schwarz, 2003). Wavelengths differ dependent on the type of laser (such as the gallium-aluminiumarsenium (GaAlAs) diode laser, Nd:YAG diode laser, Er:YAG laser and $\mathrm{CO}_{2}$ laser) and these wavelengths range from 635-10600nm (Schwartz, 2003).

Diode lasers have been introduced in both general and specialist practices (Convissar, 2011:7) and are successfully utilized for various intra-oral soft tissues procedures - such as frenectomy, gingivectomy, crown lengthening, gingivoplasty, de-epithelization of reflected periodontal flaps and tissue biopsies (Cobb, 2010).

Numerous studies investigating the application of diode lasers in the management of chronic periodontitis have been published, however these studies have yielded controversial results. It was also difficult to compare the findings of these studies, due to variation in the laser wave lengths utilized and clinical parameters assessed (Cobb, 2006). The majority of studies focused mainly on clinical outcomes, with no evaluation of changes in bacterial load within the periodontal pockets following laser application. Thus the true effect of the diode laser on the pocket biofilm has not been established (Convissar, 2011:27).

The aim of this thesis was to compare the diode laser (with a wave length of $810 \pm 10 \mathrm{~nm}$ ) as an adjunct to conventional periodontal management (i.e. scaling, root planing and polishing) alone at the initial phase of therapy, in patients with chronic periodontitis. 


\section{CHAPTER 2: LITERATURE REVIEW}

\subsection{Diode laser}

Diode lasers have varying wave lengths ranging from 810 - $1064 \mathrm{~nm}$. A variety of functions and effects can be achieved with a diode laser, dependant on the wavelength and energy setting on the laser control unit. The laser can produce coagulation, anaesthesia, ablation, incision or simple heating of the tissues (Cobb, 2006b). These lasers have also been reported to disinfect and de-epithelialize the gingival sulcus (Zingale, 2012).

Diode lasers emit an invisible laser light, with a wavelength of $810 \pm 10 \mathrm{~nm}$. This wavelength falls within that portion of the non-ionizing radiation spectrum called thermal radiation (Convissar, 2011:15).

The laser functions on the principle of energy transmission and emission to the area where the laser beam is focused. Four tissue interactions can occur during laser application, namely reflection, transmission, scattering and absorption. Transmission occurs by virtue of the crevicular fluid in the periodontal pocket as it does not absorb the laser light. In biologic tissues, scattering of the absorbed laser energy occurs upon deep tissue penetration. This absorbed energy is converted to heat and therefore increases the tissue temperature (Convissar, 2011:21).

Bacteria (such as the red complex micro-organisms) have been demonstrated to penetrate the periodontal pocket connective tissue to a depth of 500 microns (Convissar, 2011:27). Diode lasers can penetrate 1-3mm into the tissues (Convissar, 2011:23). This depth of penetration is influenced by many factors. These include the presence of chromophores (e.g. haemoglobin and pigments like melanin), inflammation and the power/energy settings of the laser (Figure 2).

Studies have shown that diode lasers with $980 \mathrm{~nm}$ wavelength (Figure 2) are well absorbed by water. There are however no studies stating that superior results can be achieved with the 980nm laser over other wavelengths of diodes (e.g. $810 \mathrm{~nm}$ diode laser) (Figure 2)

(Convissar, 2011:29). 


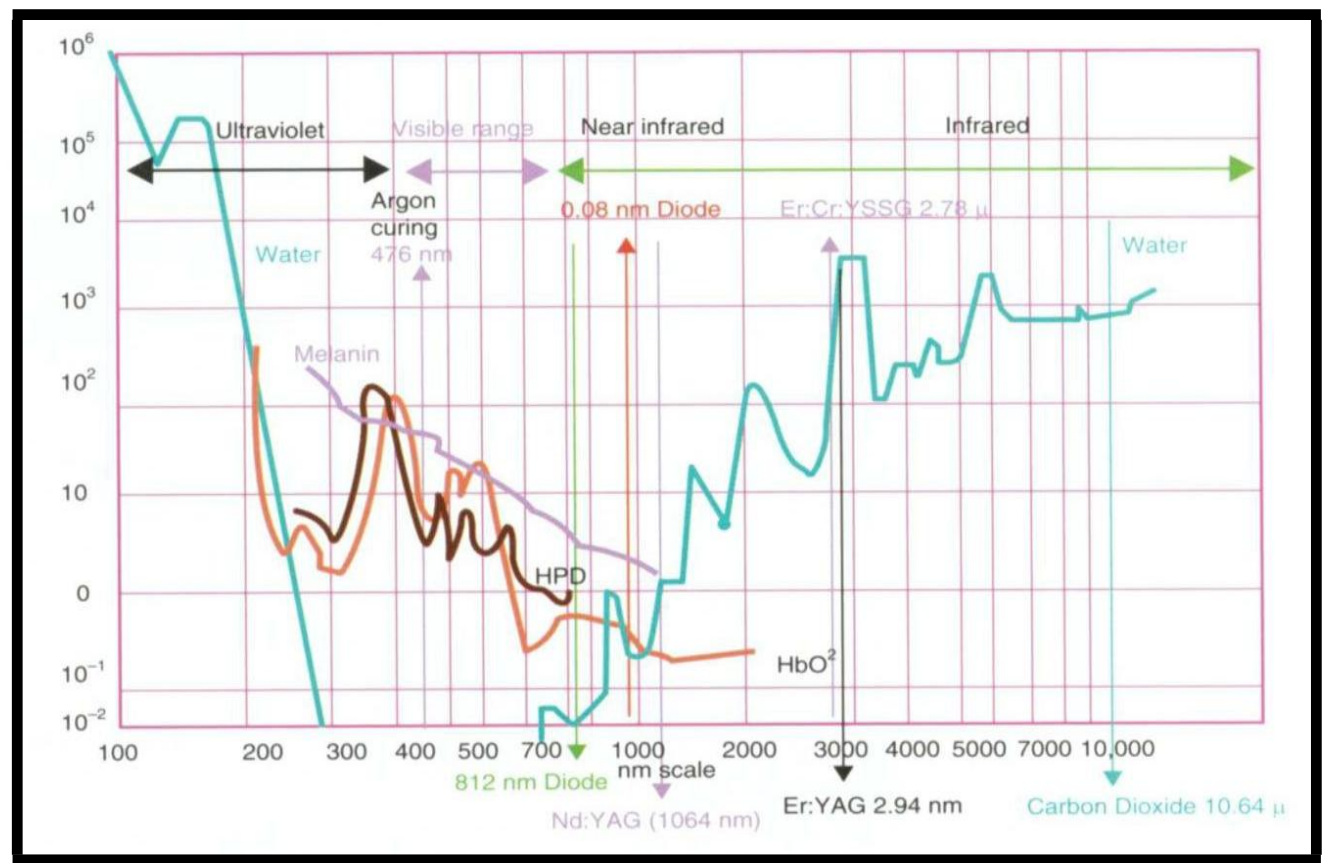

Figure 1.3 Coefficient of absorption for various components in tissue. Er:YAG, erbium: yttrium aluminium garnet; Er:YSGG, erbium: yttrium scandium gallium garnet; Er,CR:YSSG, erbium, chromium: yttrium scandium gallium garnet; HPD, dialysate of hydropenic plasma; $\mathrm{HbO}^{2}$, hemoglobin; $\mathrm{Nd}: \mathrm{YAG}$, neodymium:yttrium aluminium garnet.

Figure 2: Co-efficient of absorption of laser energy from various lasers (Blaiden, 2013:6)

The bacteriocidal properties of lasers are well established (Cobb, 2010). The mechanism whereby this occurs is hypothesized to be due to the fact that the laser energy is selectively absorbed by dark pigments (photodynamic therapy on the dark pigment), such as melanin and haemoglobin (Cobb, 2010). In inflamed periodontal pockets, the increased blood supply due to erythema and inflammation causes the laser light to be absorbed by the haemoglobin, which is elevated in the inflamed pockets (Blaiden, 2013:30-31). Chromophores (associated with periodontal inflammation) will result in greater absorption of laser energy in the inflamed tissue compared to the healthy tissue (Blaiden, 2013:30-31). Theoretically an initiated tip should only affect and eliminate inflamed tissue, with a lesser effect on the healthy tissue in the periodontal pocket (Blaiden, 2013:81).

Deep periodontal pockets also present with higher numbers of pigmented bacteria, thus allowing greater absorption of the laser energy (Convissar, 2011). It is thus assumed that the laser is effective in reducing the colony numbers of the dark pigmented bacteria, such as P.spp, P.spp and T.spp. (Cobb, 2010). 
Laser application has also been shown to also have an impact on non-pigmented bacteria by virtue of its thermal properties, resulting in a temperature increase within the periodontal pocket. The absorbed laser energy also stimulates the proliferation of endothelial cells, which promotes healing and local blood circulation by way of photobiomodulation (Convissar, 2011:28).

\subsection{Application of the diode laser in patients with chronic periodontitis}

The lack of long-term successful treatment outcomes of conventional management in some chronic periodontitis cases has emphasized the need for identification of adjunctive management modalities, such as diode lasers (Qadri, 2015).

Four studies comparing the application of the diode laser (at a wave length of $810 \pm 10 \mathrm{~nm}$ ), as an adjunct in the management of chronic periodontitis are tabulated below (Table 1).

Table 1: Comparison of studies utilizing a diode laser with a wavelength of $810 \pm 10 \mathrm{~nm}$ as an adjunct in the management of chronic periodontitis.

\begin{tabular}{|c|c|c|c|c|c|c|c|}
\hline Author & Laser & $\begin{array}{l}\text { No of } \\
\text { Participants }\end{array}$ & Power & Time & Technique & $\begin{array}{l}\text { Improvement in } \\
\text { clinical } \\
\text { parameters (test } \\
\text { vs control) }\end{array}$ & $\begin{array}{l}\text { Improvement } \\
\text { in bacterial } \\
\text { load(test vs } \\
\text { control) }\end{array}$ \\
\hline $\begin{array}{l}\text { Moritz, } \\
1998\end{array}$ & $809 \mathrm{~nm}$ & 50 & $\begin{array}{l}2.5 \mathrm{~W}, 400 \\
\mu \mathrm{m}\end{array}$ & 10 seconds & Pocket lased & None assessed & $\begin{array}{l}\text { No statistical } \\
\text { significance }\end{array}$ \\
\hline $\begin{array}{l}\text { Kreisler, } \\
(2005)\end{array}$ & $809 \mathrm{~nm}$ & 22 & $\begin{array}{l}1.0 \mathrm{~W}, 600 \\
\mu \mathrm{m}\end{array}$ & $\begin{array}{l}10 \text { seconds, } \\
\text { interruption } \\
30 \mathrm{sec} \text {. }\end{array}$ & $\begin{array}{l}\text { Fiber parallel to } \\
\text { pocket.Moved } \\
\text { along long axis of } \\
\text { tooth } 1 \mathrm{~mm} \\
\text { coronal to } \\
\text { periodontal } \\
\text { pocket. }\end{array}$ & $\begin{array}{l}\text { Improvement } \\
\text { Statistically } \\
\text { significant for } \\
\text { PPD, CAL. } \\
\text { (Parameters } \\
\text { assessed: Clinical } \\
\text { attachment loss, } \\
\text { tooth mobility, } \\
\text { Pocket depth, } \\
\text { plaque index, } \\
\text { gingival index, } \\
\text { sulcus fluid flow } \\
\text { rate) }\end{array}$ & None assessed \\
\hline
\end{tabular}




\begin{tabular}{|c|c|c|c|c|c|c|c|}
\hline $\begin{array}{l}\text { Zingale, } \\
(2012)\end{array}$ & $810 \mathrm{~nm}$ & 25 & $\begin{array}{l}0.9 \quad W, \\
? \mu \mathrm{m}\end{array}$ & $\begin{array}{l}30-45 \text { sec } \\
(\mathrm{cv})\end{array}$ & $\begin{array}{l}\text { Removal of } \\
\text { pocket epithelium }\end{array}$ & $\begin{array}{l}\text { Improvement- No } \\
\text { statistical } \\
\text { significance } \\
\text { (Parameters } \\
\text { assessed: bleeding } \\
\text { on probing, } \\
\text { clinical } \\
\text { attachment loss, } \\
\text { pocket depth) }\end{array}$ & None assessed \\
\hline $\begin{array}{l}\text { Alves } \\
2013\end{array}$ & $\begin{array}{l}808 \pm 5 \\
\mathrm{~nm}\end{array}$ & 36 & $\begin{array}{l}1.5 \mathrm{~W}, 400 \\
\mu \mathrm{m}\end{array}$ & 20 seconds & Pocket lased & $\begin{array}{l}\text { Improvement - No } \\
\text { statistical } \\
\text { significance } \\
\text { (Parameters } \\
\text { assessed: clinical } \\
\text { attachment loss, } \\
\text { pocket depth, } \\
\text { Bleeding on } \\
\text { probing, } \\
\text { recession, plaque } \\
\text { index) }\end{array}$ & $\begin{array}{l}\text { Improvement } \\
\text { - no statistical } \\
\text { significance }\end{array}$ \\
\hline
\end{tabular}

Patients with a confirmed diagnosis of chronic periodontitis and probing pocket depth (PPD) of $>4 \mathrm{~mm}$ were included in the studies (Table 1) Two studies utilised a split mouth technique (Kriesler, 2005. Alves, 2013) and assessed the efficacy of scaling, root planning and polishing with laser (test group) compared to scaling, root planning and polishing alone (control group). Moritz (1997) performed his study on 49 patients (12 in the control group and 37 in test group). The study of Moritz (1997) was included in this review as he used a diode laser ( $809 \mathrm{~nm})$ and it is one of the only two studies that assessed bacterial changes. Moritz conducted a similar study in 1998, however the control group rinsed with hydrogen peroxide. This study was thus not included for comparison due to the potential chemical interactions of the hydrogen peroxide (Moritz, 1998). Zingale (2012) compared no treatment (control group) to conventional management, as well as conventional management with the laser. Thus the study of Zingale (2012) was included in this review. 
Most of the studies assessed the same clinical parameters, namely probing pocket depth (PPD), recession (REC), clinical attachment loss (CAL), full mouth plaque score and bleeding on probing scores (BOP) for the patients participating in the studies.

\subsection{Bacterial collection and assessment of bacterial parameters}

Bacterial collection is essential to assess the effectiveness of interventions for the decontamination of the periodontal pockets. The identification and isolation of periodontal pathogens in periodontal diseases can also aid the clinical management of the disease and assist in assessment of the tissue response to therapy (Van Winkelhoff, 2005).

The laser energy has the potential to decontaminate and eliminate the bacteria in the periodontal pocket. The identification and assessment of the bacterial load is an essential part of measuring the reduction of the bacterial colonies in the periodontal pocket. Only two studies in Table 1 (Alves, 2013. Moritz, 1997), collected bacteria and counted the colony forming units (CFU's). The total bacterial load and number of black pigmented bacteria were also assessed and found to be reduced, however this reduction was not statistically significant (Moritz, 1997. Alves, 2013).

The studies of Moritz (1997) and Alves (2013) used bacterial culturing techniques to analyse the subgingival micro-organisms. Bacteria were collected with sterile paper points and cultured in petri dishes, after which colony forming units (CFU) were counted. Specific black pigmented bacterial colonies were identified via gram staining. The drawback with the agar plate method for the counting of $\mathrm{CFU}$ is that there are bacteria that could be incorrectly identified, since they look similar on the growth medium, possibly resulting in a higher CFU identification number for that bacteria. An example of such a bacteria is Haemophilus aphrophilus (H.a)that has been frequently misinterpreted as A.a or P.i. Molecular microbial techniques - such as PCR have become available to assess periodontal pathogens, which overcomes these drawbacks (Boutaga, 2006).

PCR identifies and quantifies micro-organisms with a higher level of sensitivity and specificity. PCR is more sensitive to those bacterial species that are often difficult to culture (such as anaerobic organisms (Boutaga, 2006). A study by Boutaga (2006) 
compared anaerobic bacterial culture and PCR techniques in the identification and quantification of periodontal pathogens. Boutaga (2005) demonstrated that the detection frequency in percentage of the specified bacteria for PCR was greater than that with CFUs on agar plates (Table 2) (Boutaga, 2005). This study concluded that PCR was more sensitive in detecting smaller numbers of pathogens compared to the culture techniques. PCR is also a rapid diagnostic tool, while the culture techniques requires approximately 14 days to yield the bacterial specimen for assessment (Boutaga, 2006). Thus PCR can be utilised as a rapid and highly sensitive diagnostic tool in the evaluation of periodontal pathogens in a periodontal pockets.

Table 2: Detection frequency in \% of PCR vs CFU (Boutaga, 2005)

\begin{tabular}{|c|c|c|}
\hline Bacteria & PCR (\%) & $\begin{array}{c}\text { CFUs agar plate } \\
(\%)\end{array}$ \\
\hline A. $a$ & 27.4 & 21.6 \\
\hline P.i & 83 & 83 \\
\hline T.f & 89.2 & 63.7 \\
\hline P.m & 97.3 & 91.9 \\
\hline
\end{tabular}

Only two of the relevant studies (Table 1) identified and assessed the changes in bacterial load within the periodontal pockets (Alves, 2012. Moritz, 1997). This omission of bacterial load assessment by the majority of studies may identify an additional area of study required to validate the efficacy of the diode laser as an adjunct to conventional scaling, root planing and polishing. It would be of value to assess the changes in bacterial load in the periodontal pockets with a highly sensitive and specific technique such as polymerase chain reaction $(\mathrm{PCR})$. 
A commercially available kit - Micro-IDent ${ }^{\circledR}-11$ (Hain Lifescience GmbH, Nehren, Germany) is based on multiplex PCR of $16 \mathrm{~S}$ rDNA followed by simultaneous reverse hybridization. The Micro-IDent ${ }^{\circledR}-11$ has been demonstrated to be accurate for use in periodontal pathogen detection to a significant correlation with real time PCR (Haffejee, 2009. Eick, 2011).

\subsection{Conclusion}

Periodontal diseases affect most populations worldwide (Lindhe, 2015:449), thus illustrating the importance of developing effective management modalities to manage and prevent progression of periodontal disease.

The findings studies assessing the diode laser as an adjunct to conventional periodontal management were diverse. The study of Moritz (1997) concluded that the diode laser achieved considerable bacterial elimination from periodontal pockets. One study concluded that the diode laser improved clinical parameters and was a potential adjunct to conventional scaling and root planing (Kriesler, 2005). Two studies concluded that the diode laser was not of any additional benefit to conventional management (Zingale, 2012. Alves, 2013). The diversity in these results can perhaps be attributed to heterogeneity of the study parameters, making direct comparisons or conclusions difficult (Cobb, 2006b. Boutaga, 2006).

The authors concurred on the potential use of diode lasers as an adjunct to conventional management in the treatment of periodontitis. Further studies however are required (Moritz, 1997. Kriesler, 2005). Assessment of changes in the bacterial load, with the diode laser as an adjunct, should be performed by a highly sensitive diagnostic tools, such as PCR, to determine the effect of the diode laser on the bacterial colonies (Boutaga, 2006). 


\section{CHAPTER 3: RESEARCH DESIGN AND METHODOLOGY}

\section{Terms utilized in this chapter}

- Chronic periodontitis: defined as inflammation of the gingiva extending into the adjacent attachment apparatus - characterized by a loss of clinical attachment due to the destruction of the periodontal ligament and supporting alveolar bone (Parameters of Care - American Academy of Periodontology, 2000).

- Conventional (periodontal) management: refers to scaling, root planing and polishing only.

- Control quadrants: refers to study quadrants receiving conventional management only.

- Test quadrants: refers to the study quadrants receiving conventional management and laser application as an adjunct.

- Clinical parameters: refers to clinical indices measured - consisting of probing pocket depth (PPD), recession (REC), tooth mobility, plaque scores and bleeding on probing scores (BOP).

- Red complex bacteria: refers to the groups of bacterial pathogens as described by Socransky (1998). This group includes P.g, T.d and T.f.

\subsection{Introduction}

A literature search revealed no published standardised guidelines on the management of periodontal disease with an $810 \pm 10 \mathrm{~nm}$ laser. In addition, the available studies demonstrated no consistency in study methodologies nor laser parameters utilized.

Boutaga (2006) established polymerase chain reaction (PCR) to be more effective than counting of CFU's for the assessment of bacterial parameters. Thus a PCR technique was utilised in this study to assess the bacterial load changes of eleven pathogens (with emphasis on the destructive red complex bacteria). This was performed using a commercially available kit - the Micro-IDent ${ }^{\circledR}-11$ (Hain Lifescience GmbH, Nehren, Germany).

The changes in clinical parameters were also assessed based on standard measurements currently utilised in periodontal assessment. Standard clinical goals / parameters utilised 
during periodontal assessment of patients include tooth mobility, CAL, REC, PPD, plaque scores and BOP (Lindhe, 2008:573).

\section{AIM}

To assess the efficacy of a diode laser in improving clinical parameters and bacterial load reduction of red complex organisms, as an adjunct to initial phase therapy in patients with chronic periodontitis.

\section{OBJECTIVES}

- To compare the quantitative changes in the bacterial load of pathogens in the periodontal pocket after conventional management versus conventional management plus the diode laser.

- To compare the difference in the periodontal clinical parameters after conventional management versus conventional management plus the diode laser.

\section{MATERIALS AND METHODS}

\subsection{MATERIALS}

The following materials were utilized in this study:

\section{Laser (Figure 3):}

Protective eye wear for 810nm, Diode laser: Picasso GaAlAs diode laser (AMD Laser, Indiana, USA), Diode hand piece, Fiber stripper, Fiber cutter

\section{Hand instrumentation:}

Gracey curettes (Maillefer, Sirona Dentsply), Mini fives (Hu-Friedy Co, Chicago, Illinois),

Periodontal probe (Maillefer, Sirona Dentsply), Ultradent capillary tips known as "canula". 
Bacterial and Genotype collection PCR kits (Figure 6, 7):

Bacterial collection: Micro-IDent ${ }^{\circledR}-11$ (Hain Lifescience GmbH, Nehren, Germany). Periodontal risk assessment: Genotype Interleukin- $1^{\circledR}$ (Hain Lifescience GmbH, Nehren, Germany) (Chondros, 2009).

\section{Prophylaxis:}

Medium abrasion polishing paste (Nu-Pro polishing paste, Sirona Dentsply), Rapid Care Sensodyne tooth paste (GSK), ART-PB3 Piezo-electric scaler (BonART ${ }^{\circ}$, New Taipei City, Taiwan).

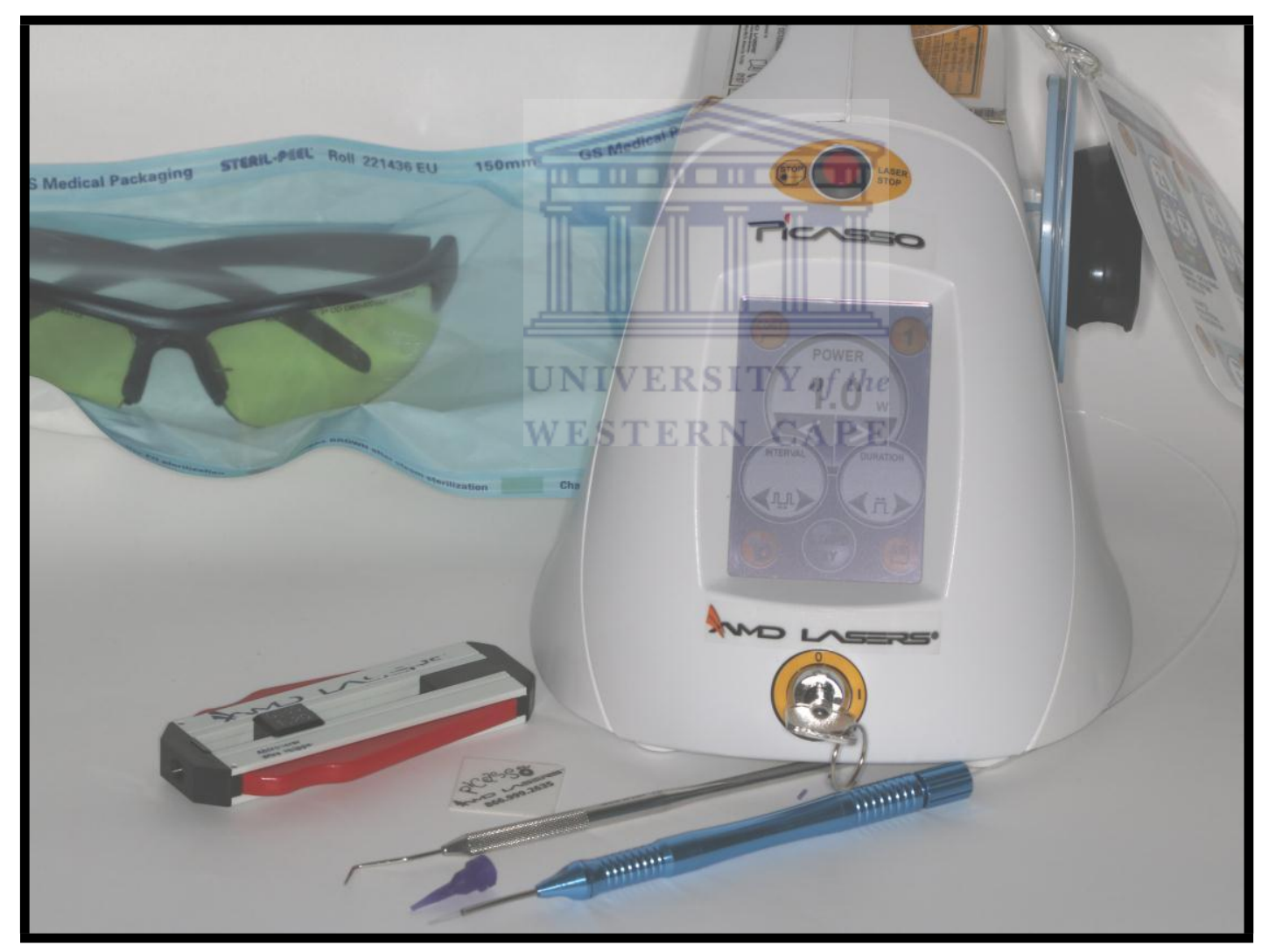

Figure 3. Picasso laser and essential accessories

Each time the laser tip was cleaved it was viewed under a magnifying class at $2 \mathrm{X}$ magnification. The fiber was cleaved in accordance to the manufacturer instructions. This is essential since a properly cleaved fiber to ensure a uniform beam profile (Figure 4). 


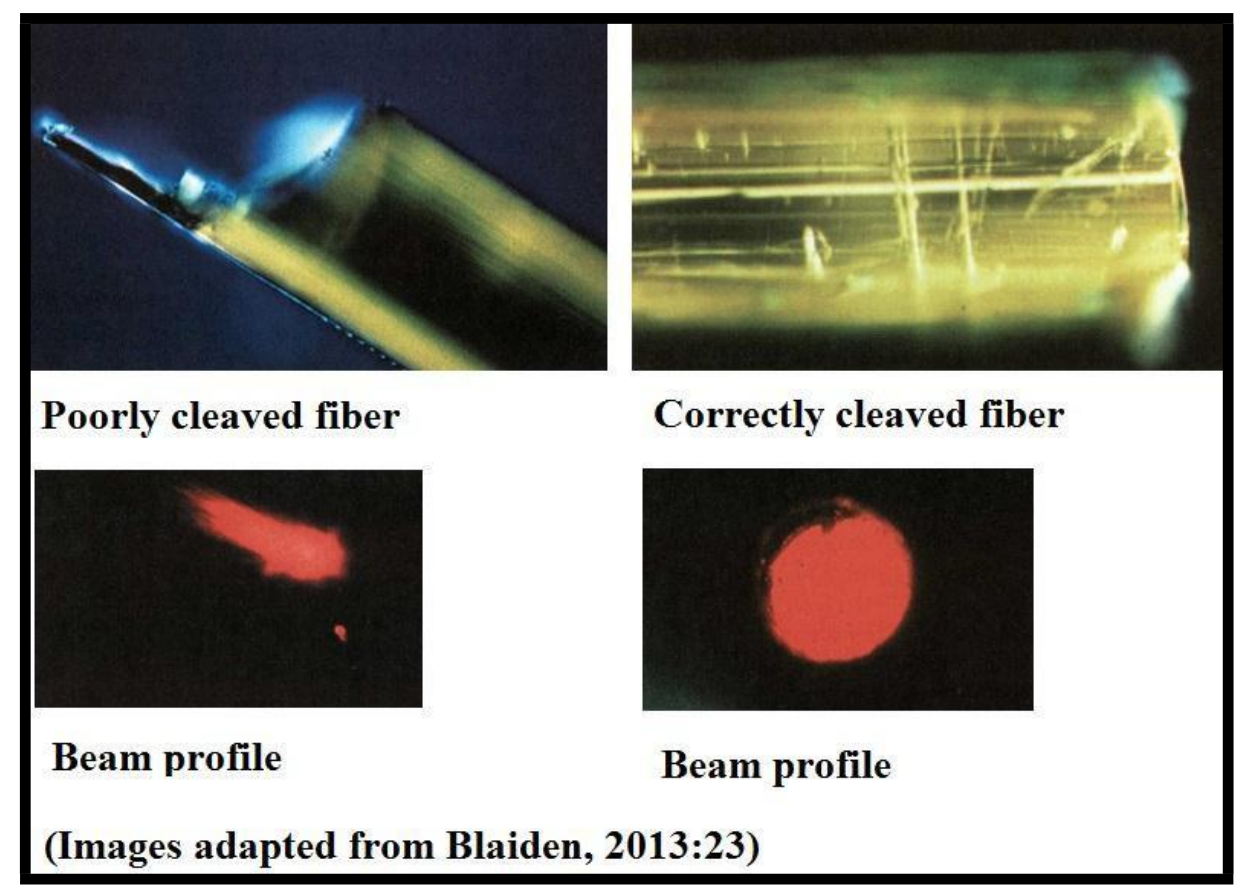

Figure 4: Illustration of the beam profile depending on cleaving status (Blaiden, 2013:23).

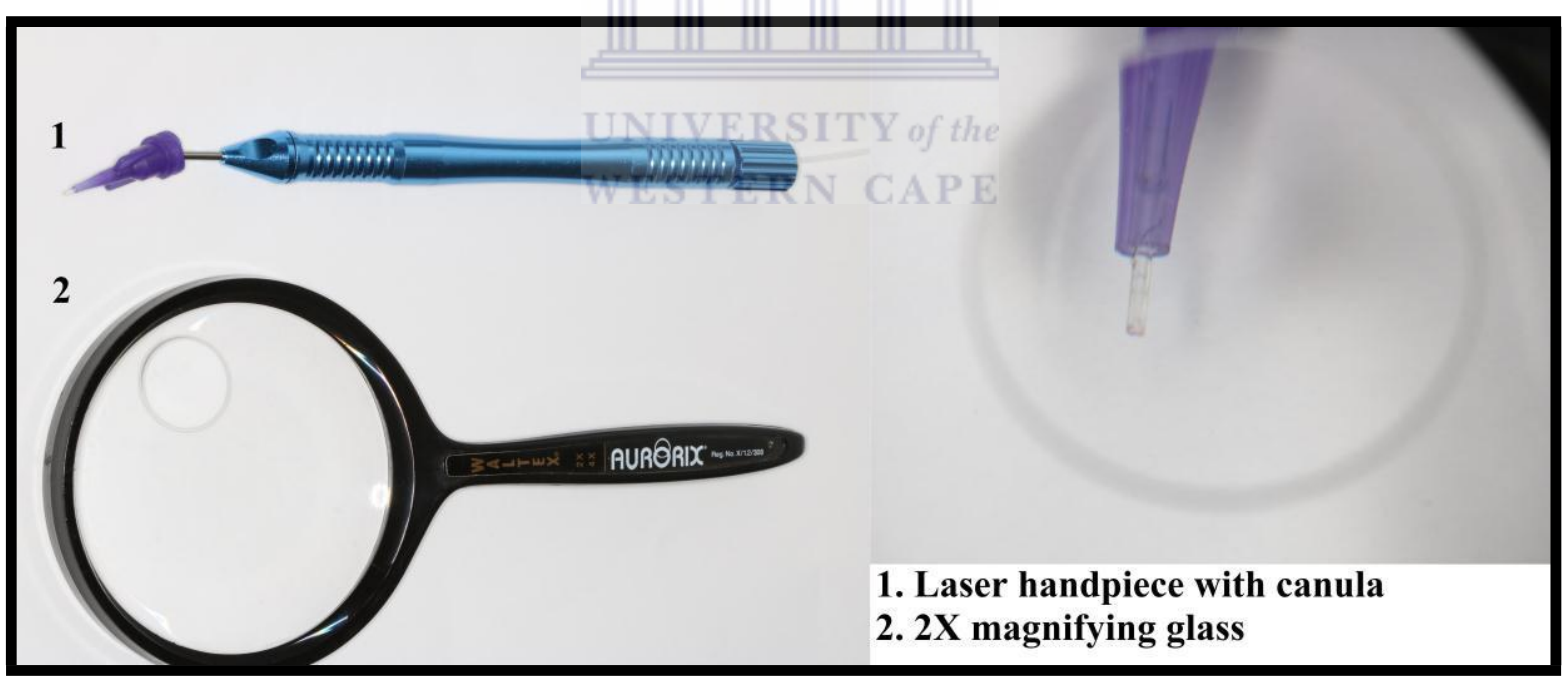

Figure 5: Correctly cleaved fiber assessed under $2 \mathrm{X}$ magnification. 


\subsection{METHODS}

\subsubsection{Study design}

A split mouth randomized control trial was employed, in which every subject is treated with at least two treatments, each being applied to a different area of the mouth (AntczakBouckoms, 1990). This technique allows the patient to be the test subject and control. (Lesaffre, 2009).

The subjects selected in this study were diagnosed with chronic periodontitis (based on the inclusion criteria according to the American Academy of Periodontology Classification, 1999 ). Two quadrants (one maxillary and one mandibular) were utilised as the test quadrants and the contra-lateral quadrants served as the control quadrants.

\subsubsection{Sampling}

The study population comprised of twenty five patients diagnosed with active chronic periodontitis, who presented at the Oral Medicine and Periodontology Department of the University of the Western Cape. These patients provided informed consent and recruitment procedures were in accordance with good clinical practice.

\subsubsection{Inclusion criteria:}

The participants had to be adult patients (over the age of 18 years). For the purpose of this study the participants were diagnosed with chronic periodontitis and had to present with a minimum of four teeth present per quadrant. At least three teeth per quadrant had to present with periodontal probing pocket depths of $5 \mathrm{~mm}$ or more in any of the six point probing areas namely mesio-buccal (MB), buccal (B), disto-buccal (DB), mesio-palatal (MP), palatal (P), disto-palatal (DP) per tooth were assessed.

Clinical features defining a diagnosis of chronic periodontitis:

- Oedema and tissue erythema

- Moderate accumulations of plaque and calculus

- Bleeding on probing (BOP)

- Increased pocket depths (minimum probing pocket depth of $4 \mathrm{~mm}$ ) 
- Radiographic evidence of bone loss (angular or horizontal)

- Tooth mobility

- Varying degrees of clinical attachment loss

- Slow to moderate rate of progression

- Amount of destruction consistent with the presence of local factors - such as plaque and calculus.

The chronic periodontitis could have presented as localised ( $<30 \%$ of sites affected) or generalized ( $>30 \%$ of sites affected). The severity of the chronic periodontitis could have presented as mild $(\mathrm{CAL}=1-2 \mathrm{~mm})$, moderate $(\mathrm{CAL}=3-4 \mathrm{~mm})$ or severe $(\mathrm{CAL}>5 \mathrm{~mm})$ (Lindhe, 2015:129). All the above mentioned variants of chronic periodontitis were included in this study.

\subsubsection{Exclusion criteria}

The only underlying medical conditions that were excluded were patients that were pregnant (or lactating) and patients undergoing radiation or chemotherapy (Kreisler, 2005).

Patients with oral pigmentation of the attached gingiva in the study area of interest were also excluded from the study, as pigments (such as melanin) absorb laser energy at varying amounts which could potentially have an effect on the results (Convissar, 2011:150).

Patients who smoked more than 10 cigarettes per day were excluded (Kreisler, 2005). Patients that had taken antibiotics in the previous 6 months were excluded (Alves, 2012). Patients who had periodontal treatment in the previous 6 months were also excluded (Alves, 2012).

\subsubsection{Selection of test and control quadrants}

Quadrants 1 \& $4(\mathrm{Q} 1$ \& Q4) were assessed together and Q2 \& Q3 were assessed together. This selection procedure for which quadrants received the adjunctive laser therapy could potentially introduce bias (Hujoel, 1998). In order to eliminate bias of quadrants selection, subjects selected one of two coloured balls from a closed, non-transparent bag - for example a blue (representing conventional management alone) and a red ball (representing the diode laser as an adjunct to conventional management). The first ball selected determined 
which treatment is performed on Q1 \& Q4. The remaining treatment option was then applied to Q2 \& Q3. The clinician was blinded to which quadrants were test quadrants, as the selection of the coloured balls designating the test and control quadrants was only performed after the conventional management (i.e. scaling, root planing and polishing) was completed. The treatment was performed by one clinician after calibration of the prescribed conventional management technique by a Specialist Periodontist in the Department.

\subsubsection{ASSESSMENT OF CLINICAL PARAMETERS}

\subsubsection{Probing pocket depth (PPD)}

PDD was measured to the nearest millimetre (with a graduated periodontal probe (Maillefer, Sirona Dentsply)) from the gingival margin to the base of the clinical pocket (Lindhe, 2015:564). Six sites (MB, B, DB, MP, P, DP) per tooth were assessed.

\subsubsection{Recession (REC)}

The Millers classification (1985) for recession was used to determine the recession. REC was measured (with a periodontal probe) to the nearest millimetre from the cemento-enamel junction to the gingival margin.

\subsubsection{Clinical attachment level (CAL)}

CAL was measured (with a periodontal probe) as the distance in millimetres from the cemento-enamel junction (or the border of a restoration) to the base of the probable pocket (Lindhe, 2015:126).

\subsubsection{Full mouth plaque score:}

A full mouth plaque score was calculated by adapting the Plaque Index by Silness \& Löe (1964) and applying this index to every tooth.

\section{- Index values :}

0 : No visible plaque

1: Plaque disclosed on probing 
2: Visible plaque

3: Abundant plaque (Lindhe, 2015:126).

\subsubsection{Full mouth bleeding on probing (BOP):}

BOP for all teeth was calculated as a percentage of the total number of pockets presenting with bleeding on probing, for quadrants Q 1 \& Q4 as a set and Q2 \& Q3 as a set.

\subsubsection{Tooth mobility}

The Millers criteria (1950) was used to assess tooth mobility.

Tooth mobility index:

- Degree 0: Normal physiological tooth movement of between 0,1-0,2 $\mathrm{mm}$ in a horizontal direction.

- Degree 1: Increased mobility of the tooth to at most $1 \mathrm{~mm}$ in a horizontal direction.

- Degree 2: Visually increased mobility of the tooth exceeding $1 \mathrm{~mm}$ in a horizontal direction.

- Degree 3: Severe mobility of the tooth both in a horizontal and vertical direction (Lindhe, 2015:126).

These clinical parameters were recorded at the initial visit and repeated after 6 weeks (Alvez, 2013).

A study conducted Morrison (1980) demonstrated that the clinical severity of periodontitis is reduced significantly 1 month following the initial phase therapy (i.e. conventional management). Thus the assessment of clinical and microbiological parameters cannot be assessed before 1 month of healing has occurred (Morrison, 1980).

At the initial and subsequent visits oral hygiene instructions and education regarding the importance of adequate plaque removal was provided. Patients were shown how to brush all the teeth twice a day for two minutes with the modified Bass technique after evening flossing (Löe, 2000). A soft bristled brush with a pea sized amount of the provided Rapid Care Sensodyne toothpaste was used. The patients were instructed not to use any form of mouth rinse during the duration of the study, since it could influence the outcome of treatment. 


\subsubsection{Collection of bacteria and assessment of bacterial load}

The analysis of the collected bacteria includes the following micro-organisms:

- Actinobacillus actinomycetemcomitans (A.a.)

- Porphyromonas gingivalis (P.g.)

- Prevotella intermedia (P.i.)

- Tannerella forsythia (T.f.)

- Treponema denticola (T.d.)

- Peptostreptococcus micros (P.m.)

- Fusobacterium nucleatum (F.n.)

- Campylobacter rectus (C.r.)

- Eubacterium nodatum (E.n.)

- Eikenella corrodens (E.c.)

- Capnocytophaga species (C.s.).

The first collection of bacteria was performed during the initial assessment appointment prior to any treatment being performed.

Bacteria was collected from the sub-gingival aspect of periodontal pockets with a commercially available kit, namely Micro-IDent ${ }^{\circledR}-11$ (Hain Lifescience GmbH, Nehren, Germany) (Figure 6) (Chondros, 2009). The manufacturer stated that as the analysis is DNAbased, no special terms of transport need to be observed. Samples may be stored in the refrigerator. In this study the collected samples were refrigerated immediately after collection and couriered in a refrigerated cooler within 24 hours of collection.

The bacteria samples were collected according to the manufacturers' instructions from the periodontal pockets on the buccal and lingual/palatal aspects of teeth. One sterile paper point (per tooth) was inserted on the buccal and lingual/palatal aspects. All the paper points of quadrant Q1 \& Q4 were grouped together to make an extract for one PCR-test and Q2 \& Q3 was grouped together for one PCR-test. 
Six weeks after the first visit (conventional management alone (Control side) / conventional management plus laser application (Test side) another set of paper points was collected for the grouped quadrants (Q1 \& Q4, Q2 \& Q3).

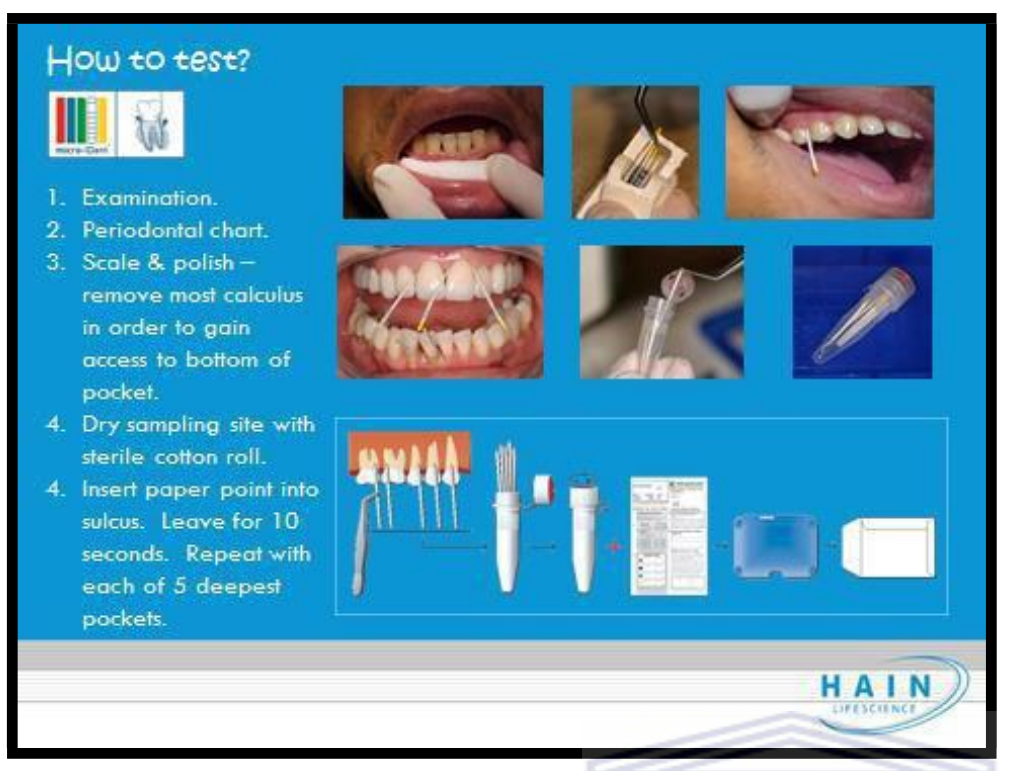

Figure 6: Micro-IDent ${ }^{\circledR}-11$ (Hain Lifescience GmbH, Nehren, Germany).

The periodontal risk status was also assessed at this stage with the Genotype Interleukin- $1^{\circledR}$ (Hain Lifescience GmbH, Nehren, Germany) (Figure 7) (Chondros, 2009). No other laser study has taken the patients' genetic predisposition to periodontal disease into account. It this study the Genotype IL-1 was determined, but it did not serve as an inclusion or exclusion criteria for patient participation in the study.

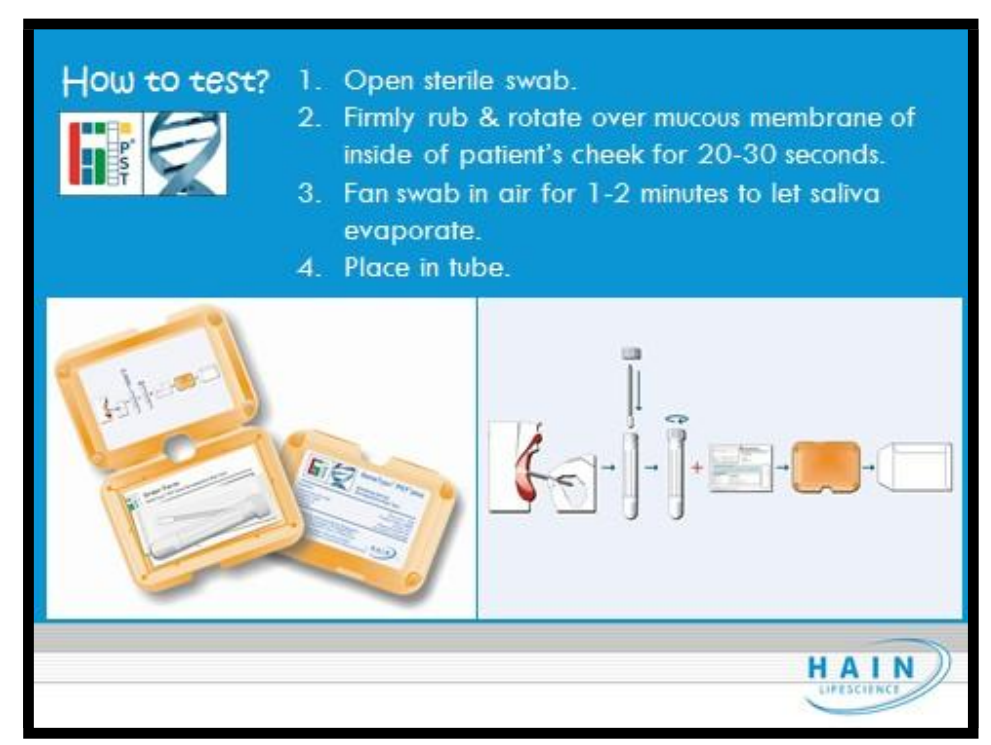

Figure 7: Genotype Interleukin- $1^{\circledR}$ (Hain Lifescience GmbH, Nehren, Germany). 


\subsubsection{Description of procedure for microbial PCR analysis (performed by Hain Lifesciences)}

\section{DNA isolation}

DNA isolation from the paper points: $400 \mu \mathrm{l} 5 \%$ Chelex 100 in $10 \mathrm{mM}$ Tris pH 8.5 were added to every sample. After centrifugation of the paper points, the samples were placed in an ultrasonic bath (Branson 5510) at $60^{\circ} \mathrm{C}$ for $15 \mathrm{~min}$. Finally, the samples were incubated for $15 \mathrm{~min}$ in a $105^{\circ} \mathrm{C}$ thermo-block. Following centrifugation, $5 \mu \mathrm{l}$ was used for the polymerase chain reaction (PCR).

\section{PCR amplification:}

PCR amplification was carried out in a reaction volume of $50 \mu 1$, consisting of $5 \mu 1$ of template DNA and $45 \mu 1$ reaction mixture containing $35 \mu$ l primer nucleotide mix (multiplex Micro-IDent ${ }^{\circledR} k i t$ ) , $5 \mu 1$ of 10X PCR buffer (Qiagen), $5 \mu 1$ of $25 \mathrm{mM} \mathrm{MgCl} 2$ and $1 \mathrm{U}$ Taq polymerase (Qiagen). The amplification profile was one cycle at $95^{\circ} \mathrm{C} / 5 \mathrm{~min}$, ten cycles at $95^{\circ} \mathrm{C} / 30 \mathrm{~s}$ and $58^{\circ} \mathrm{C} / 2 \mathrm{~min}, 20$ cycles at $95^{\circ} \mathrm{C} / 25 \mathrm{~s}, 53^{\circ} \mathrm{C} / 40 \mathrm{~s}$ and $70^{\circ} \mathrm{C} / 40 \mathrm{~s}$ and one final cycle at $70^{\circ} \mathrm{C} / 8 \mathrm{~min}$. For the species Peptostreptococcus until Capnocytophaga, a second primer nucleotide mix was used (multiplex Micro-IDent ${ }^{\circledR}-11$ Plus kit).

\section{Reverse hybridization:}

For the automatic executed hybridization, an Apollo blot automat (Matec) was used; $20 \mu \mathrm{l}$ of the amplified sample is mixed with $20 \mu \mathrm{l}$ of the denaturizing solution, for $5 \mathrm{~min}$ at room temperature. One milliliter of pre-warmed hybridization buffer was added. The specific DNA probes for the reverse hybridization are fixed on a membrane strip. Under gentle shaking, the strip was incubated for $30 \mathrm{~min}$ at $45^{\circ} \mathrm{C}$. After aspiration of the hybridization buffer, $1 \mathrm{ml}$ of stringent wash buffer was added and the strip was incubated for $15 \mathrm{~min}$ at $45^{\circ} \mathrm{C}$. The strip was washed for $1 \mathrm{~min}$ with the rinse solution at room temperature. The conjugate (streptavidin-conjugated alkaline phosphatase) was added, and the strip was incubated for 30 min at room temperature. After being washed twice for $1 \mathrm{~min}$ with water, the strip was dried between absorbing papers, and the results are evaluated, quantified and interpreted. Validated 
quantitative and qualitative test samples are used as control samples. Bacterial levels were expressed as genome equivalents $\left(<10^{3}=0,10^{3}\right.$ to $10^{4}=1,10^{4}$ to $10^{5}=2$ and $10^{5}$ to $\left.10^{6}=3\right)$. The test has a detection limit of $10^{3}$ genome equivalents.

\subsection{Conventional management that was performed}

The clinical parameters, bacterial sampling and assessment of periodontal status was performed prior to the application of conventional management. All the quadrants $(1,2,3$, 4) were treated in the same visit. Ultrasonic debridement of plaque and calculus deposits were completed with an ART-PB3 Piezo-electric scaler (BonART ${ }^{\circledR}$, New Taipei City, Taiwan) at a frequency range of 27-32 kHz. Mechanical sub-gingival debridement was performed with Gracey hand curettes and mini fives (Hu-Friedy Co., Chicago, Illinois). The supra-gingival tooth structure and root surfaces were completely debrided for all the teeth present in the patient's oral cavity. Supra-gingival tooth structure was polished with medium abrasion polishing paste (Nu-Pro polishing paste, Sirona Dentsply) and a polishing cup fitted on a slow hand piece.

\subsection{Laser decontamination of test quadrants}

\subsubsection{Laser decontamination settings}

The Picasso GaAlAs laser (AMD Lasers $^{\circledR}$, Indianapolis, Indiana, USA) with a wavelength of $810 \pm 10 \mathrm{~nm}$ was used. The laser was used with a $400 \mu \mathrm{m}(0.4 \mathrm{~mm})$ optical fibre (Figure 3). The tip was cleaved and assessed under magnifying glass at $2 \mathrm{X}$ magnification to ensure a square cleavage of the tip (Figure 5). Incorrect cleavage will result in irregular laser light distribution (Blaiden, 2013:23) (Figure 4). For periodontal pocket decontamination it is recommended that the laser tip must be initiated. This is achieved by placing the tip on cork or articulating paper. Initiated tips require less energy to achieve the same amount of energy delivery to the tissues than a non- initiated tip. This has the advantage of decreasing the temperature and the lasing time required, thus reducing the risk for thermal damage to the periodontal structures (Convissar, 2011:31).

Studies have demonstrated "sealing" of the periodontal pockets prior with the diode laser prior to conventional management in order to reduce the risk of creating a transient 
bacteraemia (Convissar, 2011:31-32). In order for this study to be a randomized control trial this technique was not utilised. This would result in identification of the test quadrants prior to the conventional management - introducing the risk of bias.

The laser application in the test quadrant pockets occurred after the tip was initiated on articulation paper. The power setting of $1 \mathrm{~W}$ continuous wave was selected. The Picasso GaAlAs laser (AMD Lasers ${ }^{\circledR}$, Indianapolis, Indiana, USA) was set at continuous wave for the "decontamination" on 1W (Kreisler, 2002) at a frequency of 50Hz (Moritz, 1997).

\subsubsection{Application of the laser in the quadrants receiving laser treatment and conventional management (Test quadrants)}

The laser tip was applied in the pocket for the extent of time that was needed to sweep the tip through the pocket. This time was maintained at $8 \pm 2$ seconds per buccal aspect of the tooth and about $8 \pm 2$ seconds per lingual/palatal aspect of the tooth. The tip was held parallel to the long axis of the tooth and $1 \mathrm{~mm}$ coronally of the periodontal base of the pocket. In order to ensure that the laser tip is placed at the correct pocket depth, a plastic canula was calibrated in millimetre segments (as found on a periodontal probe) and placed over the laser fibre and hand piece before laser decontamination commenced (Figure 8). The periodontal pocket depths from the clinical parameters served as a reference guide. If a deeper pocket required a longer fiber, the fiber could simply be fed through the hand piece.

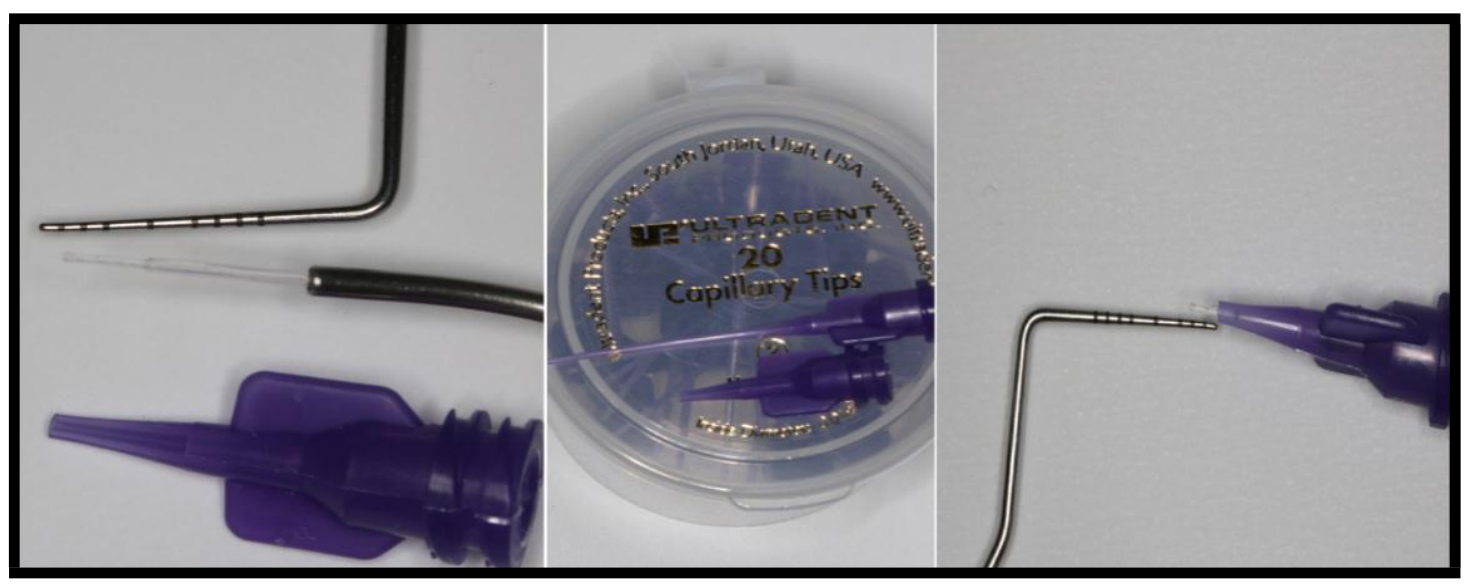

Figure 8: Illustration of how canula was calibrated for the laser fiber 
All the laser treatment commenced from the most distal tooth of the test quadrants towards the most mesial. Decontamination started on the buccal aspect of the tooth, from the distal aspect of the periodontal pocket to the mesial aspect of the periodontal pocket and then repeated on the lingual/palatal aspects of the teeth. The periodontal pockets of all the teeth of the test quadrants were rinsed with saline and a calibrated irrigation tip to allow appropriate depth in the pockets, based on the periodontal charting (Figure 9). Following the lasing and saline rinse the laser decontamination was repeated for a second time for an additional 8 seconds at the buccal and palatal/lingual aspects of the teeth. This timeframe was chosen based on the research conducted by Kreisler (2005), whom suggested 10 seconds will cause thermal damage and bacterial decontamination of more than $99 \%$ simply cannot be achieved. Damage to the root surface also occurred at settings of $1.5 \mathrm{~W}$ and higher (Kreisler, 2005). In order to avoid any patient discomfort treatment was completed under local anaesthetic. Xylotox Plain ${ }^{\circledR}$ was used in order to ensure that the presence of adrenalin could potentially not have an impact on the level of chromophores in the periodontal pocket. The necessary personal protective equipment to operate the laser was worn by the operator and the patient.

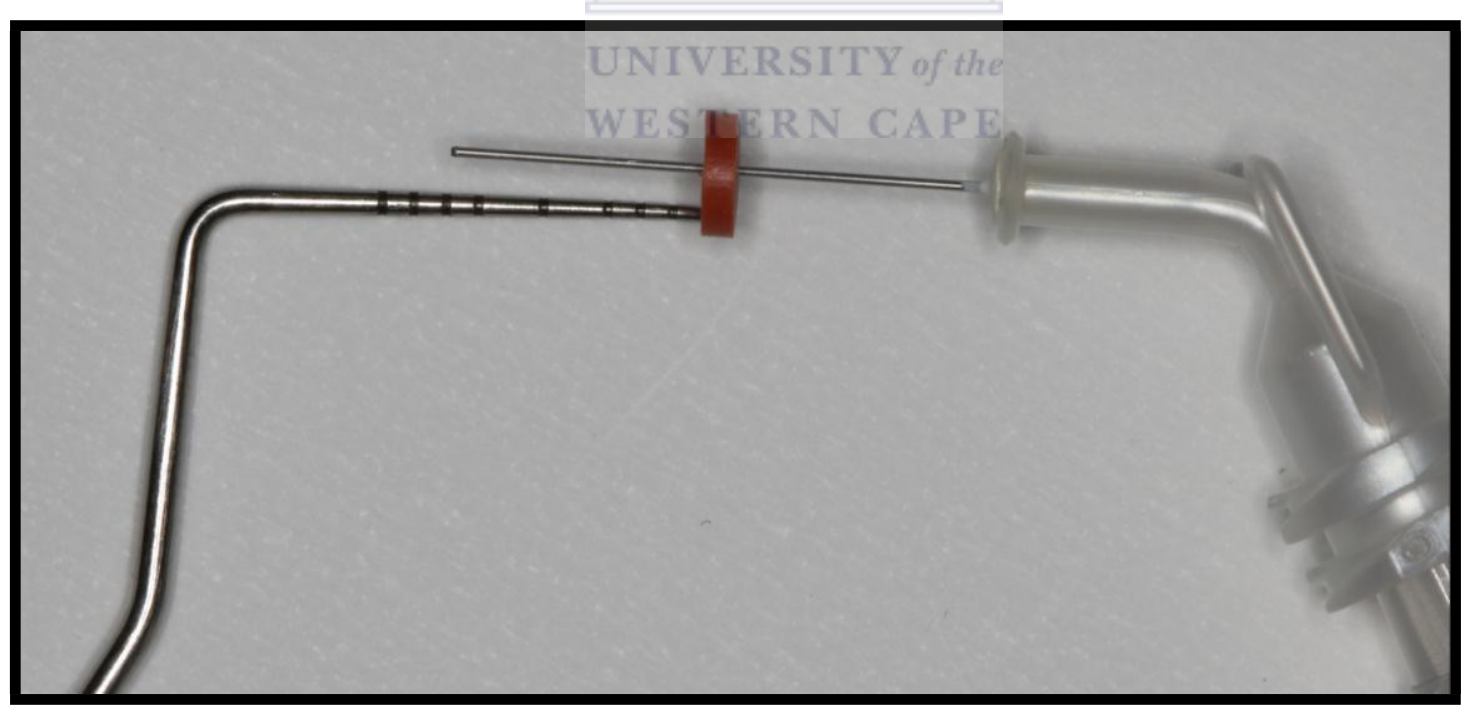

Figure 9: Calibrated Ultradent Navi 29G, 17mm tip for saline rinse. 


\subsection{STATISTICAL ANALYSIS}

\subsubsection{Reporting of the data}

The bacterial report from the Micro-IDent ${ }^{\circledR}-11$ is demonstrated in Figure 11.

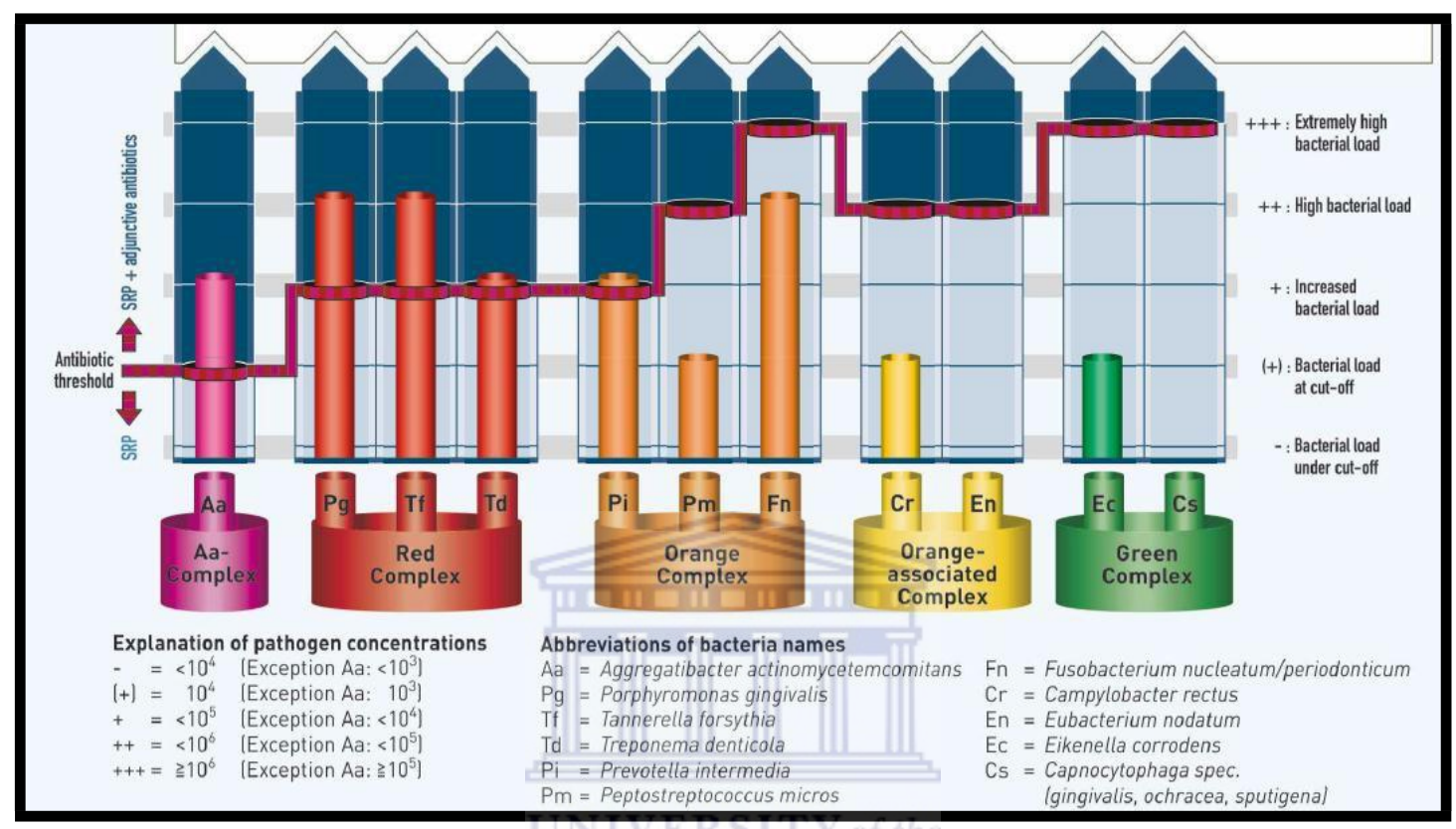

Figure 10: Bacterial report from the Micro-IDent ${ }^{\circledR}-11$ kit.

The Micro-IDent ${ }^{\circledR}-11$ report provides the bacterial pathogen load as crude " $<$ and $>$ " ranges. To facilitate statistical analysis these crude ranges were converted to pathogen concentration ranges and captured as decimal values (as established with the manufacturer) (Table 3).

Table 3: Interpretation of Micro-IDent ${ }^{\circledR}-11$ pathogen concentration for data capturing purposes for all the pathogens (excluding A.a.). 


\begin{tabular}{|c|c|c|c|}
\hline KEY & $\begin{array}{c}\text { Pathogen } \\
\text { concentration }\end{array}$ & $\begin{array}{c}\text { Exact pathogen } \\
\text { concentration range } \\
\text { (As established with } \\
\text { the manufacturer). }\end{array}$ & $\begin{array}{c}\text { Captured in data sheet } \\
\text { to facilitate statistics } \\
\text { (As established with the } \\
\text { manufacturer). }\end{array}$ \\
\hline- & $<10^{4}$ & $10^{0}-10^{3.99}$ & 0.35 \\
\hline++ & $10^{4}$ & $10^{4}$ & 0.4 \\
\hline+ & $<10^{5}$ & $10^{4.01}-10^{4.99}$ & 0.45 \\
\hline++ & $<10^{6}$ & $10^{5}-10^{5.99}$ & 0.55 \\
\hline++ & $\geq 10^{6}$ & $10^{6}-10^{\infty}$ & 0.6 \\
\hline
\end{tabular}

Table 4 illustrates the pathogen concentration as per the Micro-IDent ${ }^{\circledR}-11$ and the results captured to facilitate statistical analysis for A.a.

Upon analysis the values are converted back to the range for accuracy and interpretation purposes.

Table 4: Interpretation of Micro-IDent ${ }^{\circledR}-11$ pathogen concentration for data capturing purposes

\begin{tabular}{|c|c|c|c|}
\hline KEY & $\begin{array}{c}\text { Pathogen } \\
\text { concentration } \\
\text { A.a }\end{array}$ & $\begin{array}{c}\text { Pathogen } \\
\text { concentration range } \\
\text { (As established with } \\
\text { the manufacturer). }\end{array}$ & $\begin{array}{c}\text { Captured in data sheet } \\
\text { to facilitate statistics } \\
\text { (As established with the } \\
\text { manufacturer). }\end{array}$ \\
\hline- & $<10^{3}$ & $10^{0}-10^{2.99}$ & 0.25 \\
\hline++ & $10^{3}$ & $10^{3}$ & 0.3 \\
\hline+ & $<10^{4}$ & $10^{3.01}-10^{3.99}$ & 0.35 \\
\hline++ & $<10^{5}$ & $10^{4}-10^{4.99}$ & 0.45 \\
\hline+++ & $\geq 10^{5}$ & $10^{5}-10^{\infty}$ & 0.5 \\
\hline
\end{tabular}


The data capturing from the bacterial report (Figure 10) was efficient since a clear parameter was established with the manufacturer (Table 3; Table 4). This facilitated the statistical analysis for the 25 patients taking the decimal values into consideration to achieve a greater level of accuracy. The Micro-IDent ${ }^{\circledR}-11$ report visually illustrates the bacterial parameter sensitivity range (Figure 10).

Table 5 was constructed to demonstrate the discrepancy between evaluating the bacterial parameters as a crude " $<$ " and " $>$ " values, compared to assigning decimal values.

Based on Table 5 using T.d as example the control side had statistical significant bacterial load decreases based on the decimal values. The conclusion for control side for T.d was that the bacterial load changed from 0.47 to 0.41 based on decimal values, however the crude representation $\left(<10^{5}\right)$ indicated no change. But for the 25 patients the bacterial change was significantly decreased in the control group. This illustrates the need for decimal values for statistical analysis of bacterial parameters when PCR analysis is performed.

Table 5: Micro- IDent bacterial range applied to the test and control sides to illustrate the precise bacterial parameter range after 6 weeks.

\begin{tabular}{|c|c|c|c|c|c|}
\hline $\begin{array}{c}\text { Bacteria: } \\
\text { A. } a\end{array}$ & $\mathbf{n}$ & $\begin{array}{c}\text { Before } \\
\text { treatment }\end{array}$ & $\begin{array}{c}\text { After } \\
\text { treatment }\end{array}$ & $\begin{array}{c}\text { Micro- } \\
\text { IDent } 11 \\
\text { parameter }\end{array}$ & $\begin{array}{c}\text { Statistical } \\
\text { difference } \\
\text { found with } \\
\text { the actual } \\
\text { captured } \\
\text { decimal value }\end{array}$ \\
\hline $\begin{array}{c}\text { Control } \\
\text { side } \\
\end{array}$ & 25 & $0.28\left(<10^{3}\right)$ & $0.294\left(<10^{3}\right)$ & none & none \\
\hline Test side & 25 & $0.29\left(<10^{3}\right)$ & $0.298\left(<10^{3}\right)$ & none & none \\
\hline \multicolumn{6}{|l|}{$\begin{array}{c}\text { Bacteria: } \\
\text { P.g }\end{array}$} \\
\hline $\begin{array}{c}\text { Control } \\
\text { side } \\
\end{array}$ & 25 & $\begin{array}{l}0.468 \\
\left(<10^{5}\right) \\
\end{array}$ & $0.448\left(<10^{5}\right)$ & none & none \\
\hline Test side & 25 & $\begin{array}{l}0.468 \\
\left(<10^{5}\right)\end{array}$ & $0.44\left(<10^{5}\right)$ & none & none \\
\hline
\end{tabular}




\begin{tabular}{|c|c|c|c|c|c|}
\hline \multicolumn{6}{|l|}{$\begin{array}{c}\text { Bacteria: } \\
\text { T.f }\end{array}$} \\
\hline $\begin{array}{l}\text { Control } \\
\text { side }\end{array}$ & 25 & $0.49\left(<10^{5}\right)$ & $0.474\left(<10^{5}\right)$ & none & none \\
\hline Test side & 25 & $\begin{array}{l}0.482 \\
\left(<10^{5}\right) \\
\end{array}$ & $0.47\left(<10^{5}\right)$ & none & none \\
\hline \multicolumn{6}{|l|}{$\begin{array}{l}\text { Bacteria: } \\
\text { T.d }\end{array}$} \\
\hline $\begin{array}{l}\text { Control } \\
\text { side }\end{array}$ & 25 & $0.47\left(<10^{5}\right)$ & $0.41\left(<10^{5}\right)$ & none & Yes \\
\hline Test side & 25 & $0.4\left(10^{4}\right)$ & $0.424\left(<10^{5}\right)$ & $\begin{array}{l}\text { bacterial increase } \\
\quad\left(10^{4} \text { to } 10^{5}\right)\end{array}$ & none \\
\hline \multicolumn{6}{|l|}{$\begin{array}{c}\text { Bacteria: } \\
P . i\end{array}$} \\
\hline $\begin{array}{l}\text { Control } \\
\text { side }\end{array}$ & 25 & $\begin{array}{l}0.424 \\
\left(<10^{5}\right)\end{array}$ & $0.392\left(<10^{4}\right)$ & $\begin{array}{l}\text { bacterial decrease } \\
\left(10^{5} \text { to } 10^{4}\right)\end{array}$ & none \\
\hline Test side & 25 & $\begin{array}{l}0.388 \\
\left(<10^{4}\right)\end{array}$ & $0.394\left(<10^{4}\right)$ & none & none \\
\hline $\begin{array}{c}\text { Bacteria: } \\
\text { P.m }\end{array}$ & \multicolumn{5}{|c|}{$\begin{array}{l}\text { UNIVERSITY of the } \\
\text { WESTERN CAPE }\end{array}$} \\
\hline $\begin{array}{l}\text { Control } \\
\text { side }\end{array}$ & 25 & $\begin{array}{l}0.394 \\
\left(<10^{4}\right) \\
\end{array}$ & $0.366\left(<10^{4}\right)$ & none & none \\
\hline Test side & 25 & $\begin{array}{l}0.374 \\
\left(<10^{4}\right)\end{array}$ & $0.382\left(<10^{4}\right)$ & none & none \\
\hline \multicolumn{6}{|l|}{$\begin{array}{c}\text { Bacteria: } \\
F . n \\
\end{array}$} \\
\hline $\begin{array}{l}\text { Control } \\
\text { side }\end{array}$ & 25 & $\begin{array}{l}0.382 \\
\left(<10^{4}\right)\end{array}$ & $0.51\left(<10^{6}\right)$ & $\begin{array}{c}\text { bacterial increase } \\
\left(10^{4} \text { to } 10^{6}\right)\end{array}$ & none \\
\hline Test side & 25 & $0.51\left(<10^{6}\right)$ & $0.508\left(<10^{6}\right)$ & none & none \\
\hline \multicolumn{6}{|l|}{$\begin{array}{l}\text { Bacteria: } \\
\text { C.r }\end{array}$} \\
\hline $\begin{array}{l}\text { Control } \\
\text { side }\end{array}$ & 25 & $\begin{array}{l}0.508 \\
\left(<10^{6}\right)\end{array}$ & $0.382\left(<10^{4}\right)$ & $\begin{array}{l}\text { bacterial decrease } \\
\qquad\left(10^{6} \text { to } 10^{4}\right)\end{array}$ & none \\
\hline Test side & 25 & $0.388\left(<10^{4}\right)$ & $0.376\left(<10^{4}\right)$ & none & none \\
\hline
\end{tabular}




\begin{tabular}{|c|c|c|c|c|c|}
\hline $\begin{array}{c}\text { Bacteria: } \\
\text { E.n } \\
\end{array}$ & & & & & \\
\hline $\begin{array}{l}\text { Control } \\
\text { side }\end{array}$ & 25 & $\begin{array}{l}0.376 \\
\left(<10^{4}\right)\end{array}$ & $0.362\left(<10^{4}\right)$ & none & none \\
\hline Test side & 25 & $0.36\left(<10^{4}\right)$ & $0.364\left(<10^{4}\right)$ & none & none \\
\hline \multicolumn{6}{|l|}{$\begin{array}{c}\text { Bacteria: } \\
\text { E.c } \\
\end{array}$} \\
\hline $\begin{array}{c}\text { Control } \\
\text { side }\end{array}$ & 25 & $\begin{array}{l}0.364 \\
\left(<10^{4}\right) \\
\end{array}$ & $0.376\left(<10^{4}\right)$ & none & none \\
\hline Test side & 25 & $0.39\left(<10^{4}\right)$ & $0.394\left(<10^{4}\right)$ & none & none \\
\hline \multicolumn{6}{|l|}{$\begin{array}{c}\text { Bacteria: } \\
\text { C.s }\end{array}$} \\
\hline $\begin{array}{c}\text { Control } \\
\text { side } \\
\end{array}$ & 25 & $\begin{array}{l}0.394 \\
\left(<10^{4}\right) \\
\end{array}$ & $0.36\left(<10^{4}\right)$ & 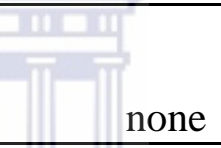 & Yes \\
\hline Test side & 25 & $\begin{array}{l}0.364 \\
\left(<10^{4}\right)\end{array}$ & $0.378\left(<10^{4}\right)$ & 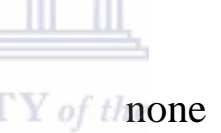 & none \\
\hline
\end{tabular}

\subsubsection{Statistical analysis}

Numbers were assigned to the bacterial collections and clinical parameters in order to maintain the anonymity of the patients. All the bacterial and clinical data was collected and inserted into an Excel spreadsheet (Excel 2012 ${ }^{\circledR}$, Microsoft1 Corp., Richmond, VA) and analysed with R Core Team (2013). R: A language and environment for statistical computing. R Foundation for Statistical Computing, Vienna, Austria.

Each pair of quadrants (Q1 \& Q4 and Q2 \& Q3) were assessed as a "unit" for the bacterial collection and the clinical parameters for the statistical comparison. Group comparison of the clinical data for the groups of Q1 \& Q4 and Q2 \& Q3 were calculated. The means and standard 
deviations were calculated from each clinical parameter that was recorded including the Micro-IDent ${ }^{\circledR}-11$ PCR results, at the various periodontal sites and statistically analysed. The statistical analysis performed was based on a one-sample t-test. It was performed on the differences of the bacterial parameters before and after treatment. It was therefore essentially a paired t-test of the mean values. The degrees of freedom used for statistical analysis with the $\mathrm{t}$-test was calculated as $\mathrm{df}=25-1=24$. The statistical analysis of the data considered each of the bacterial species before and after treatment. In order to determine if the laser was an adjunct to conventional management made a statistical difference, the final analysis of the data was completed with the differences of differences (DID). The DID was obtained when the values considered for this test was calculated in the following mathematical equation:

\section{DID = Value before Conventional management with laser - Value after Conventional management with laser - (Value before Conventional management - Value after Conventional management).}

This test therefore calculated the final outcome of the average change in bacteria that occurred over time for the conventional management plus laser treatment (Test side) in relation to the conventional management alone (Control side) for the 25 patients. The data had to be interpreted based on the mathematical values in the equation to prevent a reverse casualty. A p-value of $p<0.05$ was considered to be statistically significant (Gianelli, 2012). 


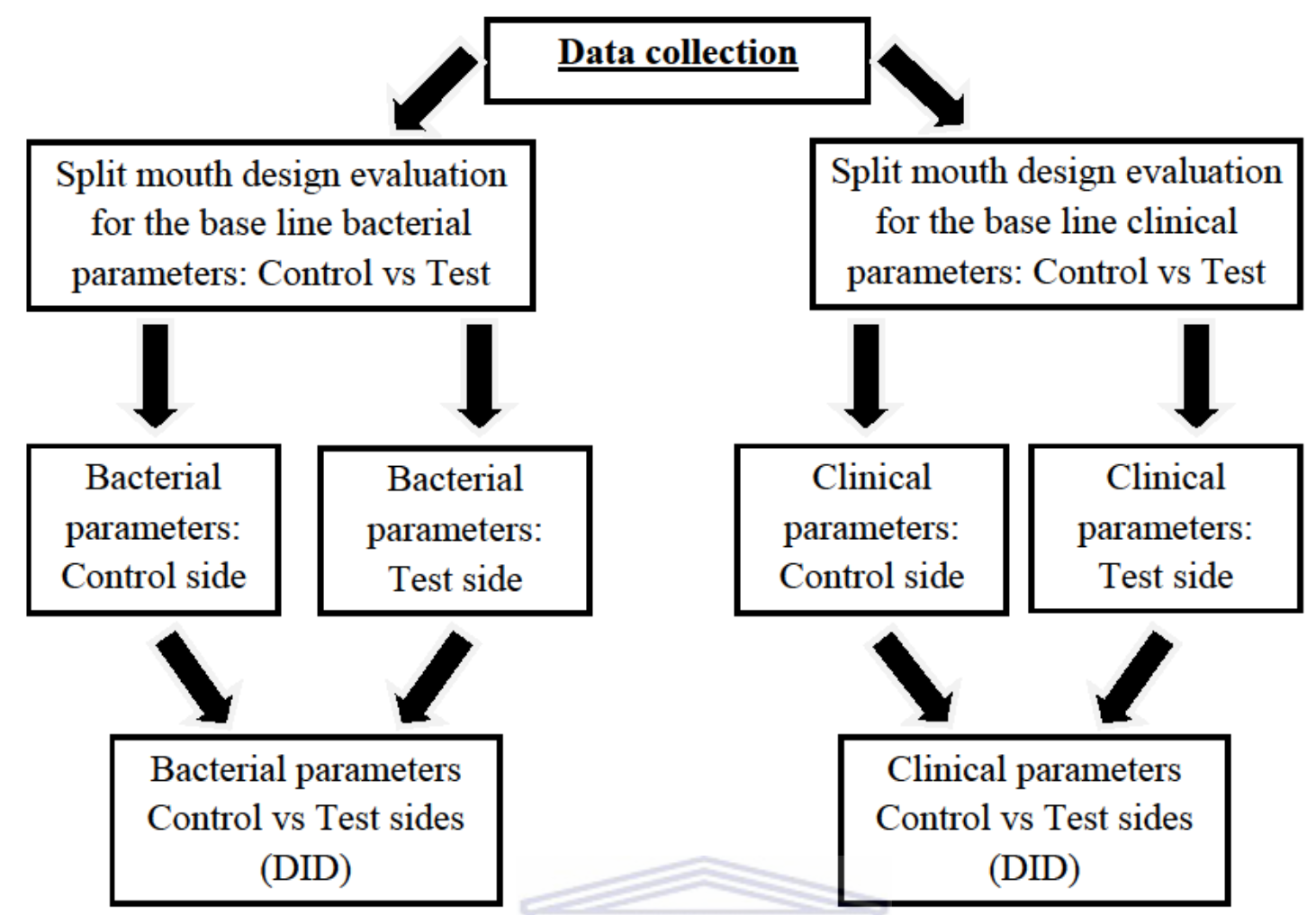

Figure 11: Flow diagram of the statistical analysis of all the bacterial parameters and clinical parameters.

\subsection{ETHICAL CONSIDERATIONS:}

Ethical approval was required for this study and obtained (Reg no: 14/9/6). All the study participants signed a consent form after an information session regarding the study and recruitment was in accordance with good clinical practice. Numbers were assigned to the bacterial collections and clinical parameters in order to maintain the anonymity of the patients.

The diode laser application was provided as an adjunct during the initial phase therapy, so the patient was not disadvantaged since, traditional clinically relevant periodontal management was still performed (namely scaling, root planing and polishing). There was no conflict of interest and no financial gain was applicable to the clinician should any discovery be made. The parameters of the laser utilised were safe according to the literature, therefore no damage or harm occurred to the patient nor any anatomical structures in the oral cavity. The operator and patient wore the approved personal protective equipment at all times during the operation 
of the laser. If this study were to prove that the laser as an adjunct does have a significant beneficial effect, the laser application would then be performed on the quadrants previously treated with conventional management alone (Control side).

\subsection{POTENTIAL LIMITATIONS:}

\section{Patient follow-up:}

The patients were followed up after 6 weeks. During the interval between visits patients were provided with detailed oral hygiene instructions and education. Patients were contacted once per week telephonically to motivate them to follow the oral hygiene instructions provided.

Although the clinician provided the instructions, education and standardised tooth paste the patients may not have always explicitly followed these instructions, which could potentially influence the outcome of this study.

This however did represent a real world scenario that clinicians are faced with in the clinical realm. This study was a split mouth randomized control trial thus the test and control sides would have been exposed to the same level of plaque control. This was confirmed by the plaque index reduction demonstrated in the both the test (320\% reduction) and control sides (310\% reduction). 


\section{CHAPTER 4: RESULTS AND DISCUSSION}

\section{Terms utilized in this chapter}

- Conventional (periodontal) management: refers to scaling, root planing and polishing only.

- Control quadrants: refers to study quadrants receiving conventional management only.

- Test quadrants: refers to the study quadrants receiving conventional management and laser application as an adjunct.

\subsection{Randomised control trial design}

There were 25 participants in this split mouth randomised controlled trial. All the bacterial and clinical data was captured at the end of the study after the follow up of the $25^{\text {th }}$ patient.

The control and test sides were tabulated according to the left and right side distribution of the patients. This demonstrated a balanced distribution of the left and right sides to be either a control or test side. This favourable distribution was noted after data capturing (Table 6).

Table 6: Randomisation of split mouth and side allocation

\begin{tabular}{|l|l|l|}
\hline & \multicolumn{1}{|c|}{$\begin{array}{c}\text { Left side of } \\
\text { participant }\end{array}$} & Right side of participant \\
\hline Control side & 12 & 13 \\
\hline Test side & 13 & 12 \\
\hline
\end{tabular}




\subsection{Statistical analysis of split mouth model}

\subsubsection{Assessment of bacterial parameters for the split mouth model (before}

conventional management was performed):

The distribution of the test and control sides were well balanced for this split mouth randomised control trial. Each patient served as his/her own control it and it was evaluated if there were significant differences in the bacterial count of the control and the test sides before conventional management. A paired t-test of the mean values was performed for each of the bacterial species that was collected at the first visit.

Table 7 represented the difference in the mean value of the 25 patients for the bacterial collection before any treatment commenced. Significant difference between the left and the right side would be considered for a $\mathrm{p}<0.05$.

Table 7: Bacterial comparison for the left and right.

\begin{tabular}{|c|c|c|}
\hline $\begin{array}{c}\text { Bacterial } \\
\text { spp }\end{array}$ & $\begin{array}{c}\text { Mean } \\
\text { difference in } \\
\text { the Bacterial } \\
\text { spp count (Left } \\
\text { and Right) }\end{array}$ & $\begin{array}{l}\text { p-value } \\
\text { UNIVE T E }\end{array}$ \\
\hline A.a & -0.01 & 0.4863 \\
\hline P.g & 0.00 & 1 \\
\hline T.f & 0.008 & 0.6557 \\
\hline T.d & 0.01 & 0.3273 \\
\hline P.i & 0.004 & 0.7391 \\
\hline P.m & -0.008 & 0.2943 \\
\hline F.n & 0.00 & 1 \\
\hline
\end{tabular}




\begin{tabular}{|c|c|c|}
\hline C.r & -0.006 & 0.6707 \\
\hline E.n & 0.002 & 0.6639 \\
\hline E.c & -0.014 & 0.1479 \\
\hline C.s & -0.004 & 0.6269 \\
\hline
\end{tabular}

The mean differences were demonstrated to be very small and close to zero (Table 7). The conclusion can therefore be drawn that there was no significant difference between the bacterial spp colonies present in the periodontal pockets of the left and right sides before conventional management. The split mouth model was therefore not biased with one side of the patient having a greater degree of bacterial colonization, compared to the opposite side. The evaluation of the side treated with the conventional management versus the conventional management plus the laser would therefore be comparable from a bacterial spp perspective (Table 7, Figure 12).

\section{Comparison of bacterial counts: Split mouth model}

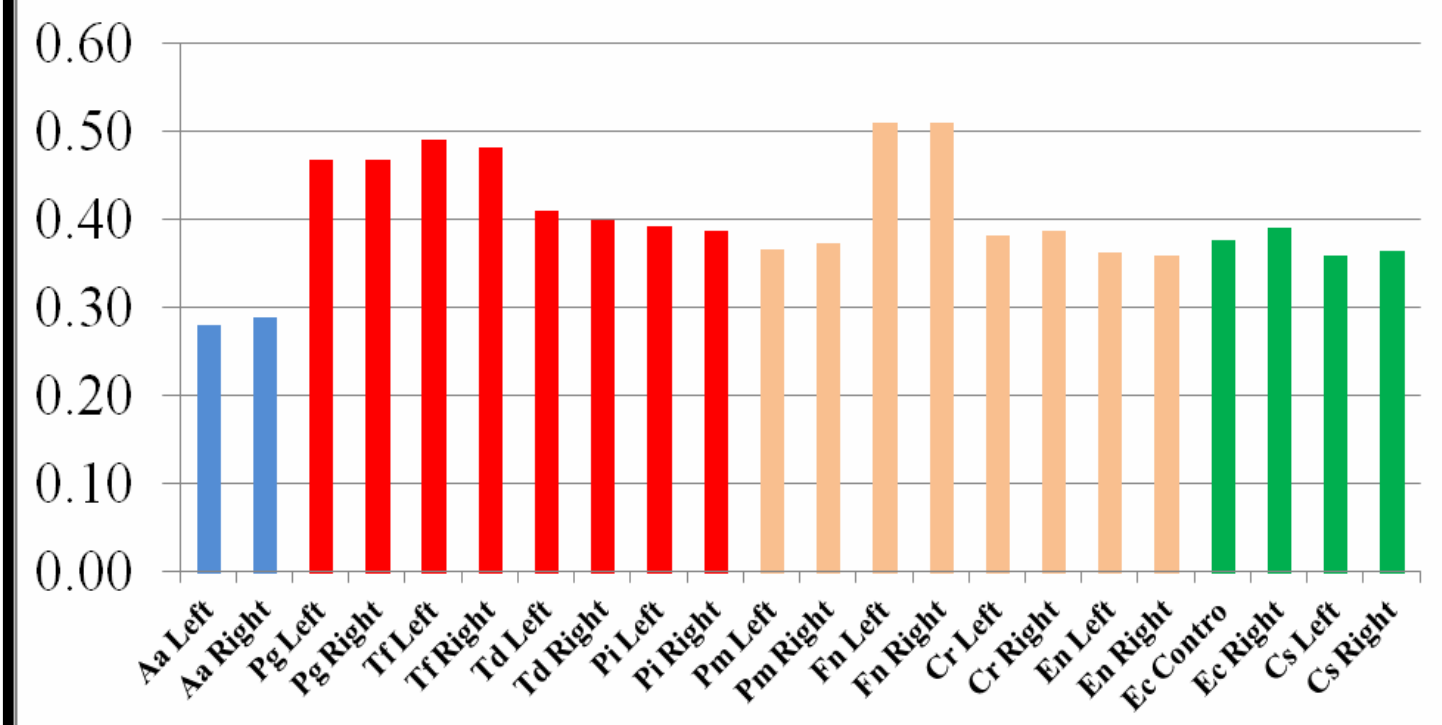

Figure 12: Bacterial load of left and right side before treatment 


\subsubsection{Assessment of clinical parameters for the split mouth model - before conventional management performed:}

The distribution of the left and right sides were well balanced for the split mouth randomised control trial. Each patient served as his/her own control, therefore it was establish if there were significant differences in the clinical parameters of the left and the right sides. A paired t-test of the mean values was performed for each of the clinical parameters that were recorded at the first visit.

Table 8 represents the difference in the mean value of the 25 patients for the clinical parameters before any conventional management was performed. Significant difference between the left and the right side would be considered for a $p$ value of $p<0.05$.

Table 8: Clinical parameter from the split mouth model

\begin{tabular}{|c|c|c|}
\hline $\begin{array}{c}\text { Clinical } \\
\text { parameter }\end{array}$ & $\begin{array}{c}\text { Mean } \\
\text { difference in } \\
\text { the clinical } \\
\text { parameter (Left } \\
\text { and Right) }\end{array}$ & p-value \\
\hline PPD & -0.0924 & 0.3063 \\
\hline REC & 0.1936 & 0.2008 \\
\hline CAL & 0.0896 & 0.5992 \\
\hline PI & -0.2 & 0.7505 \\
\hline BOP & -1.72 & 0.4729 \\
\hline
\end{tabular}

PDD, PI and BOP indices were demonstrated to be higher on the right side, but there was no significant difference between the clinical parameters of the left and right sides before conventional management (Table 8, Figures 13, 14). The split mouth model was therefore not biased with one side of the patient having a significant difference in the clinical 
parameters of periodontal disease. The evaluation of the side treated with the conventional management alone (Control side) versus the conventional management plus the laser (Test side) would therefore be comparable from a clinical perspective (Figures 13, 14), as was noted with the bacterial spp parameters (Table 7, Figure 12).

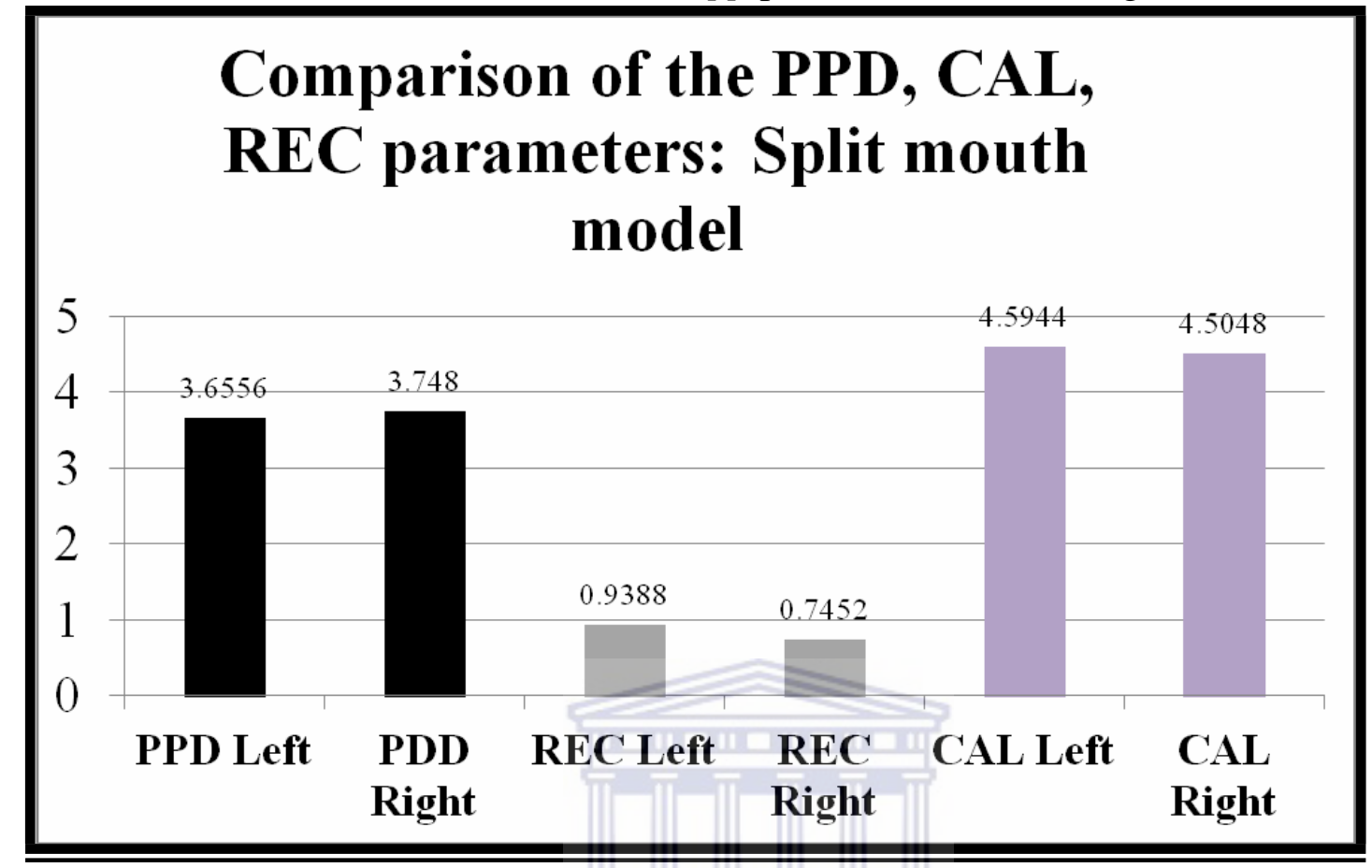

Figure 13: Graph depicting the PPD, REC, CAL parameters for the split mouth design.

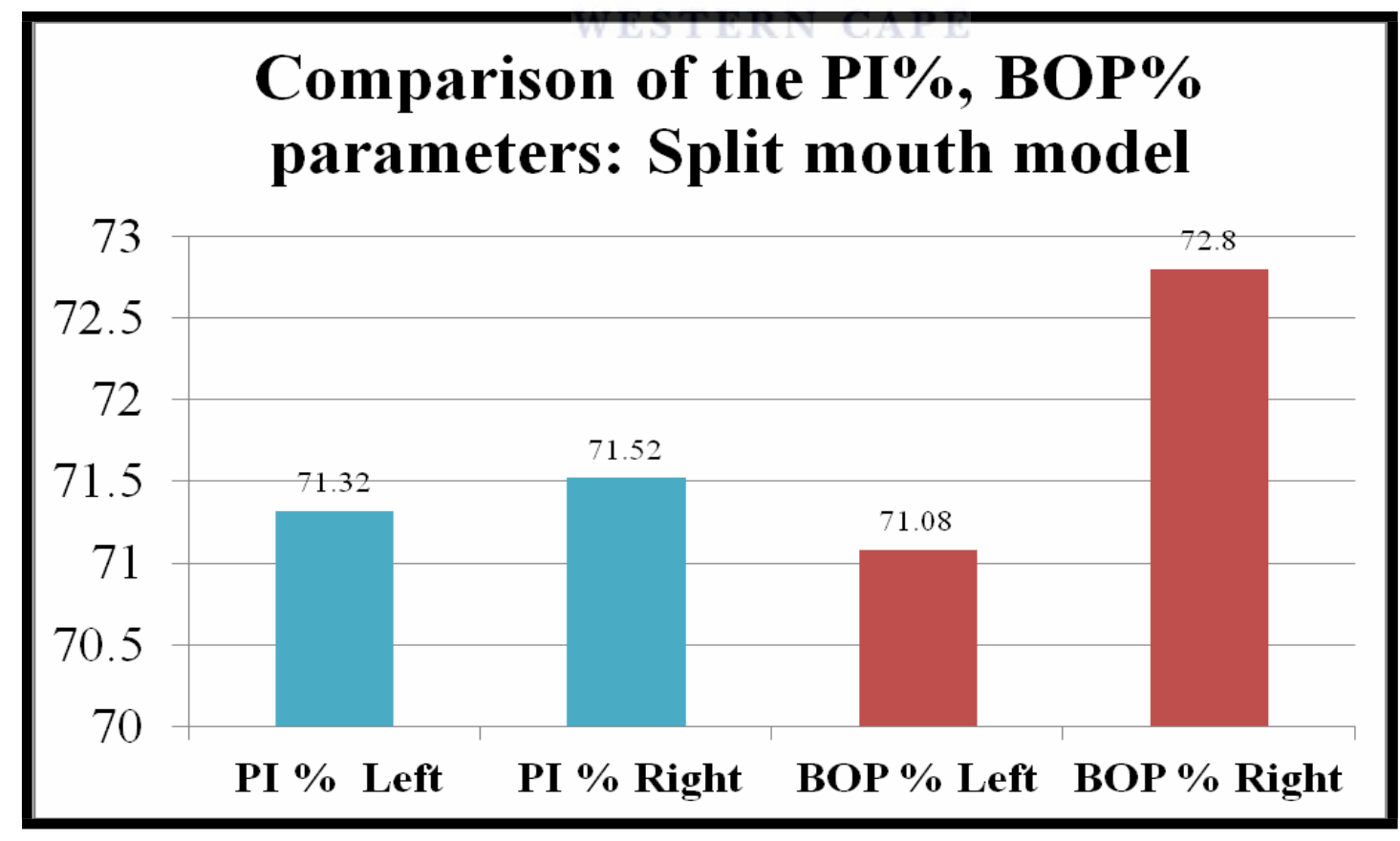

Figure 14: Graph depicting the PI\%, BOP\% parameters for the split mouth design 


\subsection{Assessment of bacterial parameters}

\subsubsection{Statistical analysis for the bacterial load of the before and after treatment}

The statistical analysis for the bacterial load for conventional management (before and after) as well as for the conventional management with the laser as adjunct (before and after) will be performed in a similar manner. The statistical analysis performed was based on a onesample t-test. It was performed on the differences of the bacterial parameters before and after treatment. It was therefore essentially a paired t-test of the mean values. The statistical analysis of the data considered each of the bacterial species before and after treatment. Significant difference would be considered for a $p$-value of $p<0.05$.

\subsubsection{Bacterial parameters after conventional periodontal therapy (Control side).}

The effectiveness of conventional management on the bacterial load at visit one was compared to the bacterial load of the follow up visit 6 weeks later.

Table 8 represents the difference in the mean value of the 25 patients for the bacterial collection after conventional management was performed on the control side. The mean was calculated by subtracting the initial bacterial spp load from the first visit (before conventional management commenced) from the bacterial collection at the second visit (follow up visit for bacterial collection after the conventional management of the first visit).

Table 9: Bacterial load for conventional periodontal treatment (Control side)

\begin{tabular}{|c|c|c|}
\hline \multicolumn{2}{|c|}{$\begin{array}{c}\text { Bacterial load for conventional } \\
\text { periodontal treatment (Control side) }\end{array}$} \\
\hline $\begin{array}{c}\text { Bacterial } \\
\text { spp }\end{array}$ & $\begin{array}{c}\text { Mean } \\
\text { difference in } \\
\text { the Bacterial } \\
\text { spp count }\end{array}$ & p-value \\
\hline A.a & -0.014 & 0.3557 \\
\hline P.g & 0.02 & 0.376 \\
\hline
\end{tabular}




\begin{tabular}{|c|c|c|}
\hline$T . f$ & 0.016 & 0.4838 \\
\hline$T . d$ & 0.06 & 0.00157 \\
\hline$P . i$ & 0.032 & 0.1148 \\
\hline$P . m$ & 0.028 & 0.07963 \\
\hline F.n & -0.128 & 5.008 \\
\hline C.r & 0.126 & 1.714 \\
\hline E.n & 0.014 & 0.1832 \\
\hline E.c & -0.012 & 0.2071 \\
\hline C.s & 0.034 & 0.005254 \\
\hline
\end{tabular}

The conclusion from Table 9 illustrated that there was only a significant reduction in the bacterial colonies of T.d and C.s. This difference between the bacterial spp colonies for T.d and $C . s$ had p-values of 0.00157 and 0.005254 respectively. A.a, F.n and E.c demonstrated an increase in the bacterial spp load after conventional management alone, although it did not have a p-value that was statistically significant (Table 9, Figure 15). 


\section{Average bacterial change: Control side}

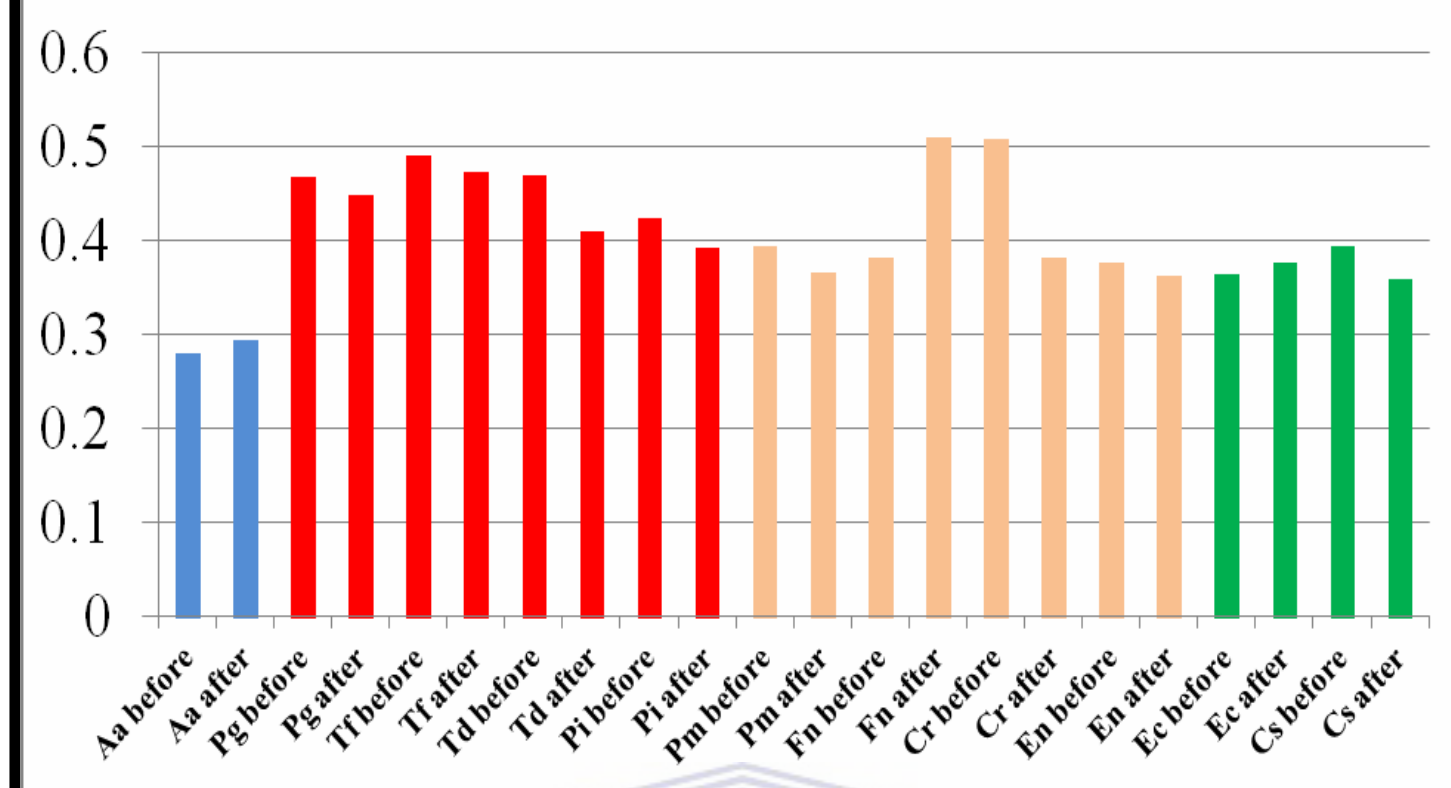

Figure 15: Bacterial load after conventional management (Control side)

\subsubsection{Bacterial parameters after conventional management plus laser treatment (Test} side).

The effectiveness of conventional management with the laser as an adjunct on the bacterial load at visit one (before any treatment) was compared to the bacterial load of the follow up visit 6 weeks later (after conventional management plus diode laser).

Table 9 represents the difference in the mean value of the 25 patients for the bacterial collection after conventional management with the laser treatment was performed. The mean was calculated by subtracting the initial bacterial spp load from the first visit (before conventional management with laser) from the bacterial collection at the second visit (follow up visit for bacterial collection after the conventional management and laser therapy). 
Table 10: Bacterial load for conventional management plus the laser (Test side)

\begin{tabular}{|c|c|c|}
\hline \multicolumn{3}{|c|}{$\begin{array}{c}\text { Conventional periodontal treatment plus } \\
\text { laser (Test side) }\end{array}$} \\
\hline $\begin{array}{l}\text { Bacterial } \\
\quad \text { spp }\end{array}$ & $\begin{array}{c}\text { Mean } \\
\text { difference in } \\
\text { the Bacterial } \\
\text { spp count }\end{array}$ & p-value \\
\hline A. $a$ & -0.008 & 0.3563 \\
\hline P.g & 0.028 & 0.06961 \\
\hline T.f & 0.012 & 0.4907 \\
\hline T.d & -0.024 & 0.1102 \\
\hline$P . i$ & -0.006 & 0.7045 \\
\hline P.m & -0.008 & 0.4048 \\
\hline$F . n$ & 0.002 & 0.8898 \\
\hline C.r & 0.012 & 0.2982 \\
\hline E.n & -0.004 & 0.4907 \\
\hline E.c & -0.004 & 0.6917 \\
\hline C.s & -0.014 & 0.08968 \\
\hline
\end{tabular}

The conclusion from Table 9 demonstrated no significant reduction in the bacterial ssp. A slight increase was demonstrated in A.a, T.d, P.i, P.m, E.n, E.c, C.s bacterial spp load on the 
test side, however this difference was not statistically significant. The remaining bacteria demonstrated a slight decrease, which was not statistically significant (Table 10, Figure 16).

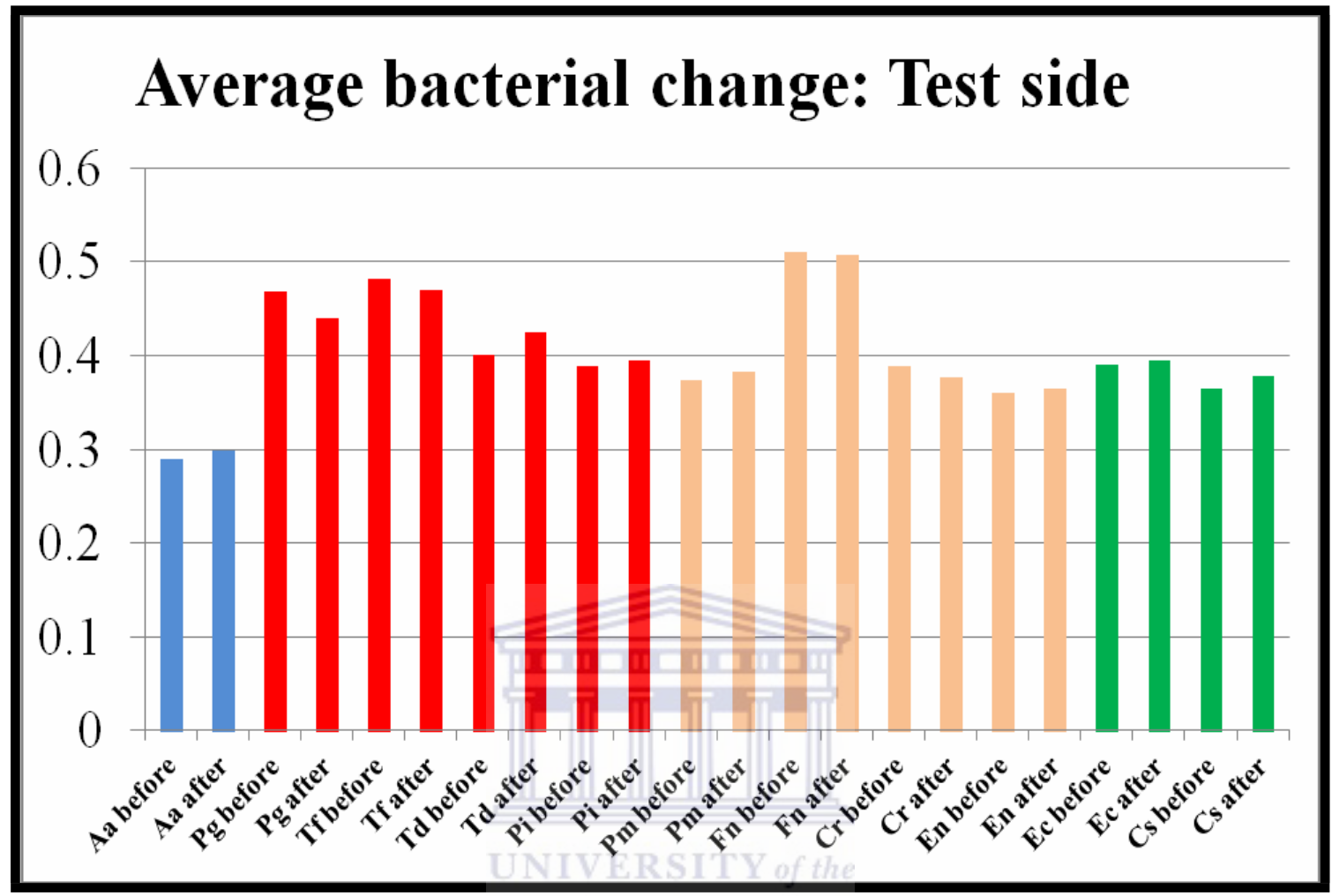

Figure 16: Bacterial parameters after conventional management plus laser (Test side).

4.3.4. Determining the effectiveness of the conventional plus laser (Test side) to the conventional management alone (Control side) for the bacterial parameters.

The final analysis of the data was completed with the differences of differences (DID). The DID is obtained when the values considered for this test are calculated in the following mathematical equation:

DID = Value before Conventional management with laser - Value after Conventional management with laser - (Value before Conventional management - Value after Conventional management).

This test therefore calculated the final outcome of the average change in bacteria that occurred over time for the conventional management plus laser treatment (Test side) in 
relation to the conventional management alone (Control side) for the 25 patients. The data had to be interpreted based on the mathematical values in the equation to prevent a reverse casualty. This reverse casualty could occur, since the data is multi-dimensional data that was obtained over the course of the treatment. For example in the case of A.a. the DID p-value of 0.7332 (Table 11) illustrates that for A. $a$ there is no significant difference between laser as an adjunct, nor for conventional management alone for the reduction of A.a. Based on the individual p-values 0.3557 (A.a conventional management; Table 9) and 0.3563 (A.a laser as adjunct; Table 10) it can be calculated that these methodologies are equally in-effective in reducing A.a. The mean value -0.014 (A.a conventional management; Table 9) and -0.008 (A.a laser as adjunct; Table 10) indicated a slight increase in A.a numbers, although not statistically significant. A significant difference between the control and the test side would be considered for a $\mathrm{p}<0.05$.

Table 11: The calculated DIDs for the conventional management plus laser (Test side) compared to conventional management alone (Control side).

\begin{tabular}{|c|c|c|}
\hline \multicolumn{3}{|c|}{$\begin{array}{c}\text { Conventional management plus laser } \\
\text { (Test side) compared to Conventional } \\
\text { management alone (Control side) }\end{array}$} \\
\hline $\begin{array}{c}|c| \\
\text { Bacterial } \\
\text { spp }\end{array}$ & DID Mean & p-value \\
\hline A.a & 0.006 & 0.7332 \\
\hline P.g & 0.008 & 0.6716 \\
\hline T.f & -0.004 & 0.8519 \\
\hline T.d & -0.084 & 0.004216 \\
\hline P.i & -0.038 & 0.2159 \\
\hline P.m & -0.036 & 0.09816 \\
\hline
\end{tabular}




\begin{tabular}{|c|c|c|}
\hline F.n & 0.13 & 3.235 \\
\hline C.r & -0.114 & 6.663 \\
\hline E.n & -0.018 & 0.185 \\
\hline E.c & 0.008 & 0.5573 \\
\hline C.s & -0.048 & 0.00356 \\
\hline
\end{tabular}

The conclusion was that the laser as an adjunct to conventional management resulted in a statistically significant increase in the bacterial colonies of T.d and C.s (Table 11). The mean value 0.06 (T.d) (Red complex) and 0.034 (C.s) (Green complex) (conventional management alone); indicated a reduction in the bacterial load. For the laser adjunct side -0.024 (T.d) and 0.014 (C.s) (Table 10) represented an increase in the bacterial load when conventional management with laser as adjunct was performed (Table 9).

With regards to the remaining red complex bacteria $(P . g, T . f, P . i)$ no significant difference was found when using the diode laser as an adjunct to conventional management alone (Table $11)$.

\subsection{Assessment of clinical parameters}

\subsubsection{Statistical analysis for the clinical parameters before and after treatment}

The statistical analysis for the clinical parameters for conventional management alone (Control side) (before and after) as well as for the conventional management with the laser as an adjunct (Test side) (before and after) was performed in a similar manner. The statistical analysis performed was based on a one-sample t-test. It was performed on the differences of the clinical parameters before and after treatment. It was therefore essentially a paired t-test of the mean values. The statistical analysis of the data considered each of the clinical parameters before and after treatment. Significant difference would be considered for a $\mathrm{p}$ value of $\mathrm{p}<0.05$. 


\subsubsection{Clinical parameters after conventional management alone (Control side)}

The effectiveness of conventional management alone on the clinical parameters at visit one was compared to the clinical parameters of the follow up visit 6 weeks later.

Table 12 represents the difference in the mean value of the 25 patients for the clinical parameters after conventional management was performed. The mean was calculated by subtracting the initial clinical parameters from the first visit (before conventional management commenced) from the clinical parameters at the second visit (follow up visit for clinical parameters after the conventional management was performed).

Table 12: Clinical parameters for conventional management alone (Control side)

\begin{tabular}{|c|c|c|}
\hline \multicolumn{2}{|c|}{$\begin{array}{c}\text { Clinical parameters for conventional } \\
\text { periodontal treatment (Control side) }\end{array}$} \\
\hline $\begin{array}{c}\text { clinical } \\
\text { parameters }\end{array}$ & $\begin{array}{c}\text { Mean } \\
\text { difference in } \\
\text { the clinical } \\
\text { parameters }\end{array}$ & p-value \\
\hline PPD & 0.4644 & 0.0002301 \\
\hline REC & 0 & N/A \\
\hline CAL & 0.4648 & 0.0002267 \\
\hline PI & 48.4 & 2.2 \\
\hline BOP & 41.64 & 8.038 \\
\hline
\end{tabular}




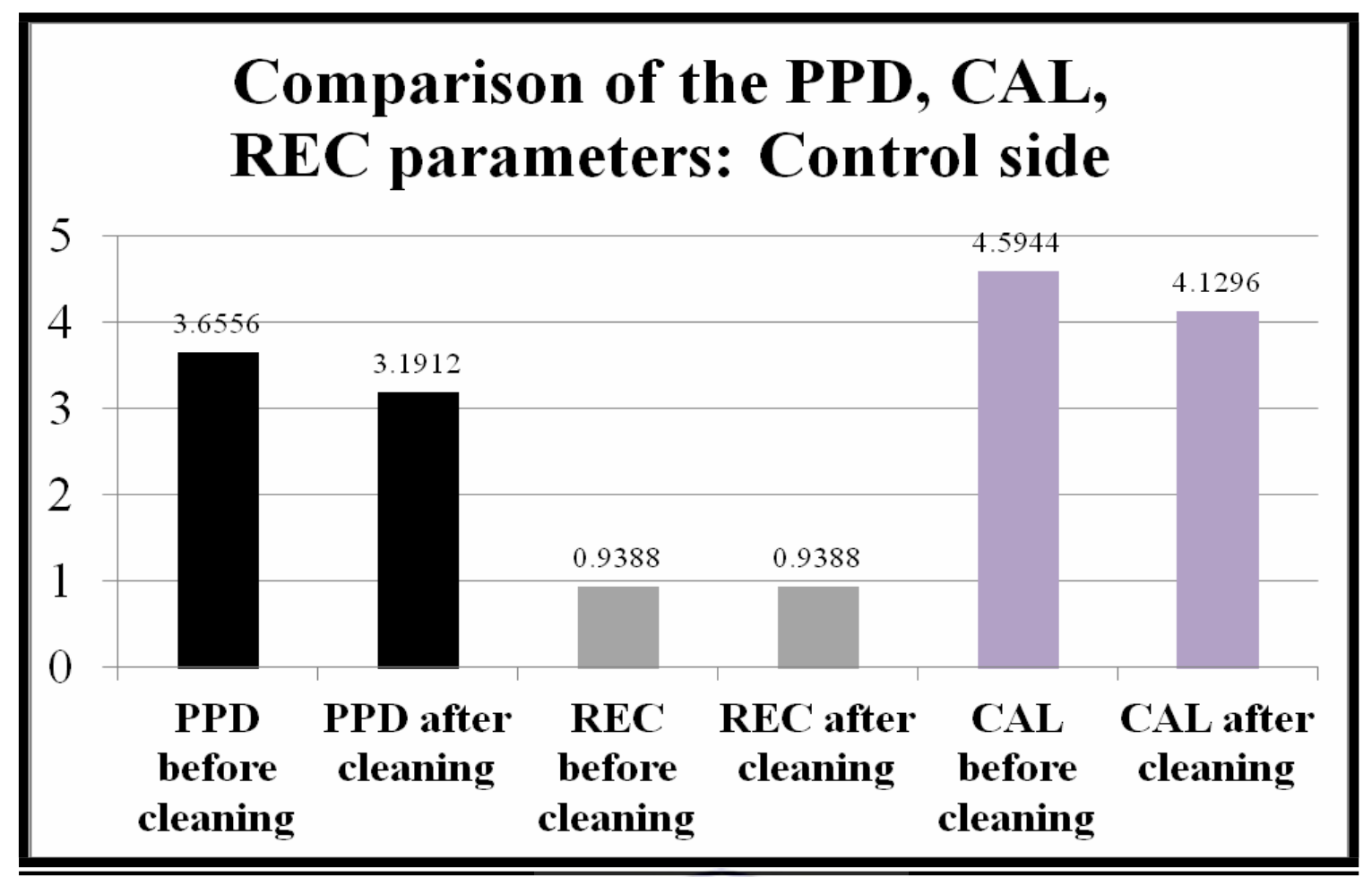

Figure 17: Graph depicting the PPD, REC, CAL parameters before and after conventional management (Control side).

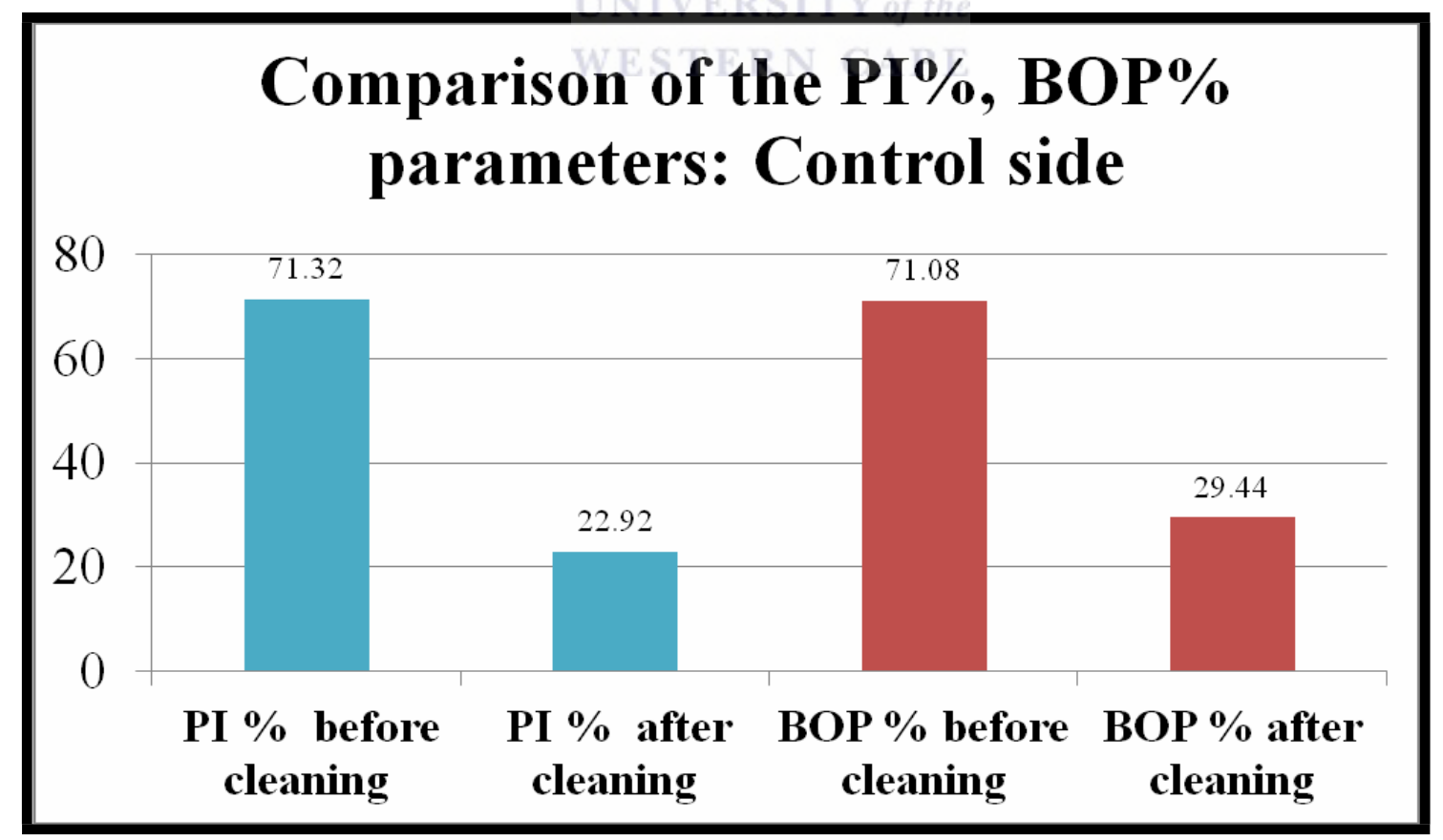

Figure 18: Graph depicting the $\mathrm{PI} \%, \mathrm{BOP} \%$ parameters before and after conventional management (Control side). 
The conclusion from Table 12 was that there was only a statistically significant reduction in the clinical parameters for PPD and CAL. This difference between the clinical parameters for PPD and CAL had p-values of 0.0002301 and 0.0002267 respectively.

The REC before conventional therapy and after had no difference at all and a mean and pvalue could therefore be calculated The PI\% and BOP\% had a $310 \%$ and $240 \%$ reduction respectively, but no statistical p-values were obtained (Table 12, Figures 17, 18).

\subsubsection{Determining the effectiveness of the conventional management plus laser as adjunct (Test side) for the clinical parameters}

The effectiveness of conventional management with the laser as adjunct on the clinical parameters at visit one (before treatment) was compared to the clinical parameters of the follow up visit 6 weeks later.

Table 13 represents the difference in the mean value of the 25 patients for the clinical parameters after conventional management with the laser as adjunct treatment was performed. The mean was calculated by subtracting the initial clinical parameters from the first visit (before conventional management with laser as adjunct) from the clinical parameters at the second visit (follow up visit for clinical parameters after the conventional management with laser as adjunct).

Table 13: Clinical parameters for conventional management plus the laser (Test side).

\begin{tabular}{|c|c|c|}
\hline \multicolumn{3}{|c|}{ Conventional management plus laser } \\
(Test side) \\
\hline $\begin{array}{c}\text { clinical } \\
\text { parameters }\end{array}$ & $\begin{array}{c}\text { Mean } \\
\text { difference in } \\
\text { the clinical } \\
\text { parameters }\end{array}$ & p-value \\
\hline PPD & 0.4984 & 3.852 \\
\hline
\end{tabular}




\begin{tabular}{|c|c|c|}
\hline REC & 0 & N/A \\
\hline CAL & 0.5288 & 5.588 \\
\hline PI & 49.4 & 2.2 \\
\hline BOP & 50.144 & 1.302 \\
\hline
\end{tabular}

The data from Table 13 illustrated that the use of the laser as an adjunct to conventional management resulted in no significant reduction in any of the clinical parameters. The REC before conventional management and after had no difference at all and a mean and p-value could therefore not be calculated. The PI\% and BOP\% each had a 320\% reduction, but no statistical p-values were obtained (Table 13, Figures 19, 20).

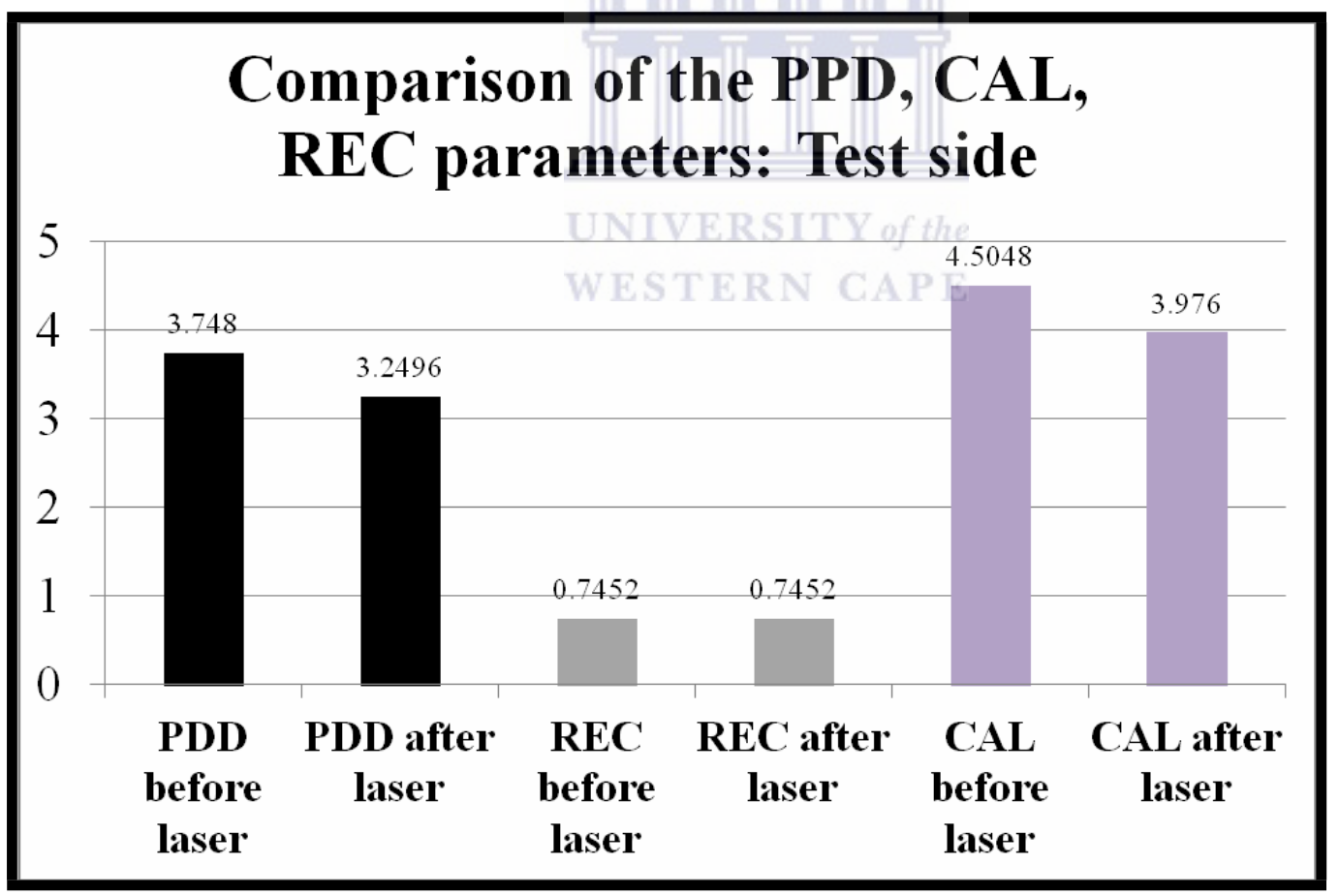

Figure 19: Graph depicting the PPD, REC, CAL parameters before and after conventional management plus laser (Test side) 


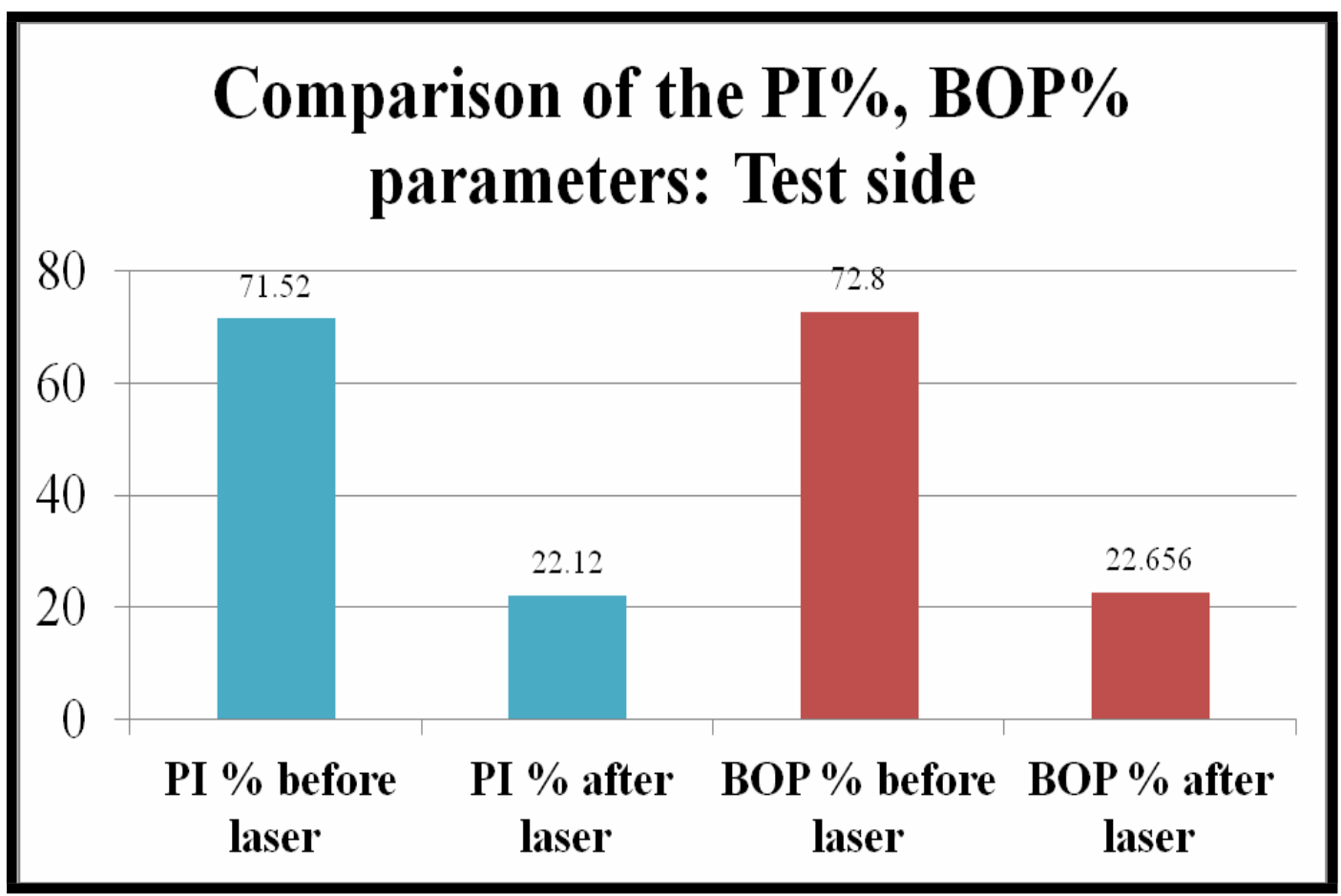

Figure 20: Graph depicting the $\mathrm{PI} \%, \mathrm{BOP} \%$ parameters before and after conventional management plus laser (Test side).

4.4.4. Determining the effectiveness of the conventional management with laser as adjunct (Test side) compared to the conventional management alone (Test side) for the clinical parameters.

The final analysis of the data was completed with the differences of differences (DID). The DID is obtained when the values considered for this test is calculated in the following mathematical equation:

$\mathrm{DID}=$ Value before Conventional management with laser - Value after Conventional management with laser - (Value before Conventional management - Value after Conventional management). 
Table 14: The calculated DIDs for the conventional management plus laser (Test side) compared to conventional management alone (Control side)

Conventional management plus laser

(Test side) compared to conventional management alone (Control side)

\begin{tabular}{|c|c|c|}
\hline $\begin{array}{c}\text { clinical } \\
\text { parameters }\end{array}$ & DID Mean & p-value \\
\hline PPD & 0.034 & 0.7626 \\
\hline REC & 0 & N/A \\
\hline CAL & 0.064 & 0.586 \\
\hline PI & 1 & 0.2448 \\
\hline BOP & 8.504 & 0.005035 \\
\hline
\end{tabular}

The data from Table 14 illustrated that the test side (conventional management with laser as adjunct) compared to the control side (conventional management only) and no significant difference was found, with the exception of BOP\% which was statistically significant $\mathrm{p}<0.05$ (Table 14)

\subsection{Patient distribution of Interleukin -1}

Genotype

In this study the Interleukin-1 genotype was assessed. 
Table 15: The patient distribution that presented with high and low risk IL-1 genotype

\begin{tabular}{|l|l|l|}
\hline $\begin{array}{c}\text { Total number of } \\
\text { patients: }\end{array}$ & Low risk: & High risk: \\
\hline 25 & 18 & 7 \\
\hline
\end{tabular}

Table 15 illustrated that the sample size of 25 patients was distributed as 7 High risk and 18 Low risk I terleukin-1 genotypes.

\subsubsection{Bacterial parameters for the High vs Low risk Genotype}

A Welch two sample t-test of the mean values was performed for each of the bacterial species that was collected at the first visit.

The difference in the mean values of the 18 low risk and 7 high risk genotype patients for the bacterial collection before any treatment commenced was assessed. Significant differences between genotype risks would be considered for a $\mathrm{p}<0.05$.

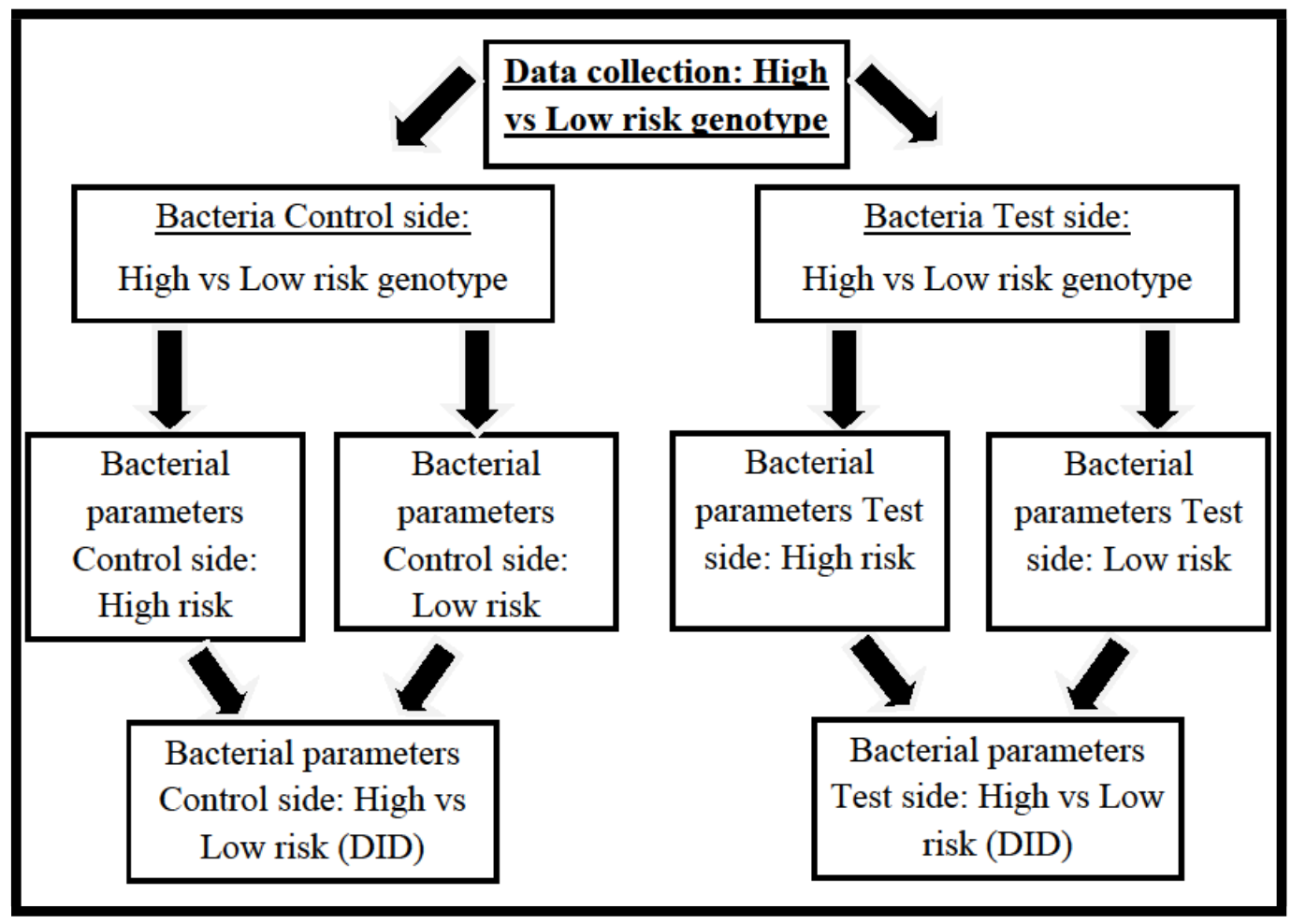


Figure 21: Flowchart of Bacterial comparison for High vs Low risk Genotype

Figure 22 illustrates the bacterial parameters at base line values of the first visit between the High and Low risk genotype patients.

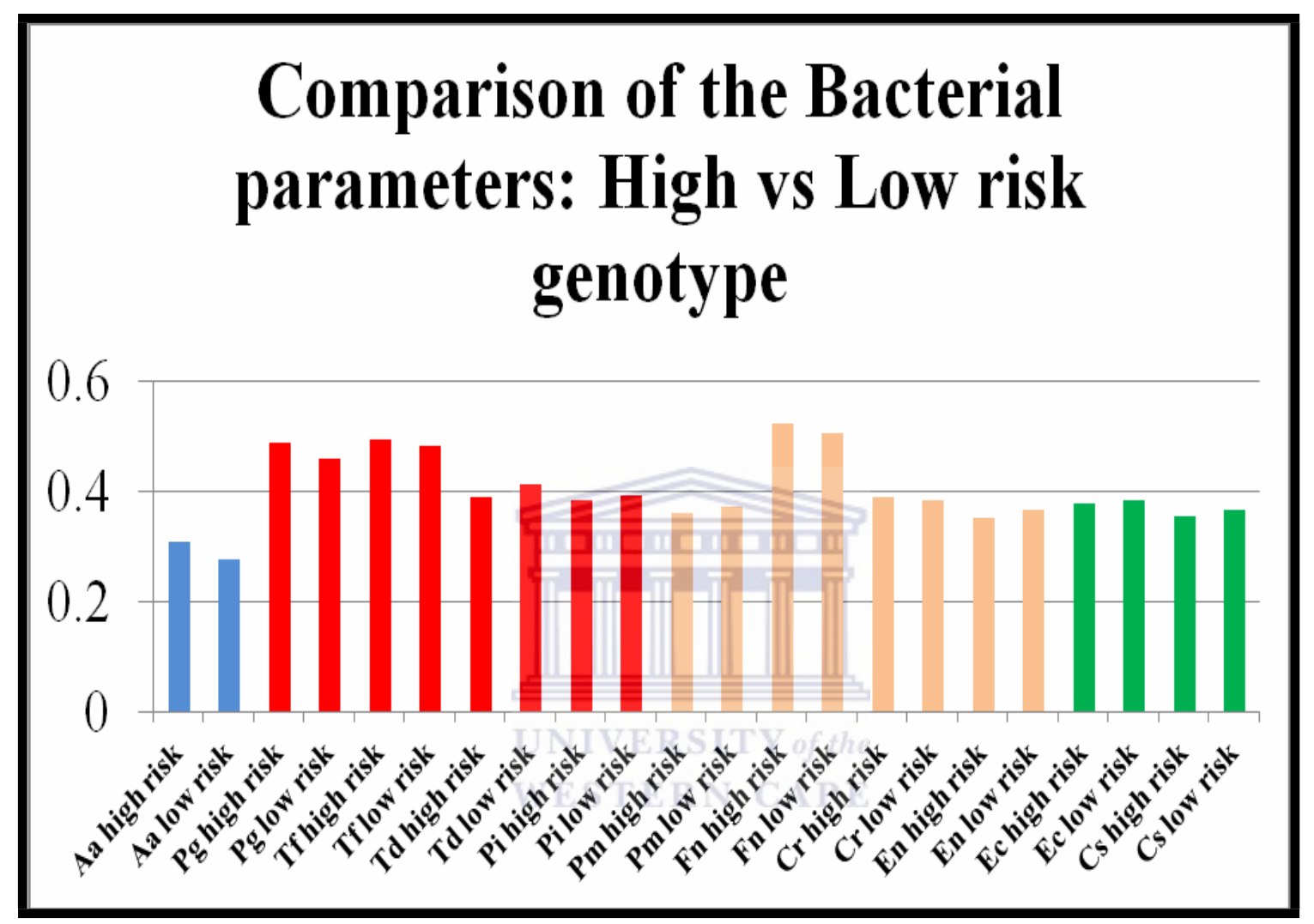

Figure 22: Bacterial parameters of High risk vs Low risk genotype at baseline

A paired t-test of the mean values was performed for each of the bacterial species that was collected at the first visit. These mean values per bacterial species were compared for statistical significance between the high risk and low risk genotype.

Table 16 represented the differences in the mean values of the 7 high risk and 18 low risk genotype patients for the bacterial collection before any treatment commenced. Significant difference between genotype risks would be considered for a $\mathrm{p}<0.05$. 
Table 16: Bacterial parameters at base line between High and Low genotype risk.

\begin{tabular}{|c|c|c|}
\hline $\begin{array}{c}\text { Bacterial } \\
\quad \text { spp }\end{array}$ & $\begin{array}{c}\text { Mean } \\
\text { difference in } \\
\text { the Bacterial } \\
\text { spp count (High } \\
\text { and Low risk } \\
\text { genotype) }\end{array}$ & p-value \\
\hline A. $a$ & 0.031 & 0 \\
\hline P.g & 0.03 & 0.872 \\
\hline T.f & 0.009 & 1.0 \\
\hline T.d & -0.022 & 0.247 \\
\hline$P . i$ & -0.011 & 0.346 \\
\hline P.m & -0.013 & $\begin{array}{l}\text { UNTVER } \\
0.305\end{array}$ \\
\hline$F . n$ & 0.016 & 0 \\
\hline C.r & 0.006 & 0.595 \\
\hline E.n & -0.015 & 0 \\
\hline E.c & -0.006 & 0.393 \\
\hline C.s & -0.012 & 0.289 \\
\hline
\end{tabular}

There were no significant differences in the mean values comparing the base line bacterial species parameters. The conclusion was that irrespective if the patient was determined to be of the High risk or Low risk genotype, at base line the differences in the bacterial parameters were not statistically significant. 


\subsubsection{Bacterial parameters of Control and Test sides after treatment}

Table 17 represented the differences between the mean values per genotype and control or test sides, to establish if there were statistical significances after treatment.

Table 17: Bacterial comparison for High vs Low risk Genotype

\begin{tabular}{|c|c|c|c|c|c|c|c|c|c|}
\hline $\begin{array}{c}\text { Bacterial } \\
\text { spp }\end{array}$ & $\begin{array}{c}\text { Mean } \\
\text { difference } \\
\text { in the } \\
\text { Bacterial } \\
\text { spp count } \\
\text { (High) } \\
\text { Control }\end{array}$ & $\begin{array}{c}\text { Mean } \\
\text { difference } \\
\text { in the } \\
\text { Bacterial } \\
\text { spp count } \\
\text { (Low) } \\
\text { Control }\end{array}$ & $\begin{array}{c}\text { p- } \\
\text { value }\end{array}$ & $\begin{array}{c}\text { Mean } \\
\text { difference } \\
\text { in the } \\
\text { Bacterial } \\
\text { spp count } \\
\text { (High) } \\
\text { Test }\end{array}$ & $\begin{array}{c}\text { Mean } \\
\text { difference } \\
\text { in the } \\
\text { Bacterial } \\
\text { spp count } \\
\text { (Low) } \\
\text { Test }\end{array}$ & $\begin{array}{c}\text { p- } \\
\text { value }\end{array}$ & $\begin{array}{c}\text { Mean } \\
\text { difference } \\
\text { in the } \\
\text { Bacterial } \\
\text { spp count } \\
\text { (High) } \\
\text { DID }\end{array}$ & $\begin{array}{c}\text { Mean } \\
\text { difference } \\
\text { in the } \\
\text { Bacterial } \\
\text { spp count } \\
\text { (Low) } \\
\text { DID }\end{array}$ & $\begin{array}{c}\text { p- } \\
\text { value }\end{array}$ \\
\hline A. $a$ & -0.007 & -0.016 & 0.833 & 0.014 & -0.016 & 0.157 & 2.142 & 3.081 & 0.709 \\
\hline P.g & 0.071 & 0 & 0.192 & 0.042 & 0.022 & 0.561 & -0.028 & 0.022 & 0.398 \\
\hline T.f & 0.092 & -0.013 & $\begin{array}{r}0.024 \\
\quad\end{array}$ & $\begin{array}{l}0.021 \\
T E R \\
\end{array}$ & $\begin{array}{l}0.008 \\
\text { CAP E }\end{array}$ & 0.708 & -0.071 & 0.022 & 0.099 \\
\hline T.d & 0.028 & 0.072 & 0.214 & -0.028 & -0.022 & 0.813 & -0.057 & -0.094 & 0.438 \\
\hline$P . i$ & 0.014 & 0.038 & 0.607 & -0.028 & 0.002 & 0.3 & -0.042 & -0.036 & 0.917 \\
\hline P.m & 0.042 & 0.022 & 0.476 & -0.014 & -0.005 & 0.583 & -0.057 & -0.027 & 0.424 \\
\hline F.n & -0.157 & -0.116 & 0.335 & 0.035 & -0.011 & 0.316 & 0.192 & 0.105 & 0.272 \\
\hline C.r & 0.092 & 0.138 & 0.111 & 0.035 & 0.002 & 0.28 & -0.057 & -0.136 & 0.113 \\
\hline E.n & 0.014 & 0.013 & 0.981 & -0.007 & -0.002 & 0.678 & -0.021 & -0.016 & 0.838 \\
\hline E.c & -0.007 & -0.013 & 0.708 & 0.007 & -0.008 & 0.41 & 0.014 & 0.005 & 0.708 \\
\hline C.s & 0.035 & 0.033 & 0.918 & -0.021 & -0.011 & 0.624 & -0.1 & 0.07 & 0.75 \\
\hline
\end{tabular}


T.f. demonstrated a statistical significant difference in the mean values of the High and the Low risk genotype patients in the control group. This p-value indicated the statistical significant difference between these mean values $\mathrm{p}=0.024$. The overall DID effect of the laser as an adjunct in the High and the Low risk genotypes was not statistically significant.

\subsubsection{Clinical parameters for the High vs Low risk Genotype}

A Welch two sample t-test of the mean values was performed for each of the clinical parameters that was collected at the first visit.

The difference in the mean values of the 7 High risk and 18 Low risk genotype patients for the clinical parameters before any treatment commenced was assessed. Significant difference between genotype risks would be considered for a $\mathrm{p}<0.05$.

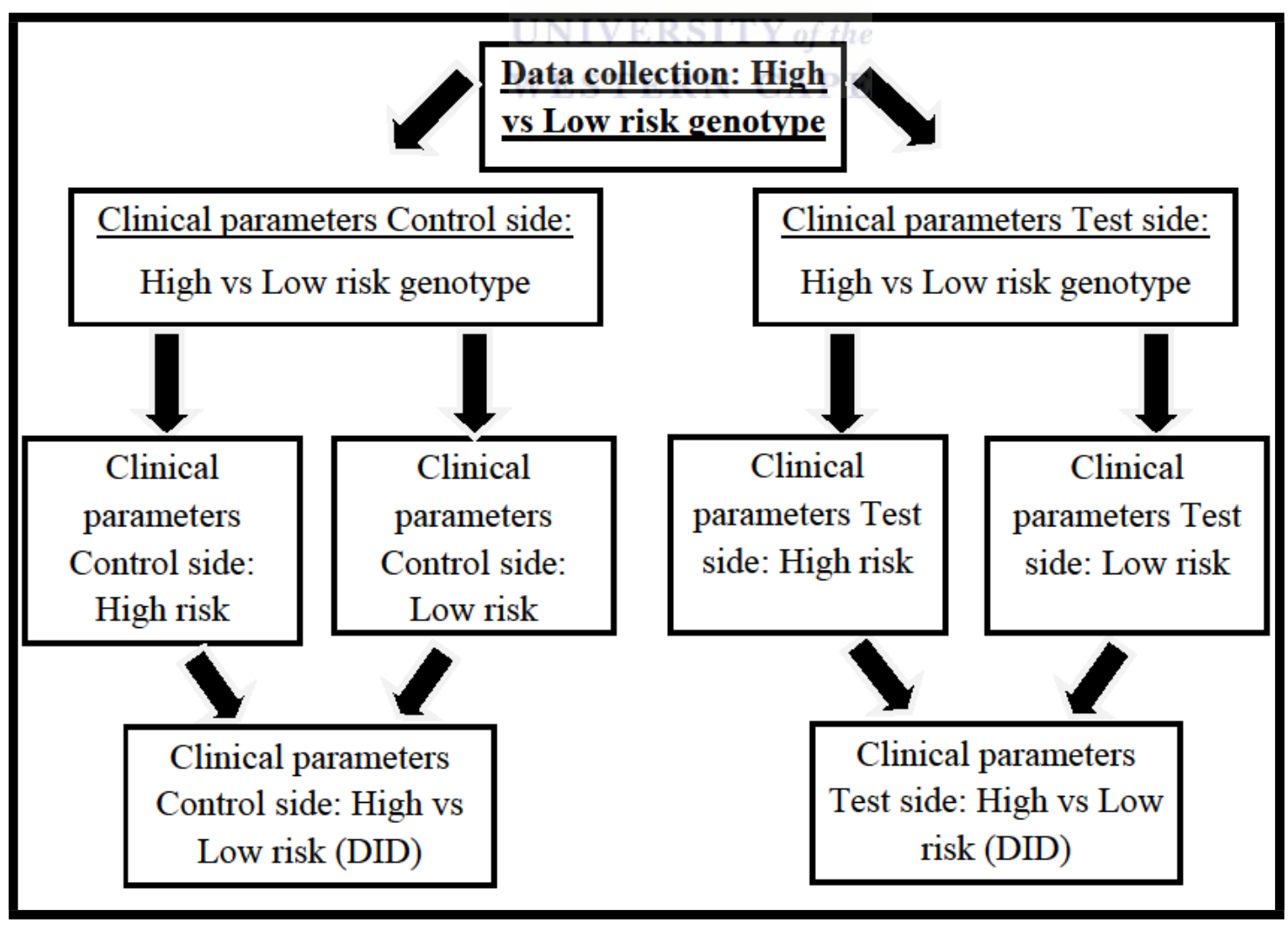

Figure 23: Flowchart of Clinical parameters comparison for High vs Low risk Genotype 
A paired t-test of the mean values was performed for each of the clinical parameters that were collected at the first visit. These mean values of the clinical parameters were compared for statistical significance between High risk and Low risk genotype.

Table 18: Clinical parameters for High vs Low risk genotype at base line

\begin{tabular}{|c|c|c|}
\hline \multicolumn{3}{|c|}{ genotype at base ine } \\
\hline $\begin{array}{c}\text { clinical } \\
\text { parameters }\end{array}$ & $\begin{array}{c}\text { Mean } \\
\text { difference in } \\
\text { the mean } \\
\text { clinical } \\
\text { parameters }\end{array}$ & p-value \\
\hline PPD & 0.344 & $\frac{1}{11}$ \\
\hline REC & 0.467 & 0.757 \\
\hline CAL & 0.796 & $0.866 \mathrm{E}$ \\
\hline PI & 2.098 & 0.567 \\
\hline BOP & -2.298 & 0.430 \\
\hline
\end{tabular}

Figures 24, 25 illustrated the clinical parameters at base line values of the first visit between the 7 High and 18 Low risk genotype patients indicated no difference at all. Although the standard deviation differed between High and Low risk genotypes the mean values were the same. Therefore there was no statistical differences could be calculated for the 7 High risk compared to the 18 Low risk patients. 


\section{Comparison of the PPD, REC, CAL: High vs Low risk genotype}

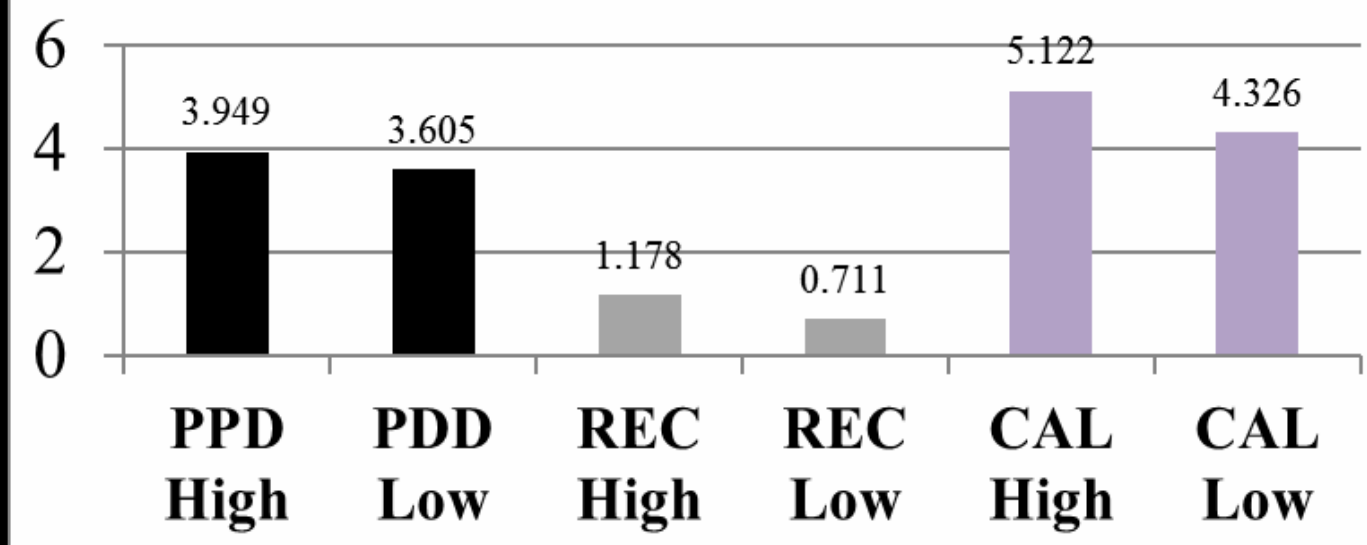

Figure 24: Graph depicting the PPD, REC, CAL parameters for the High and Low risk genotype

\section{Comparison of the PI\%, BOP\%: High vs Low risk genotype}

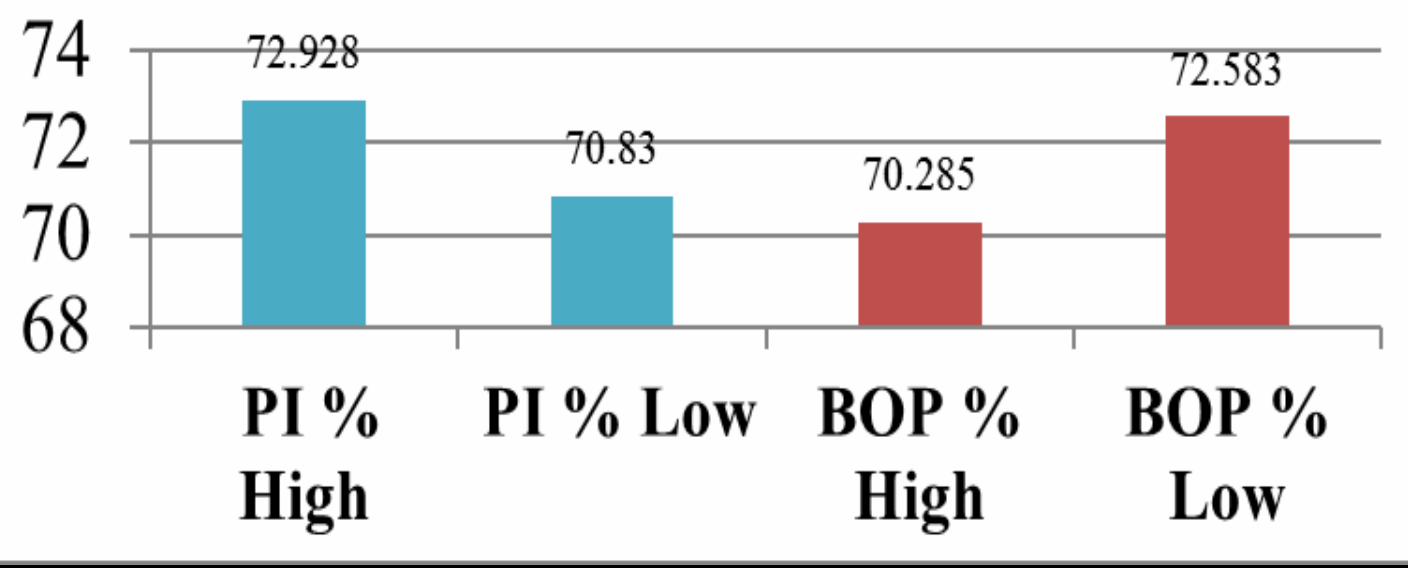

Figure 25: Graph depicting the PI\%, BOP\% parameters for the High and Low risk genotype 
Table 19 represents the differences between the mean values per genotype and control or test sides, to establish if there were statistical significance after treatment for the clinical parameters.

Table 19: Clinical parameters for High vs Low risk Genotype

\begin{tabular}{|c|c|c|c|c|c|c|c|c|c|}
\hline $\begin{array}{c}\text { Clinical } \\
\text { parameter }\end{array}$ & $\begin{array}{c}\text { Mean } \\
\text { difference } \\
\text { in the } \\
\text { Clinical } \\
\text { parameter } \\
\text { count } \\
\text { (High) } \\
\text { Control }\end{array}$ & $\begin{array}{c}\text { Mean } \\
\text { difference } \\
\text { in the } \\
\text { Clinical } \\
\text { parameter } \\
\text { count } \\
\text { Control } \\
\text { Control }\end{array}$ & $\begin{array}{c}\text { p- } \\
\text { value }\end{array}$ & $\begin{array}{c}\text { Mean } \\
\text { difference } \\
\text { in the } \\
\text { Clinical } \\
\text { parameter } \\
\text { count } \\
\text { (High) } \\
\text { Test }\end{array}$ & $\begin{array}{c}\text { Mean } \\
\text { difference } \\
\text { in the } \\
\text { Clinical } \\
\text { parameter } \\
\text { count } \\
\text { (Low) } \\
\text { Test }\end{array}$ & $\begin{array}{c}\text { p- } \\
\text { value }\end{array}$ & $\begin{array}{c}\text { Mean } \\
\text { difference } \\
\text { in the } \\
\text { Clinical } \\
\text { parameter } \\
\text { count } \\
\text { (High) } \\
\text { DID }\end{array}$ & $\begin{array}{c}\text { Mean } \\
\text { difference } \\
\text { in the } \\
\text { Clinical } \\
\text { parameter } \\
\text { count } \\
\text { (Low) } \\
\text { DID }\end{array}$ & $\begin{array}{c}\text { p- } \\
\text { value }\end{array}$ \\
\hline PPD & 0.32 & 0.52 & 0.241 & 0.588 & 0.463 & 0.451 & 0.268 & -0.057 & 0.072 \\
\hline REC & 0 & 0 & NA & 0 & 0 & NA & 0 & 0 & NA \\
\hline CAL & 0.32 & 0.521 & 0.239 & 0.578 & 0.509 & 0.685 & 0.258 & -0.011 & 0.148 \\
\hline PI & 47.571 & 48.722 & 0.842 & 45.714 & 50.833 & 0.264 & -1.857 & 2.111 & 0.057 \\
\hline BOP & 38.428 & 42.888 & 0.5 & 48.428 & 50.811 & 0.817 & 10 & 7.922 & 0.791 \\
\hline
\end{tabular}

There was no statistical significance for any clinical parameter between the high and low risk genotypes for the control or test sides. There was also no DID significance for the use of the laser as an adjunct on the high and low risk genotype patients. 


\subsection{DISCUSSION:}

\subsubsection{Split mouth study design:}

The results of the split mouth comparison in this study, demonstrated that the split mouth study design was a viable methodology to compare changes in the bacterial load and clinical parameters. The results demonstrated no significant difference between the bacterial spp load present in the periodontal pockets of the left and right sides before any treatment was performed.

The clinical parameters (namely PDD, PI and BOP indices) were demonstrated to be slightly higher on the right side, but there was no significant difference between the clinical parameters of the left and right sides before any treatment was performed. The split mouth model was therefore not biased with one side of the patient having a significant difference in the clinical parameters of periodontal disease, compared to the other side.

\subsubsection{Bacterial and clinical parameters:}

In a review by Cobb (2010) on lasers as an adjunct, marked differences within study methodologies where found, making direct comparisons between pre-operative and postoperative treatment parameters difficult. Despite the study heterogeneity, this study's findings and conclusion were similar.

\subsubsection{Bacterial parameters:}

Two of the reviewed studies assessed improvement in bacterial load with the diode laser as an adjunct to conventional treatment (Moritz, 1997. Alves, 2013) (Table 1). The reviewed studies used techniques such as bacterial culturing and the counting of colony forming units (CFU), to assess these changes in the bacterial load. These studies revealed improvements in bacterial load in periodontal pockets, however these results were also not statistically significant for the diode laser as an adjunct (Moritz, 1997. Alves, 2013). 
This study utilised PCR to assess the changes in bacterial load. The control side demonstrated only a significant reduction in the bacterial colonies of T.d and C.s. A slight increase in the bacterial spp load of A.a, F.n and E.c was demonstrated on the control side, however this increase was not statistically significant.

The test side demonstrated no significant reduction in the bacterial ssp. A slight increase was demonstrated in A.a, T.d, P.i, P.m, E.n, E.c, C.s bacterial spp load on the test side, however this difference was not statistically significant. The remaining bacteria demonstrated a slight reduction, which was not statistically significant.

Further analysis (DID) was performed to determine the effectiveness of the laser as an adjunct when comparing the control side to the test side for the bacterial parameters. This study demonstrated that the laser as an adjunct resulted in statistically significant increases in the bacterial colonies of $T . d$ and C.s. With regards to the remaining red complex bacteria (P.g, T.f,) no significant difference was found when comparing the laser as an adjunct to conventional management alone.

A recent study (Hajishengallis, 2011) has demonstrated that even when present in low numbers $P$.g. plays a significant role in altering the composition of the biofilm. P.g. can be considered as a "keystone pathogen" as it directs the genetic response of the other organisms (Hajishengallis, 2011). The fact that the diode laser as an adjunct did not significantly have an impact on the levels of P.g. in this thesis, can be hypothesized as a possible reason for failure of the laser to cause significant reductions in the bacterial parameters.

The true effect of the diode laser alone on periodontal pathogens on a cellular and molecular level has not been established. The potential structural changes that could occur in the periodontal pathogens (i.e. cell wall destruction, bacterial virulence reduction, decreased colony forming ability etc.) could be an essential component to establish the true effect of the laser.

Harris (2004) assessed the effect of the $810 \mathrm{~nm}$ diode laser on the periodontal pathogen P.g on blood agar. The hypothesis was that the blood agar represented the periodontal pocket, since the haemoglobin will absorb the laser energy in a similar manner as the periodontal pocket. The conclusion was that the $810 \mathrm{~nm}$ laser results in ablation of both P.g and the agar (Harris, 2004). Therefore the true ablation capacity of the diode laser for P.g could be masked by the haemoglobin absorption and the resulting cumulative absorption 
in the periodontal pocket. This could explain the significant decrease in BOP with the laser as an adjunct. Although P.g. was not statistically decreased, the inflamed pocket that contains the haemoglobin chromophores absorbed the laser energy, resulting in the removal of the inflamed tissue.

\subsubsection{Clinical parameters:}

Three studies assessed improvement in clinical parameters (Kriesler 2005. Zingale, 2012. Alves, 2013). Alves (2013) found no difference in clinical parameters between the test and control sides for the CAL, PI, PPD and BOP. No significant differences were found for CAL, PPD and BOP (Zingale, 2012). Only one of these studies demonstrated a statistical significant change in clinical parameters (PPD; CAL) with the diode laser as an adjunct to conventional management (Kriesler, 2005). However, Kriesler (2005) demonstrated no statistical difference for PI, GI, BOP.

In this study the control side demonstrated reductions in BOP $\%$, however the results were not statistically significant. The control side demonstrated a statistically significant reduction in the clinical parameters for PPD and CAL. The test side demonstrated reductions BOP \% was not statistically significant. The test side demonstrated no significant reduction in any other clinical parameters.

Further analysis was performed to determine the effectiveness control side compared to the test side for the clinical parameters. This data was completed with the DID formula. The results demonstrated no significant difference between the test and control sides for improvement in clinical parameters, with exception of BOP\% which demonstrated significant improvement on the test side compared to control side.

An essential difference in this thesis was that the bacterial collection, clinical parameter assessment and treatment was performed at the first visit. Thus the patient had no prior knowledge of the study and could therefore not perform an elevated level of oral hygiene practices before the first visit. Moritz (1997) performed the base line bacterial collection at beginning of week 2, after one conventional management appointment had already been performed. Kriesler (2005) performed laser treatment after two visits of conventional 
periodontal treatment. Alves (2012) collected the bacterial and clinical parameters at the beginning of week 2 , after four preceding conventional management appointments.

Kriesler (2005) and Alves (2013) performed a randomised split mouth study. Although lasing and conventional management timelines differed they were the closest in study design to this thesis. The question that however becomes apparent when considering the study designs of Kriesler (2005) and Alves (2013): "Is it the laser that results in the clinical and bacterial parameters changing, or simply the multiple conventional management visits that were performed?". The continuous disruption of the biofilm in the studies of Kriesler (2005) and Alves (2013) could have brought about the changes in clinical parameters observed. Studies have demonstrated that disruption of the bacterial biofilm is paramount to the effective management of periodontitis (Kinane, 2005).

The result from Moritz (1997) and Alves (2013) for the bacterial parameters tested was similar to this thesis with no significant difference in the bacterial parameters demonstrated in the laser test groups (P.i, P.g, A.a) (Cobb, 2010. Alves, 2013).

\subsubsection{Interleukin-1 genotype and its association with bacterial and clinical parameters:}

This study also assessed the possible impact of a high risk Interleukin-1 genotype on baseline clinical and bacterial parameters, as well as treatment outcomes.

Based on the results there is no significant difference between the high versus low risk patient genotypes when comparing baseline bacterial and clinical parameters. The data demonstrates that irrespective of the patient's genotype (High or Low risk), the laser had no significant impact on the bacterial parameters nor the clinical parameters as an adjunct.

Socransky (2000) performed a study to assess the association with between the interleukin 1 genotype and the bacterial parameters. The study sample was divided into groups based on the periodontal pocket depth. This study demonstrated that pockets $<4 \mathrm{~mm}$ and pockets between 4-6mm had statistically less red and complex bacteria, compared to pockets $\geq 6 \mathrm{~mm}$. in those individuals with a high risk interleukin -1 genotype, the bacterial parameters (red and orange complex) were significantly higher in pockets of $\geq 6 \mathrm{~mm}$. 
In this study the mean PPD at baseline was $3.7( \pm 0.61) \mathrm{mm}$. Based on the findings of Socransky (2000) it is plausible that due to the lower mean PPD values in this study, no significant association was thus demonstrated between the high risk genotype and the bacterial parameters.

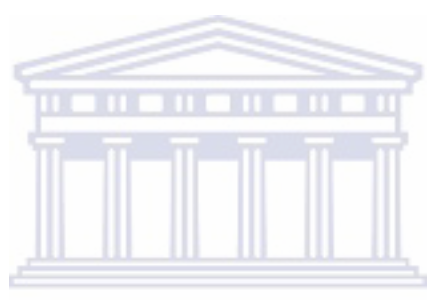

UNIVERSITY of the 


\section{CHAPTER 5: CONCLUSION AND RECOMMENDATIONS}

The review of the literature identified four studies (Table 1) which evaluated the diode laser as an adjunct in the management of chronic periodontitis. The conclusion that can be drawn from these studies was that the diode laser as an adjunct provided very little bacterial or clinical benefit to the patient.

The American Academy of Periodontology (2011) stated that the use of lasers as an adjunct to non-surgical periodontal therapy has no beneficial effect.

A systematic review by Cheng (2016) came to the conclusion that no full consensus on the efficacy of adjunctive laser therapy has been reached. No beneficial effect of the diode laser as an adjunct compared to the conventional management has been demonstrated for the laser used at various treatment intervals, due to inappropriate study designs and the limited number of studies that had assessed the clinical effects of adjunctive laser therapy (Cheng, 2016).

This thesis demonstrated that the use of the diode laser (810nm) as an adjunct at the initial visit provided no benefit for the clinical parameters, with the exception of a significant improvement in $\mathrm{BOP} \%$. The diode laser as an adjunct also did not have a significant effect on the reduction of bacterial load of the red complex bacteria $(P . g, T . f$, ) with the exception of T.d. that demonstrated a statistical increase. None of the other bacteria assessed (A.a, P.m, F.n, C.r, E.n, E.c) demonstrated a significant reduction, with the exception of C.s which also demonstrated a statistically significant increase.

It can be concluded that within the limitations of this study, that the utilization of the diode laser $(810 \pm 10 \mathrm{~nm})$ as an adjunct at the initial visit had no statistical effect in the reduction of the bacterial parameters nor resulted in an overall improvement of the clinical parameters. 


\section{Recommendations:}

Further laboratory studies (such as live cell studies under confocal microscopy) are required to assess the true effect of the diode laser $(810 \pm 10 \mathrm{~nm})$ on the bacterial biofilm and periodontal tissues. Only upon establishment of the effect of the diode laser on the biofilm, could clinical recommendations be made for the correct power, wave length settings and frequency of laser application. Longitudinal studies are required to evaluate the long-term post therapeutic effect of the diode laser $(810 \pm 10 \mathrm{~nm})$ on clinical and bacterial parameters. 


\section{REFERENCES:}

Alves, VTE. De Andrade, VT. Toaliar, JM. Conde, MC. Zezell, DM. Cai, S. Pannuti, CM. De Micheli, G. (2013). Clinical and microbiological evaluation of high intensity diode laser as adjunct to non-surgical periodontal treatment: A 6 month clinical trial. Clinical Oral Investigations; 17: 87-95.

American Academy of Periodontology (2011). Statement of the efficacy of lasers in the nonsurgical treatment of periodontal disease. J Clin Periodontol; 82(4): 513-514.

Antczak-Bouckoms, AA. Tulloch, JF. \& Berkey, CS. (1990). Split mouth and cross-over designs in dental research. J Clin Periodontol; 17: 446-53.

Barnett, A. (2009). Periodontal disease and general health: implications for cardiovascular disease and diabetes. Pract Diab Int; 26:1.

Blaiden, J. Mott, A. (2013). Soft-tissue lasers in dental hygiene. Wiley-Blackwell. ISBN: 978-0-470-95854-4.

Boutaga, K. Van Winkelhoff, AJ. Vandenbrouke,G. CMJE. And Savelkoul, PHM. (2006). The additional value of real-time PCR in the quantitative detection of periodontal pathogens. J Clin Periodontal; 33:427-433.

Boutaga, K. Van Winkelhoff,AJ. Christiana, M. Vandenbrouke,G. Paul, HM. (2005). Periodontol pathogens: A quantitive comparison of anaerobic culture and real time PCR. FEMS Immunology and Medical Microbiology; 45: 191-199.

Bullon, P. Morillo, JM. Ramirez-Tortosa, M. Quiles, J. Battino, M. (2009). Metabolic Syndrome and Periodontitis: Is Oxidative stress a common link? J Dent Res; 88(6): 503-518.

Cobb, CM. (1996 a) Non-surgical pocket therapy: mechanical. Ann Periodontol; 1:443-490.

Cobb, CM. (1996 b). Lasers in Periodontics: A review of the literature. AAP-Commissioned review. J Periodontol; 77: 545-564.

Cobb, C. (2006). Lasers in Periodontics: A review of the literature. AAP-Commissioned Review. J Peridontol; 77:4. 
Cobb, CM. (2010). Lasers and the treatment of chronic periodontitis. Dent Clin Am; 54:3553.

Cheng,Y. Chen, JW. Ge, MK. Zhou, ZY. Yin, X. Zou, SJ. (2016). Efficacy of adjunctive laser in non-surgical periodontal treatment: a systematic review and meta-analysis. Lasers Med Sci; 31: 151-163.

Chondros, P. Nikolidakis, D. Christodoulides, N. Rossler, R. Gutknecht, N. Sculean, A. (2009). Photodynamic therapy as an adjunct to non-surgical periodontal treatment in patients on periodontal maintenance: a randomized controlled clinical trial. Lasers Med Sci; 24: 681688.

Convissar, RA. (2011). Principles and Practice of Laser Dentistry. Mosby Elsevier. ISBN 978-0-323-06206-0

Darveau, RP. Tanner, A. Page, RC. (1997).The microbial challenge in periodontitis. Periodontology 2000; 14:12-32.

Dukic, W. Bago, I. Aurer, A. (2013). Clinical effectiveness of diode laser therapy as an adjunct to non-surgical periodontal treatment: a randomized clinical study. J Periodontol; 84:1111-1117.

Eick, S. Straubbe,A. Guentsch,A. Pfister,W. Jentsch, H. (2011). Comparison of real-time polymerase chain reaction and DNA strip technology in microbiological evaluation of periodontitis treatment. Diagnostic Microbiology and Infectious Disease; 69(1): 12-20.

Forner, L. Larsen, T. Kilian, M. Holmstrup, P. (2006). Incidence of bacteraemia after chewing, tooth brushing and scaling in individuals with periodontal inflammation. J Clin Periodontol; 33: 401-407.

Greenstein, G. (2000). Non-surgical periodontal therapy in 2000: A literature review. J Am Dent Assoc, 131:1580-1592.

Haffajee, AD. Yaskell, T. Torresyap, G. Teles, R. Socransky, S. (2009). Comparison between polymerase chain-reaction-based and checkerboard DNA hybridization techniques for microbial assessment of subgingival plaque samples. J Clin Periodontol; 36: 642-649. 
Hajishengallis, G. Liang, S. Payne, MA. (2011). Low-abundance biofilm species orchestrates inflammatory periodontal disease through the commensal micro-biota and complement. Cell Host Microbe; 10(5): 497-506.

Harris, DM. Yessik, M. (2004). Therapeutic ratio quantifies laser antisepsis: Ablation of Porphyromonas gingivalis with dental lasers. Lasers Surg Med; 35(3):206-213.

Holt, SC. Ebersole, JL. (2005). Porphyromonas gingivalis, Treponema denticola and Tannerella forsythia: the red complex, a prototype polybacterial pathogenic consortium periodontitis. Periodontology 2000; 3:72-122.

Horliana, AC. Chambrone, L. Foz, AM. Artese, HP. Rabelio, M. \& Romito, GA. (2014). Dissemination of periodontal pathogens in the bloodstream after periodontal procedures: A systematic Review. PLoS ONE; (5): e98271.

Hujoel, P. (1998). Design and analysis issues in split mouth clinical trials. Community Dentistry and Oral Epidemiology; 26: 85-86.

Kinane, DF. Attstrom, R. (2005). European Workshop in Periodontology group B. Advances in the pathogenesis of periodontitis. Group B consensus report of the fifth European Workshop in Periodontology. J Clin Periodontol; 32(6): 130-131.

Kreisler, M. Haj, H. D’Hoedt, B. (2005). Clinical efficacy of semiconductor laser application as an adjunct to conventional scaling and root planning. Lasers in surgery and medicine; 37 : $350-355$.

Lesaffre, E. Philstrom, B. Needleman, I. Worthington, H. (2009). The design and analysis of split-mouth studies: what statisticians and clinicians should know. Statistics in Medicine; 28: 3470-3082.

Lindhe, J. Lang, NP. Karring, T. (2008). Clinical periodontology and Implant Dentistry. Blackwell Munksgaard. (2): 183-249.

Lindhe, J. Lang, NP. Karring, T. (2015). Clinical periodontology and Implant Dentistry. Blackwell Munksgaard.

Li, X. Kolltveit, KM. Tronstad, L. Olsen, I. (2000). Systemic diseases caused by oral infection. Clinical Microbiology Reviews; 547-558. 
Löe, H. (2000). Oral hygiene in the prevention of caries and periodontal disease. International Dental Journal; 50: 129-139.

Mani, Am. Tejnani, AH. Babita, P. Marawar, P. (2013). The relationship between periodontitis and systemic disease - Hype or Hope. Journal of Clinical and Diagnostic Research; 7(4): 758-762.

Marsh, PD. Moter, A. \& Devine, DA. (2011). Dental plaque biofilms: communities, conflict and control. Periodontology 2000; 55: 16-35.

Morrison, E.C. , Ramford, P. \& Hill, R. (1980). Short term effects of initial nonsurgical periodontal treatment (hygienic phase). Journal of Clinical Periodontology; 7: 199-211.

Moritz, A. Gutknecht, N. Doertbudak, O. Schoop, U. Schaer, P. \& Sperr, W. (1997). Bacterial reduction in periodontal pockets through irradiation with a diode laser: A pilot study. Journal of clinical laser medicine and surgery; 15: 33-37.

Moritz, A. Schoop, U. Gorharkhay, K. et al (1998). Treatment of periodontal pockets with a diode laser. Lasers Surg Med; 22(5) 302-11.

Nishihara, T. Koseki, T. (2004). Microbial etiology of periodontitis. Periodontology 2000; 36: 14-26.

Parameters of Care - American Academy of Periodontology (2000). Journal of Periodontology; 71(5).

Socransky, SS. Haffajee, AD. Cugini, MA. Smith, C. Kent, RL. (1998). Microbial complexes in subgingival plaque. J Clin Periodontol, 25: 134-144.

Socransky, SS. \& Haffajee, AD. (2002). Dental biofilms: difficult therapeutic targets. Periodontology 2000, 22:12-55. 
Socransky, SS. \& Haffajee, AD. (2005). Periodontal microbial ecology. Periodontology 2000, 38:135-187.

Scharwz, F. Sculean, A. Berakdar, M. Szathmari, L. Georg,T. Becker, J. (2003). In vivo and In vitro effects of an Er:YAG laser, a GaA1As diode laser, and scaling and root planning on periodontally diseased root surfaces: A comparative histologic study. Lasers in surgery and medicine; 32: 359-366.

Van Winkelhoff, AJ. Winkel, EG. (2005). Microbiological diagnostics in periodontics: biological significance and clinical validity. Periodontology 2000; 39: 40-52.

Zingale, J. Harpenau, L. Chambers, D. Lundergan, W. (2012). Effectiveness of root planning with a diode laser curettage for the treatment of periodontitis. Journal of the California Dental Association;40:786-793. 


\section{APPENDICES}

\section{Consent form}

\section{University of the Western Cape (UWC)}

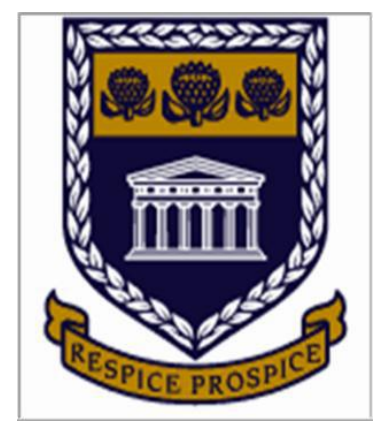

Dear Patient

(place patient sticker)

Dr. Sune Mulder - van Staden is performing research on "the use of a diode laser in the treatment of periodontitis". In order to conduct this research, the laser will be used in addition to scaling, root planing and polishing on one side of your mouth. Patient confidentiality will be preserved.

By signing this form you grant permission for:

- the taking of xrays ( pantomograph and periapicals )

- the taking of clinical photographs

- the assessment of the current periodontal status

- treatment of periodontitis by means of scaling, root planing and polishing

- the application of the diode laser on one side of the mouth

- the results of the study can be used for publication, without revealing patient identity

If this study were to prove that the laser does have a significant beneficial effect, the laser treatment will then be performed on the quadrants previously treated with conventional management alone.

Signature:

Date: 


\section{Ethical approval}

- The research project is completed.

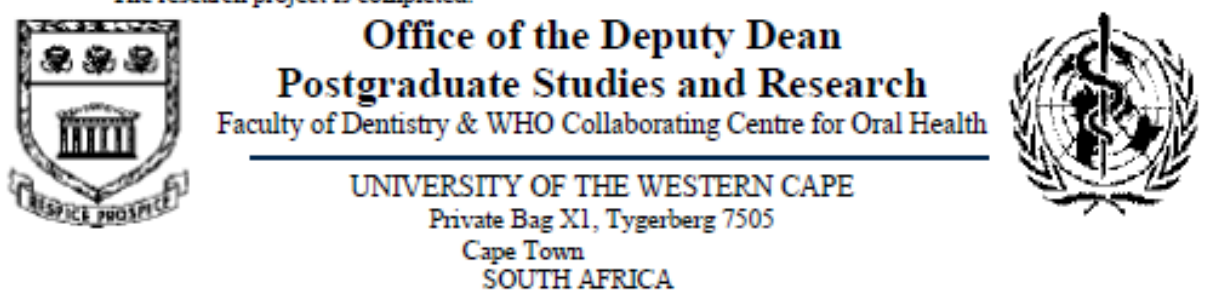

Date: $24^{\text {th }}$ October 2014

For Attention: Dr S Mulder-ran Staden

Department of Oral Medicine \& Periodontology

Faculty of Dentistry

Tygerberg Campus

Dear Dr S Mulder-van Staden

STUDY PROJECT: Diode laser as an additional therapeutic measure in reducing red complex bacteria in chronic periodontitis

PROJECT REGISTRATION NUMBER: 14/9/6

ETHICS: Approved

At a meeting of the Senate Research Committee held on Friday $24^{\text {th }}$ October 2014 the abovementioned project was approved. This project is therefore now registered and you can proceed with the study. Please quote the above-mentioned project title and registration number in all further conrespondence. Please carefully read the Standards and Guidance for Researchers below before canying out your study.

Patients participating in a research project at the Tygerberg and Mitchells Plain Oral Health Centres will not be treated free of charge as the Provincial Administration of the Western Cape does not support research financially.

Due to the heavy workload auxiliary staff of the Oral Health Centres cannot offer assistance with research projects.

Yours sincerely

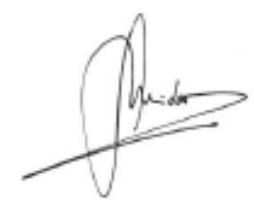

Professor Sudeshni Naidoo

Tel -27-21-937 3148 (w); Fax -27-21-931 2287 e-mail: suenaidoo@guwc.ac.za 


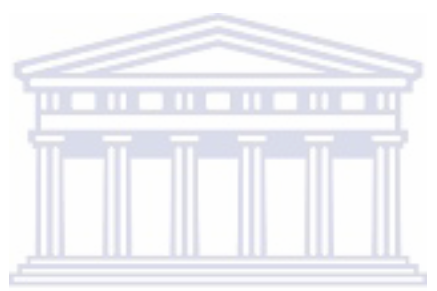

UNIVERSITY of the WESTERN CAPE 